University of Rhode Island

DigitalCommons@URI

Open Access Master's Theses

1994

\title{
Thin Film Sensors for High Performance Silicon Nitride Ceramics
}

Gregg E. Aniolek

University of Rhode Island

Follow this and additional works at: https://digitalcommons.uri.edu/theses

\section{Recommended Citation}

Aniolek, Gregg E., "Thin Film Sensors for High Performance Silicon Nitride Ceramics" (1994). Open Access Master's Theses. Paper 1351.

https://digitalcommons.uri.edu/theses/1351

This Thesis is brought to you for free and open access by DigitalCommons@URI. It has been accepted for inclusion in Open Access Master's Theses by an authorized administrator of DigitalCommons@URI. For more information, please contact digitalcommons-group@uri.edu. 
THIN FILM SENSORS FOR HIGH PERFORMANCE SILICON NITRIDE CERAMICS

BY

GREGG E. ANIOLEK

A THESIS SUBMITTED IN PARTIAL FULFILLMENT OF THE REQUIREMENTS FOR THE DEGREE OF MASTER OF SCIENCE

IN

CHEMICAL ENGINEERING 
MASTER OF SCIENCE THESIS

OF

GREGG E. ANIOLEK

APPROVED:

Thesis Committee

Major Professor

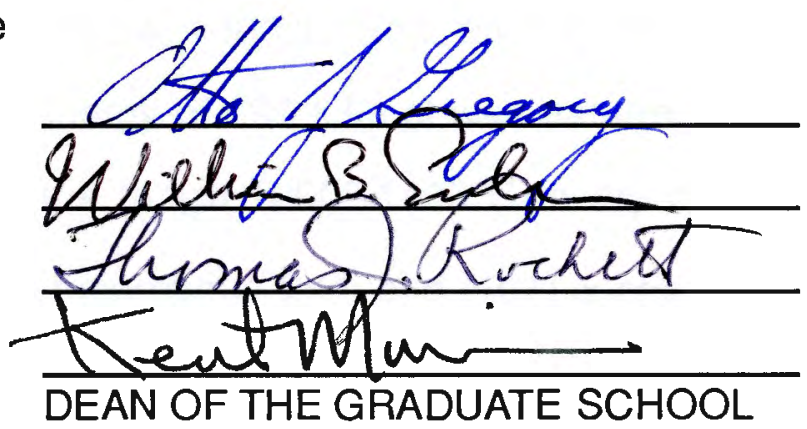

UNIVERSITY OF RHODE ISLAND 


\section{ABSTRACT}

With the incorporation of more high strength ceramic components into the gas turbine engine, there is a subsequent increase in efficiency and thrustto-weight ratio since operating temperatures can be be significantly increased. Surface mount technology represents the best alternative to accurately measure the surface temperature of these ceramic components. Therefore, a thin film thermocouple system was developed and tested for hot isostatically pressed (HIP'ed) $\mathrm{Si}_{3} \mathrm{~N}_{4}$ ceramic substrates.

Oxidation studies were performed on the hot isostatically pressed $\mathrm{Si}_{3} \mathrm{~N}_{4}$ substrates to determine the stability of these ceramics in a variety of oxidizing ambients at high temperature. These studies indicated that the growth kinetics of the oxide scale were strongly dependent on the oxygen partial pressure and the oxidation temperature. Parabolic growth kinetics were observed at temperatures $>1300^{\circ} \mathrm{C}$ and oxygen partial pressures $>0.02$ atm, while logarithmic kinetics were observed below $1300^{\circ} \mathrm{C}$ and an oxygen partial pressures of $0.20 \mathrm{~atm}$. An activation energy of $297 \mathrm{~kJ} / \mathrm{mol}$ was determined for samples oxidized at temperatures in the range $1200^{\circ}-1400^{\circ} \mathrm{C}$ in dry oxygen. The oxide scale generally consisted of amorphous $\mathrm{SiO}_{2}$ and (101) $\alpha$-cristobalite with small amounts of yttrium silicate incorporated into the growing scale. Scanning electron microscopy show a cracked oxide scale due to the $\beta$ to $\alpha$ cristobalite transformation at $273^{\circ} \mathrm{C}$. This as-oxidized surface was not suitable for sputter-deposited sensor elements. Therefore, a surface treatment was employed to improve stability and adhesion, which consisted of thermal and sputtered oxide interlayers to act as a diffusion barrier to high temperature oxidation. Formation of a stable surface prior to sensor element deposition was a critical step in the fabrication of a reliable, accurate sensor. 
Thin film thermocouples consisted of $1 \mu \mathrm{m}$ thick type $S$ thermocouple sensor elements sputter-deposited onto the specially prepared substrates. Lead wires were bonded to the films using parallel gap welding and an $\mathrm{Al}_{2} \mathrm{O}_{3}$ overcoat was sputtered over the entire sensor pattern to prevent high temperature oxidation of the sensor elements. The thin film sensors were tested in a high temperature furnace where they were exposed to a variety of oxidizing conditions. Scanning electron microscopy of failed sensors revealed that emf drift and sensor failure was due to the oxidation of platinum and rhodium along with thermal sintering of the metal films. Aluminum oxide overcoats minimized the effects of both of these degradation mechanisms. 


\section{ACKNOWLEDGEMENT}

In the three years I have worked on this research project I have had a great deal of assistance from a large number of people. Therefore this research was, by no means, a solo effort and may not have been possible without their assistance.

I would like to thank Dr. Otto Gregory for taking me into his research group and, quite often, allowing me to chose the direction in which our experimentation would progress. He has by far given me the vast majority of my guidance and knowledge in the field of engineering. In addition Dr. Ken Burbank, Dr. Everett Crisman, and Dr. Thomas Rockett have contributed largely to my graduate studies at URI.

Thanks must be extended to Steve Mina, Mark Boissevain and Harvey Niska of AlliedSignal Engines for their intellectual and monetary support of which made this research project possible in the first place.

I must also extend my thanks to several other individuals including; Stephen Dyer, Mike Trottier, Mike Platek, Joseph Gausditis, Peter Brown, Scott Lawing, Eve Arnold, Kurt Fleishig and John Dixon at KDF Inc., and especially Arnout Bruins Slot, who was most often helping me fix whatever went wrong during my experimentation.

I also appreciate the friendship of Juliet who has helped me maintain some form of sanity over these many years.

Finally I would like to thank my brother and sisters; Jeff, Jill, Jane, along with my parents Nancy and Edward Aniolek for there support during my college years. A very special thanks goes to my father who's engineering knowledge first sparked my interest in the field and who is probably the only person, outside of my fellow colleagues, who could really understand how a long difficult road this has been for me. 


\section{PREFACE}

This thesis is written in the manuscript plan approved by the University of Rhode Island Graduate School. Both manuscripts were prepared according to the format of scholarly publications in the field. Manuscript II has been accepted, and will appear in the proceedings of the International Conference on Metallurgical Coatings and Thin Films 94'. Manuscript I will be submitted to the Journal of the American Ceramic Society. 


\section{TABLE OF CONTENTS}

CHAPTER

PAGE NO.

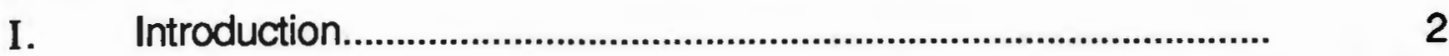

II. High Temperature Oxidation of HIP'ed $\mathrm{Si}_{3} \mathrm{~N}_{4}$

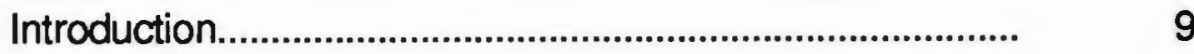

Experimental........................................................................ 12

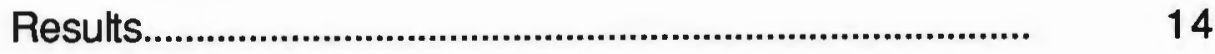

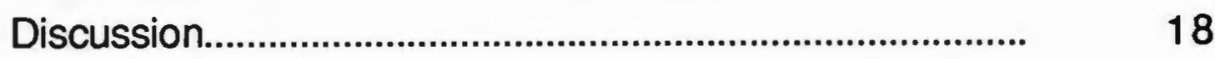

Conclusions.................................................................... 23

Literature Cited................................................................... 25

III. Thin Film Thermocouples for Advanced Ceramic Gas Turbine Engines

Introduction.................................................................... 42

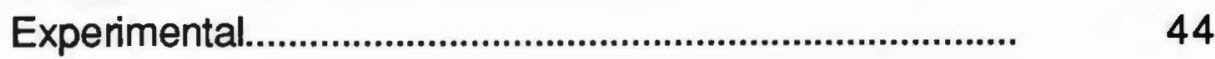

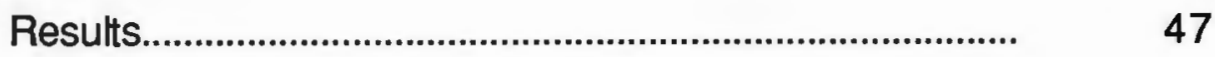

Discussion....................................................................... 50

Conclusions.................................................................... 53

Literature Cited................................................................ 54

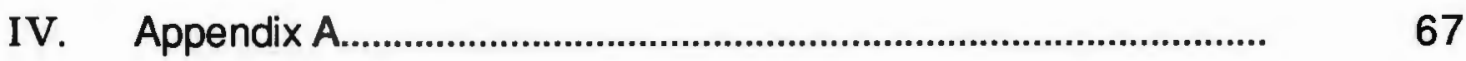

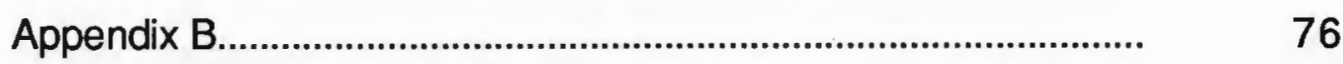

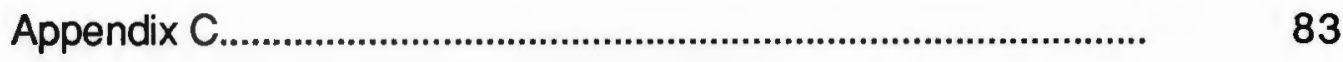

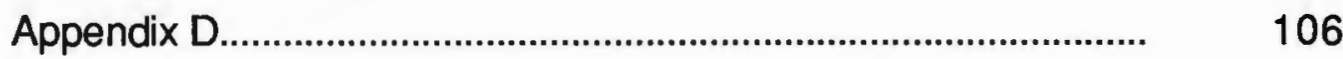

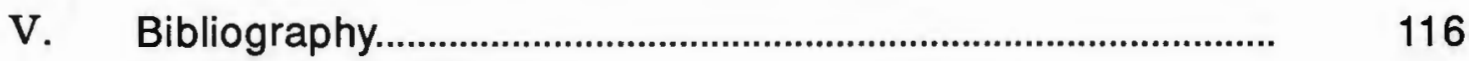




\section{LIST OF FIGURES}

\section{CHAPTER II}

Figure

Page No.

1. ESCA depth profile of an as-received HIP'ed silicon nitride coupon.

2. Experimental setup used for high temperature oxidation runs.

3. Weight change versus time curves for HIP'ed silicon nitride coupons oxidized in dry oxygen at 1 atm pressure.

4. Parabolic oxidation curves for HIP'ed silicon nitride coupons oxidized in dry oxygen at $1 \mathrm{~atm}$ pressure.

5. Parabolic rate constants for HIP'ed silicon nitride coupons oxidized in dry oxygen at $1 \mathrm{~atm}$ pressure as a function of reciprocal temperature.

6. Weight change versus time curves for HIP'ed silicon nitride coupons oxidized in dry air at $1 \mathrm{~atm}$ pressure.

7. XRD peak intensity of (101) $\alpha$-cristobalite relative to (200) $\beta-\mathrm{Si}_{3} \mathrm{~N}_{4}$ for HIP'ed silicon nitride coupons oxidized at various temperatures in dry oxygen.

8. XRD peak intensity of (101) $\alpha$-cristobalite relative to (200) $\beta$-Si $\mathrm{N}_{4}$ for HIP'ed silicon nitride coupons oxidized at various temperatures in dry air.

9. XRD peak intensity of (101) $\alpha$-cristobalite relative to (200) $\beta$ - $\mathrm{Si}_{3} \mathrm{~N}_{4}$ for HIP'ed silicon nitride coupons oxidized under various oxygen partial pressures at $1400^{\circ} \mathrm{C}$

10. SEM micrograph of a HIP'ed silicon nitride coupon oxidized in dry oxygen at $1300^{\circ} \mathrm{C}$

11. SEM micrograph of a HIP'ed silicon nitride coupon oxidized in dry oxygen at $1500^{\circ} \mathrm{C}$

12. ESCA depth profile of a HIP'ed silicon nitride coupon oxidized at $1300^{\circ} \mathrm{C}$ in dry air and etched in HF. 


\section{Chapter III}

Figure

Page No.

1. ESCA depth profile of a silicon nitride coupon that was oxidized in air at $1300^{\circ} \mathrm{C}$ for $100 \mathrm{~h}$ and then etched in concentrated HF.

2. Drift of thin film thermocouples fabricated on silicon nitride and tested in various atmospheres without overcoats.

3. SEM micrograph of a sputtered Pt:10Rh film heat treated in air at $1300^{\circ} \mathrm{C}$

4. ESCA depth profile of a Pt:10Rh film after $1 \mathrm{~h}$ exposure in air at $1000^{\circ} \mathrm{C}$

5. SEM micrograph of a sputtered Pt:10Rh film heat treated in nitrogen at $1300^{\circ} \mathrm{C}$.

6. SEM micrograph of a sputtered Pt film heat treated in nitrogen at $1300^{\circ} \mathrm{C}$

7. SEM micrograph of a sputtered Pt film heat treated in air with an imposed $600^{\circ} \mathrm{C}$ temperature gradient. Note the edges of the film have receded from the original position.

8. Drift of a thin film thermocouple fabricated with a sputtered $\mathrm{Al}_{2} \mathrm{O}_{3}$ overcoat. The deviation of the thin film thermocouple from a reference (wire) thermocouple provides a basis of comparison between the emf outputs.

9. SEM micrograph of a Pt:10Rh thermocouple element fabricated with a $1.6 \mu \mathrm{m} \mathrm{Al}_{2} \mathrm{O}_{3}$ overcoat. Note extensive blistering around edge of the metal pattern where the step coverage is poor.

\section{Appendix A}

Figure

Page No.

1. Schematic of a typical sputtering system......................................... 73

2. Affect of bias sputtering onto samples with trenches machined into the surface of the substrate. 


\section{Appendix B}

Figure

Page No.

1. Stator blade with split epoxy mold........................................................... 78

2a. Epoxy mold positioning on stator blade................................................ 79

2b. Epoxy mold positioning on stator blade............................................... 79

3. Aluminum mask formed on stator blade without adhesive................... 80

4. Sputtered metal pattern on stator blade............................................. 81

\section{Appendix C}

Figure

Page No.

1 a. SEM micrograph of a flattened lead wire prior to welding (low magnification).

1b. SEM micrograph of a flattened lead wire prior to welding (high magnification).

2a. SEM micrograph of a $0.003^{\prime \prime} \mathrm{Pt}$ wire bonded to a $4 \mu \mathrm{m}$ Pt film with a voltage setting of $0.50 \mathrm{~V}$ using a new electrode tip (low magnification).

2 b. SEM micrograph of a $0.003 " \mathrm{Pt}$ wire bonded to a $4 \mu \mathrm{m}$ Pt film with a voltage setting of $0.50 \mathrm{~V}$ using a new electrode tip

(high magnification).

3a. SEM micrograph of a $0.003^{\prime \prime} \mathrm{Pt}$ wire bonded to a $4 \mu \mathrm{m}$ Pt film with a voltage setting of $0.55 \mathrm{~V}$ using a new electrode tip (low magnification).

$3 \mathrm{~b}$. SEM micrograph of a 0.003 " Pt wire bonded to a $4 \mu \mathrm{m}$ Pt film with a voltage setting of $0.55 \mathrm{~V}$ using a new electrode tip (high magnification).

4a. SEM micrograph of a $0.003^{\prime \prime} \mathrm{Pt}$ wire bonded to a $4 \mu \mathrm{m}$ Pt film with a voltage setting of $0.60 \mathrm{~V}$ using a new electrode tip (low magnification)

$4 \mathrm{~b}$. SEM micrograph of a $0.003^{\prime \prime} \mathrm{Pt}$ wire bonded to a $4 \mu \mathrm{m}$ Pt film with a 
voltage setting of $0.60 \mathrm{~V}$ using a new electrode tip (high magnification).

5. SEM micrograph of Pt wires welded at various voltages using a worn electrode tip. Top wire - various settings; second from top - $0.85 \mathrm{~V}$; third from top $-0.80 \mathrm{~V}$; fourth from top $-0.75 \mathrm{~V}$; second from bottom $-0.70 \mathrm{~V}$; bottom $-0.65 \mathrm{~V}$

6a. SEM micrograph of a $0.003^{\prime \prime} P t$ wire bonded to a $4 \mu \mathrm{m}$ Pt film using a worn electrode tip at a voltage setting of $0.65 \mathrm{~V}$

$6 \mathrm{~b}$. SEM micrograph of a 0.003 " Pt wire bonded to a $4 \mu \mathrm{m}$ Pt film using a worn electrode tip at a voltage setting of $0.70 \mathrm{~V}$.

7a. SEM micrograph of a $0.003^{\prime \prime} \mathrm{Pt}$ wire bonded to a $4 \mu \mathrm{m}$ Pt film using a worn electrode tip with an applied voltage of $0.85 \mathrm{~V}$ (low magnification)

$7 \mathrm{~b}$. SEM micrograph of a $0.003^{\prime \prime} \mathrm{Pt}$ wire bonded to a $4 \mu \mathrm{m}$ Pt film using a worn electrode tip with an applied voltage of $0.85 \mathrm{~V}$ (high magnification).

8. Platinum weld strengths as a function of applied voltage that used a worn electrode tip. (film thickness $=4 \mu \mathrm{m}$ ) 99

9. SEM micrograph of a $0.003 " \mathrm{Pt}: 10 \mathrm{Rh}$ wire bonded to a $4 \mu \mathrm{m}$ Pt:10Rh film with a voltage setting of $1.1 \mathrm{~V}$. (Note that some recrystallization of the wire has occurred and grain boundaries are now visible most likely due to thermal etching in the vicinity of the heat affected zone)

10a.SEM micrograph of a $0.003 " \mathrm{Pt}: 10 \mathrm{Rh}$ wire bonded to a $4 \mu \mathrm{m}$ Pt:10Rh film with a voltage setting of 1.3V. (Note the columnar grains in the liquid to solid fusion zone).

$10 \mathrm{~b}$.SEM micrograph of a $0.003 "$ Pt:10Rh wire bonded to a $4 \mu \mathrm{m}$ Pt:10Rh film with a voltage setting of $1.3 \mathrm{~V}$. (Note the columnar grains in the liquid to solid fusion zone).

11 a.SEM micrograph of a $0.003 " \mathrm{Pt}: 10 \mathrm{Rh}$ wire bonded to a $4 \mu \mathrm{m}$ Pt:10Rh film with a voltage setting of $1.5 \mathrm{~V}$.

$11 \mathrm{~b}$. SEM micrograph of a $0.003 " \mathrm{Pt}: 10 \mathrm{Rh}$ wire bonded to a $4 \mu \mathrm{m}$ Pt:10Rh film with a voltage setting of $1.5 \mathrm{~V}$.. 
12a.SEM micrograph of a $0.003^{\prime \prime} \mathrm{Pt}: 10 \mathrm{Rh}$ wire bonded to a $4 \mu \mathrm{m}$ $\mathrm{Pt}: 10 \mathrm{Rh}$ film with a voltage setting of $1.7 \mathrm{~V}$. (Note the area inside the deformed wire is the charging of the $\mathrm{Si}_{3} \mathrm{~N}_{4}$ substrate and not the film).

12 b.SEM micrograph of a $0.003 " \mathrm{Pt}: 10 \mathrm{Rh}$ wire bonded to a $4 \mu \mathrm{m}$ $\mathrm{Pt}: 10 \mathrm{Rh}$ film with a voltage setting of $1.7 \mathrm{~V}$. (Note the area inside the deformed wire is the charging of the $\mathrm{Si}_{3} \mathrm{~N}_{4}$ substrate and not the film)

13. Pt:10Rh weld strengths as a function of applied voltage (film thickness $=4 \mu \mathrm{m}$ ) 104

\section{Appendix D}

Figure

Page No.

1a. Burner rig testing apparatus 109

1b. $S i_{3} N_{4}$ with sputtered type $S$ thermocouple affixed in the burner rig setup

2. Strip chart recording of the thin film thermocouple temperature during high temperature exposure.

3a. Photograph of the thin film thermocouple after testing

3b. High magnification photograph of the thin film thermocouple after testing. Note the break in the platinum leg and the bluing of the bar as a result of the flame test....

4. SEM micrograph of the failed region on the platinum thermoelement.

5. SEM micrograph showing a section of the platinum thermoelement that had buckled off the substrate.

6. SEM high magnification micrograph of the $\mathrm{Al}_{2} \mathrm{O}_{3}$ overcoat. 
Chapter I 


\section{INTRODUCTION}

Several studies of $\mathrm{Si}_{3} \mathrm{~N}_{4}$, have been completed over the past two decades in an effort to apply them in high temperature structural applications or use for masking purposes for integrated circuit fabrication [1-16]. One area of potential use for ceramics that has inspired considerable interest is their introduction into gas turbine engines. With the introduction of lighter weight ceramics into such components as stator and turbine blades, there is a corresponding increase in the thrust-to-weight ratio. In addition, faster engine adjustments can be made during operation since smaller inertial forces have to be overcome. Higher operating temperatures can be achieved with these ceramics and with this increase in the operation temperature, there is also a corresponding increase in engine efficiency $(v)$ according to the equation:

$$
v=\left(T_{h}-T_{c}\right) / T_{h} \times 100 \%
$$

where $T_{h}$ is the operating temperature and $T_{c}$ is the inlet gas temperature. Therefore, for modeling purposes, it is important to know the surface temperature of these engine components during operation.

Historically, the surface temperature of gas turbine engine components has been measured with embedded wire thermocouples. These devices can change the dynamics of engine components during actual operation and lead to considerable error in the measurement itself. Embedded thermocouples can also effect the dynamics of gas flow through the engine, and thus in essence change the engine characteristics. Finally, embedded thermocouples are not considered a viable option for ceramics due to the difficulty in machining them without effecting the strength of the component. Pyrometry offers a non-contact method (and non-temperature limited technique) of determining the temperature of engine components by measuring the emitted radiant energy. 
However, pyrometry requires a knowledge of emittance of the surface, and with ceramics these emittances can vary widely. Another problem associated with pyrometry is is that the emitted radiant energy is a mixture of energy emitted at different depths in the material, along with reflected radiation from combustion gases, results in a significant bias in the measurement. Finally, optical access is needed for measurement, and with the limited space in gas turbine engines, this access can be difficult to accommodate. Therefore, thin film temperature sensors were determined to be the most practical alternative for surface temperature measurement of ceramic components.

The operation of thin film sensors are identical to conventional wire thermocouples in that two dissimilar metals are joined at a junction that produces an electromotive force (emf), otherwise known as the Seebeck voltage. The temperature at this junction is a function of the composition of the two metals and the measured emf. Instead of using wires as the thermocouple legs, thin film metal lines are formed on the desired component by a physical vapor deposition process, such as sputtering. The principles of if sputtering has been previously described [17] and are included in Appendix A. The thin films are non-intrusive and add little weight to the component. However, thin film thermocouples do come with their own set of problems with adhesion of the metal films to the substrate material being the most significant. To address the problem of adhesion, it is important to know how the substrate material behaves at high temperatures, since the interaction of the ceramic substrate with the metal film can lead to metallurgical interaction, such as silicide formation.

Hot isostatically pressed $\mathrm{Si}_{3} \mathrm{~N}_{4}$, more specifically $\mathrm{NT} 154^{1}$, is the leading candidate material for use in gas turbine engines due to its strength retention at high temperatures and excellent oxidation resistance at temperatures below $1300^{\circ} \mathrm{C}$. However, NT154 can still oxidize at temperatures

\footnotetext{
${ }^{1}$ Norton TRW Co., Northboro, MA
} 
below $1300^{\circ} \mathrm{C}$ but at significantly reduced rates. For a thin film sensor to remain adherent and provide a stable and reliable signal, a chemically stable surface is required. Significant outgassing of nitrogen from the reaction of NT154 with oxygen can cause spalling of the thin metal films and thereby, create an unstable surface. Therefore, a comprehensive oxidation study of NT154 was necessary to determine the high temperature behavior of the material in a variety of oxidizing ambients.

The overall goal of this research program was to develop techniques to fabricate a reliable, accurate thin film thermocouple on the surface of hot isostatically pressed silicon nitride engine components. The first manuscript in this thesis will discuss the oxidation of hot isostatically pressed silicon nitride. The second manuscript discusses the fabrication and testing of thin film thermocouples on NT154 substrates. 


\section{LITERATURE CITED}

[1] Choi, S. R.; Tikare, V.; and Pawlik, R."Crack Healing in Silicon Nitride Due to Oxidation.", Ceramic Engineering and Science Proceedings, 12 [9-10], 21902202, 1991.

[2] Strangeman, T. E.; and Fox D. S."Strength Retention of NT154 Silicon Nitride Exposed to High-Temperature Oxidation and Hot Corrosion Environments", Presented at the 184th Meeting of The Electrochemical Society, New Orleans, LA, October 12, 1993.

[3] Cranmer, D. C.; Hockey, B. J.; and Wiederhorn, S. M.“Creep and Creep Rupture of HIP'ed $\mathrm{Si}_{3} \mathrm{~N}_{4}$.", Ceramic Engineering and Science Proceedings, 12 [9-10], 1862-1872, 1991.

[4] Tripp, W. C.; and Graham, H. C."Oxidation of $\mathrm{Si}_{3} \mathrm{~N}_{4}$ in the Range $1300^{\circ}$ to $1500^{\circ} \mathrm{C}$.", Journal of the American Ceramic Society, Vol. 5 9, No. 9-10, 399-403, 1976.

[5] Kiehle, A. J.; Heung, L. K.; Gielisse, P. J.; and Rockett, T. J."Oxidation Behavior of Hot-Pressed $\mathrm{Si}_{3} \mathrm{~N}_{4}$.", Journal of the American Ceramic Society, Vol. 58 , No. 1-2, 17-20, 1975.

[6] Cubicciotti, D.; and Lau, K. H."Kinetics of Oxidation of Hot-Pressed Silicon Nitride Containing Magnesia.", Journal of the American Ceramic Society, Vol. 61, No. 11-12, 512-517, 1978.

[7] Loewenstein, L. M.; and Tipton, C. M."Chemical Etching of Thermally Oxidized Silicon Nitride: Comparison of Wet and Dry Etching Methods.", Journal of the Electrochemical Society, Vol. 138, No. 5, 1389-1394, 1991.

[8] Gregory, O. J.; and Richman, M. H."Thermal Oxidation of Sputter-Coated Reaction-Bonded Silicon Nitride.", Journal of the American Ceramic Society, Vol. 6 7, No. 5, 335-340, 1984.

[9] Fourrier, A.; Bosseboeuf, A.; Bouchier, D.; and Gautherin, G."Thermal Oxidation in Wet Oxygen Reactive Ion-Beam Sputter-Deposited Silicon Nitride Films.", Journal of the Electrochemical Society, Vol. 138, No. 4, 1084-1089, 1991.

[10] Vaughn, W. L. and Machs, H. G."Active-to-Passive Transition in the Oxidation of Silicon Carbide and Silicon Nitride in Air.", Journal of the American Ceramic Society, Vol. 73 [6], 1540-1543, 1990.

[11] Wu, C. C.; McKinney, K. R.; Rice, R. W.; McDonough, W. J.; and Freiman, S. 
W."Oxidation Weight Gain and Strength Degradation of $\mathrm{Si}_{3} \mathrm{~N}_{4}$ with Various Additives.", Journal of Material Science, 1 6, 3099-3104, 1981.

[12] Clarke, D. R.; and Lange, F. F."Oxidation of $\mathrm{Si}_{3} \mathrm{~N}_{4}$ Alloys: Relation to Phase Equilibria in the System $\mathrm{Si}_{3} \mathrm{~N}_{4}-\mathrm{SiO}_{2}-\mathrm{MgO}$.", Journal of the American Ceramic Society, Vol. 6 3, No. 9-10, 586-593, 1980.

[13] Singhal, S. C."Thermodynamics and Kinetics of Oxidation of Hot-Pressed Silicon Nitride.", Journal of Materials Science, 11, 500-509, 1976.

[14] Hirai, T.; Niihara, K. and Goto, T."Oxidation of CVD $\mathrm{Si}_{3} \mathrm{~N}_{4}$ at $1550^{\circ}$ to $1650^{\circ} \mathrm{C}$.", Journal of the American Ceramic Society, Vol. 63 , No 7-8, 419-424, 1980.

[15] Mieskowski, D. M.; and Sanders, W. A."Oxidation of Silicon Nitride Sintered with Rare-Earth Oxide Additions.", Journal of the American Ceramic Society, Vol. 68 [7], C-160-C-163, 1985.

[16] Du, H.; Tressler, R. E.; Spear, K. E.; and Pantano, C. G."Oxidation Studies of Crystalline CVD Silicon Nitride.", Journal of the Electrochemical Society, Vol. 136, No. 5, 1527-1536, 1989.

[17] Smith, S. W., "Fabrication of Thin Film Thermocouples for Gas Turbine Engine Applications', Masters Thesis, The University of Rhode Island, 1989. 
CHAPTER II 


\section{ABSTRACT}

Oxidation studies of hot isostatically pressed $\mathrm{Si}_{3} \mathrm{~N}_{4}$ were performed in flowing dry oxygen and dry oxygen-nitrogen-argon gas mixtures at 1 atm pressure and at temperatures between $1100^{\circ} \mathrm{C}$ and $1400^{\circ} \mathrm{C}$. Parabolic growth kinetics were observed in dry oxygen atmospheres over the entire temperature range studied. A single activation energy of $297 \mathrm{~kJ} / \mathrm{mol}$ was established over the temperature range $1200^{\circ}-1400^{\circ} \mathrm{C}$ and little weight gain was observed at temperatures below $1200^{\circ} \mathrm{C}$. Reducing the oxygen partial pressure to $0.20 \mathrm{~atm}$ resulted in logarithmic growth kinetics at temperatures of $1200^{\circ} \mathrm{C}$ and $1300^{\circ} \mathrm{C}$. A further reduction in oxygen partial pressure to $0.02 \mathrm{~atm}$ yielded negligible weight gain, even at $1400^{\circ} \mathrm{C}$. The oxide scale consisted primarily of amorphous $\mathrm{SiO}_{2},(101) \alpha$-cristobalite and small amounts of $\alpha, \beta$, and $\delta-\mathrm{Y}_{2} \mathrm{Si}_{2} \mathrm{O}_{7}$. The yttrium silicates form primarily from the solid state reaction between the $\mathrm{Y}_{2} \mathrm{O}_{3}$ sintering aid and the silica oxidation product. X-Ray diffraction of the oxide scale showed an increase in intensity of the (101) $\alpha$-cristobalite peaks were increased as temperature and oxygen partial pressure. The logarithmic growth rate observed for oxidations performed in air are believed to be induced by a porous oxide scale formed at the outset of oxidation that continues to grow until a coherent, dense, oxide scale is formed, thereby creating a diffusion barrier that reduces further oxidation. The parabolic growth rates observed in dry oxygen are a direct result of the rapid formation of thin, dense oxide layer during the initial stages of oxidation which thickens with time. 


\section{INTRODUCTION}

There has been considerable interest in the use of $\mathrm{Si}_{3} \mathrm{~N}_{4}$ ceramics for high temperature structural applications. In particular, its high temperature strength, creep resistance, and thermal shock resistance, make it ideal for use in gas turbine engines. However, the stability of $\mathrm{Si}_{3} \mathrm{~N}_{4}$ in oxidizing atmospheres at very high temperatures is limited. Since $\mathrm{SiO}_{2}$ is a more stable phase than $\mathrm{Si}_{3} \mathrm{~N}_{4}$, in oxidizing atmospheres, the ceramic readily oxidizes to the stable $\mathrm{SiO}_{2}$ phase and forms a passive oxide scale that acts as a diffusion barrier to further oxidation. The extent of this oxidation and its growth rate (oxidation kinetics) should be established prior to the insertion of these materials into engine applications. There have been a number of studies on the passive oxidation of hot pressed $\mathrm{Si}_{3} \mathrm{~N}_{4}$ (HPSN) [1-7], sintered $\mathrm{Si}_{3} \mathrm{~N}_{4}$ [8,9], CVD $\mathrm{Si}_{3} \mathrm{~N}_{4}$ [10-14], and reaction bonded $\mathrm{Si}_{3} \mathrm{~N}_{4}$ (RBSN) [15,16]. Although high temperature strength and creep resistance has been investigated for hot isostatically pressed $\mathrm{Si}_{3} \mathrm{~N}_{4}$ (HIPSN) [17], no comprehensive study of the oxidation behavior has been performed on this form of hot isostatically pressed $\mathrm{Si}_{3} \mathrm{~N}_{4}$.

Hot pressed $\mathrm{Si}_{3} \mathrm{~N}_{4}$ is similar to hot isostatically pressed $\mathrm{Si}_{3} \mathrm{~N}_{4}$, in that both heat and external pressure are applied to the powder compact to produce a fully dense ceramic. Hot pressed $\mathrm{Si}_{3} \mathrm{~N}_{4}$ typically contains a small amount of an oxide sintering aid such as $\mathrm{MgO}$ or $\mathrm{Y}_{2} \mathrm{O}_{3}$, which forms a liquid phase during to promote densification. Hot isostatic pressing utilizes a previously sintered product that is enclosed in a compressible, refractory metal can with a small amount of oxide sintering aid and subjected to pressurized gas. This process reduces the porosity in the product and thus, produces a dense ceramic product.

High temperature oxidation of hot pressed $\mathrm{Si}_{3} \mathrm{~N}_{4}$ in oxidizing

\footnotetext{
${ }^{1}$ NT154, Norton TRW Co., Northboro, MA.
} 
atmospheres produces both amorphous and crystalline $\mathrm{SiO}_{2}$ on the $\mathrm{Si}_{3} \mathrm{~N}_{4}$ substrate according to the reaction:

$$
\mathrm{Si}_{3} \mathrm{~N}_{4}(\mathrm{~s})+3 \mathrm{O}_{2}(\mathrm{~g})-->3 \mathrm{SiO}_{2}(\mathrm{~s})+2 \mathrm{~N}_{2}(\mathrm{~g})
$$

Some oxidation studies $[\mathbf{1 0 , 1 1 , 1 4 , 1 8 ] ~ h a v e ~ r e p o r t e d ~ a ~ s i l i c o n ~ o x y n i t r i d e ~}$ $\left(\mathrm{Si}_{2} \mathrm{~N}_{2} \mathrm{O}\right)$ intermediate phase which is believed to form initially, and subsequently reacts with additional oxygen to form $\mathrm{SiO}_{2}$. In addition to $\mathrm{SiO}_{2}$, silicates are frequently found in the oxide scale. The formation of these silicates phases was due to the diffusion of the cation impurities associated with the sintering aid, along the grain boundaries to the surface where it reacts with the $\mathrm{SiO}_{2}$ scale to form various $\mathrm{M}_{\mathrm{x}} \mathrm{Si}_{\mathrm{y}} \mathrm{O}_{z}$ silicates ( $\mathrm{M}$ is the cation impurity). The formation of the silicate phases reduces oxidation resistance and strength of these ceramics. The oxidation resistance of HPSN is dependent on the amount and composition of the sintering aid used for densification.

Previous oxidation studies [1-6] of two forms of HPSN (HS-130 and NC132) fabricated with $\mathrm{MgO}$ as a densification aid showed very similar results to those described above. Singhal [1] studied the passive oxidation behavior of HS-130, containing $\approx 1 \mathrm{wt} \% \mathrm{MgO}$, in the temperature range of 1000 to $1400^{\circ} \mathrm{C}$ in dry oxygen at $1 \mathrm{~atm}$. He observed parabolic rate behavior with an activation energy of $375 \mathrm{~kJ} / \mathrm{mol}$. Tripp and Graham [2] reported oxidation kinetics similar to those of Singhal below $1440^{\circ} \mathrm{C}$ in dry oxygen at 150 torr for HS-130. Above $1440^{\circ} \mathrm{C}$ there was a sharp increase in the activation energy which indicated a possible breakdown of the scale. Cubicciotti and Lau [6] calculated the activation energy of $\mathrm{NC}-132$, that contained $0.5 \mathrm{wt} \% \mathrm{MgO}$, to be $440 \mathrm{~kJ} / \mathrm{mol}$ in the temperature range of $1250-1450^{\circ} \mathrm{C}$ with 120 torr of oxygen.

Babini et. al. [7] found similar oxidation behavior of HPSN with $\mathrm{Y}_{2} \mathrm{O}_{3}$ and $\mathrm{SiO}_{2}$ additions as densification aids. Apparent activation energies ranged from 260-623 kJ/mol, with smaller energies corresponding to lower amounts of oxide 
additives, while higher energies corresponded to increased $\mathrm{Y}_{2} \mathrm{O}_{3}$ and $\mathrm{SiO}_{2}$ additions.

The main focus of this study was the passive oxidation behavior of HIPSN (NT154) over the temperature range $1100-1400^{\circ} \mathrm{C}$ in various oxygen partial pressures. Part of this objective was to establish the nature of the oxidation products formed on hot isostatically pressed $\mathrm{Si}_{3} \mathrm{~N}_{4}$ and evaluate the oxide kinetics as a function of temperature and oxygen partial pressures. Once this was accomplished a comparison of the activation energies to other $\mathrm{Si}_{3} \mathrm{~N}_{4}$ materials could be made and appropriate mechanisms identified. 


\section{EXPERIMENTAL}

Hot isostatically pressed bars of NT154 measuring $1.80 \mathrm{~cm} \times 0.89 \mathrm{~cm} \times$ $0.16 \mathrm{~cm}$ were used as substrates for this oxidation study. These silicon nitride substrates were provided by Norton TRW and had approximately $4 w t \% \quad \mathrm{Y}_{2} \mathrm{O}_{3}$ added as a densification aid. The $\mathrm{Si}_{3} \mathrm{~N}_{4}$ coupons were diamond ground to a $0.25 \mu \mathrm{m}$ surface finish. XRD analysis of the as-received coupons indicated that the material consisted primarily of $\beta-\mathrm{Si}_{3} \mathrm{~N}_{4}$ with approximately $15 \% \alpha-\mathrm{Si}_{3} \mathrm{~N}_{4}$. No oxide or oxynitride phases including $\mathrm{SiO}_{2}, \mathrm{Y}_{2} \mathrm{O}_{3}, \mathrm{Y}_{2} \mathrm{Si}_{2} \mathrm{O}_{7}$ or $\mathrm{Si}_{2} \mathrm{ON}_{2}$ were present in the XRD spectra of the as-received material. However, ESCA analysis of the as-received $\mathrm{Si}_{3} \mathrm{~N}_{4}$ coupons (Figure 1) showed a high concentration of oxygen at the surface of the coupons, most likely in the form of non-crystalline $\mathrm{SiO}_{2}$ and $\mathrm{Y}_{2} \mathrm{O}_{3}$ that resulted from the fabrication/finishing process. Therefore, all coupons were etched in $48-50 \%$ concentrated HF solution to remove this oxide layer to get a better representation of the oxidation resistance of the bulk material.

The apparatus used for all oxidations is shown in Figure 2. The $\mathrm{Si}_{3} \mathrm{~N}_{4}$ coupons were resistively heated with $\mathrm{MoSi}_{2}$ elements in a high temperature alumina muffle furnace. The hot zone of the furnace was calibrated over the range of oxidation temperatures to within $\pm 4^{\circ} \mathrm{C}$. A VTI corporation microbalance system, sensitive to $1 \mu \mathrm{g}$, was used to continuously monitor the weight change of the NT154 coupon. The coupons were supported on a sapphire fiber that extended to the furnace hot zone. The furnace tube was sealed with water cooled endcaps, containing Viton o-rings, and tested for leaks. MKS mass flow controllers were used to meter in furnace gases. The gas line was passed through a Neslab Instruments refrigeration unit at set at $-20^{\circ} \mathrm{C}$ to condense any excess water vapor in the gas stream prior to entry in the furnace. The exiting

\footnotetext{
'Bomas Machine Specialties Inc., Somerville, MA.
} 
gas stream, from the furnace, was passed through a check valve, followed by an oil bubbler to prevent backstreaming. High purity argon gas $(99.999 \%)$ was used to purge into the system for at least 10 hours prior to high temperature exposure. Isothermal oxidations were performed at temperatures between $1100^{\circ}-1400^{\circ} \mathrm{C}$, and at a total pressure of $1 \mathrm{~atm}$. To determine the effect of oxygen partial pressure on the overall oxidation kinetics, oxidations were performed in atmospheres containing 1.0, $0.20,0.02$ and 0.004 atm of oxygen. The furnace was ramped up to temperature in flowing argon until the oxidation temperature was achieved, at which time the oxidizing gas was leaked into the system and the weight gain data was recorded. The NT154 coupons were exposed to these different oxidizing atmospheres for $100 \mathrm{~h}$.

X-Ray diffraction spectra were generated in a Scintag XRD system model \#XDS-2000, to determine the phases of oxidation products in the scale. A Perkin Elmer multitechnique surface analyzer model \# PHI-5500 was used to perform ESCA analysis (Electron Spectroscopy for Chemical Analysis) on various oxide scales to determine both chemistry and scale thickness. This analyzer was equipped with an argon ion sputtering gun to thin the sample as the chemical bonding information was being collected. Morphological and microstructural features of the scale formed on the specimens after oxidation were analyzed with an ISI-SX40A scanning electron microscope. 


\section{RESULTS}

Oxidation Kinetics The oxidation behavior of hot isostatically pressedsilicon nitride was dependent on oxidation temperature, oxygen partial pressure and nitrogen partial pressure in the furnace. Figure 3 shows the weight change behavior of hot isostatically pressed coupons exposed to dry oxygen at temperatures between $1200^{\circ} \mathrm{C}$ and $1400^{\circ} \mathrm{C}$. Parabolic growth kinetics were observed over the entire temperature range with negligible weight gains being observed at temperatures below $1200^{\circ} \mathrm{C}$. Parabolic rate constants were calculated from the slopes straight lines replotted in Figure 4. These straight lines were based on the original weight gain data presented in Figure 3. All of the straight lines generated from this data intersected the $y$ ordinate at slightly positive values, with the exception of the data at $1400^{\circ} \mathrm{C}$. This suggests that these oxidation rates were slightly greater than those predicted by a perfect parabolic rate law, which concurs previous studies [6]. The rate data was fitted to the parabolic equation:

$$
W^{2}=k_{p} t+c
$$

where $W$ is the sample weight gain, $k_{p}$ is the parabolic rate constant, $t$ is the time, and $c$ a constant which accounts for the initial reaction. When the logarithm of the parabolic rate constants were plotted as a function of reciprocal temperature, a typical Arrhenius relationship resulted (Figure 5). The best straight line fit through these points corresponded to an activation energy of 297 $\mathrm{kJ} / \mathrm{mol}$. This value is comparable to that obtained by Singhal [1] and Tripp and Graham [2], who reported activation energies of $378 \mathrm{~kJ} / \mathrm{mol}$ and $289 \mathrm{~kJ} / \mathrm{mol}$ respectively, for their oxidation studies on HS-130 HPSN.

Oxidations performed under reduced oxygen partial pressures resulted in very different rate behavior. The most interesting result of these reduced 
oxygen partial pressure oxidations was that logarithmic rate behavior was observed at lower temperatures. The insert in Figure 6 shows the logarithmic rate behavior at $1200^{\circ} \mathrm{C}$ and $1300^{\circ} \mathrm{C}$. Here, the majority of the weight gain occurred within the first $30 \mathrm{~min}$, with only a slight weight gain observed for the remainder of the run. Weight gain measurements were repeated at these temperatures and the rate behavior again confirmed this result. To verify the reproducibility of the weight change measurements taken with this TGA apparatus, a piece of CVD $\mathrm{Si}_{3} \mathrm{~N}_{4}$ was oxidized at $1300^{\circ} \mathrm{C}$ in dry oxygen and the results were compared to those found in the literature [10]. This confirmed that the thickness of the oxide formed on the CVD coupon was within acceptable experimental error of the previously reported data for this material.

Phase Analysis In addition to the $\beta$ and $\alpha-\mathrm{Si}_{3} \mathrm{~N}_{4}$ peaks observed in the as-received material, (101) $\alpha$-cristobalite as well as $\alpha$ and $\delta-Y_{2} \mathrm{Si}_{2} \mathrm{O}_{7}$ peaks were observed in the spectra, regardless of temperature and atmosphere. Relatively small $\alpha$ and $\delta-Y_{2} \mathrm{Si}_{2} \mathrm{O}_{7}$ peaks were observed and were independent of oxygen partial pressure and temperature. The (101) $\alpha$-cristobalite peak intensity varied considerably with oxidizing conditions, with the most intense peaks found at high oxygen partial pressures and temperatures, whereas, only weak (101) $\alpha$ cristobalite peaks were observed at low oxygen partial pressures (0.004 atm) regardless of oxidation temperature. Figure 7 shows the relative peak intensity of the (101) $\alpha$-cristobalite peak relative to the (200) $\beta-\mathrm{Si}_{3} \mathrm{~N}_{4}$ peak for coupons oxidized in pure oxygen at $1200,1250,1300,1350$, and $1400^{\circ} \mathrm{C}$, while Figure 8 shows the relative peak intensities of the (101) a-cristobalite phase for coupons oxidized in air at 1200,1300 , and $1400^{\circ} \mathrm{C}$. In addition the peak intensity was found to decrease as oxygen partial pressure decreased, as shown in Figure 9. 
Once again the relative peak intensities of the (101) $\alpha$-cristobalite was compared to the (200) $\beta-\mathrm{Si}_{3} \mathrm{~N}_{4}$ which did not vary during oxidation. In addition to these oxidations, a coupon was oxidized in dry oxygen at $1500^{\circ} \mathrm{C}$ to determine if other phases had formed at elevated temperatures. This coupon exhibited two additional silicate phases, a small peak associated with $\beta$ $\mathrm{Y}_{2} \mathrm{Si}_{2} \mathrm{O}_{7}$, which results from the transformation of $\alpha-\mathrm{Y}_{2} \mathrm{Si}_{2} \mathrm{O}_{7}$ to $\beta-\mathrm{Y}_{2} \mathrm{Si}_{2} \mathrm{O}_{7}$ between $1350^{\circ}-1400^{\circ} \mathrm{C}$ [19] and another strong peak identified as $\mathrm{Y}_{4} \mathrm{Si}_{3} \mathrm{O}_{12}$. Apparently, at very high temperature, $\left(>1500^{\circ} \mathrm{C}\right)$, transport of the $\mathrm{Y}_{2} \mathrm{O}_{3}$ densification agent is accelerated along the grain boundaries to the external scale or a liquid phase is formed. However, no weight gain data was taken at this condition to substantiate this.

Morphological Analysis SEM micrographs of the as-received $\mathrm{Si}_{3} \mathrm{~N}_{4}$ surfaces were relatively featureless, with the exception being small residual grinding marks. All oxidized coupons exhibited a microcracked scale similar to the coupon oxidized at $1300^{\circ} \mathrm{C}$ in air, which is shown in Figure 9. The fissures in this scale were attributed to the $\beta->\alpha$ cristobalite phase transformation at $273^{\circ} \mathrm{C}$. Small acicular crystallites of $\mathrm{Y}_{2} \mathrm{Si}_{2} \mathrm{O}_{7}$ were also observed on top of the cracked scale. At higher temperatures and oxygen partial pressures, these silicate crystallites were much more pronounced. Much larger needle-like crystals with larger aspect ratio were observed in pure oxygen at $1500^{\circ} \mathrm{C}$ as shown in Figure 10.

ESCA Analysis ESCA depth profiles of all oxidized specimens showed approximately the same surface concentrations of oxygen, silicon, yttrium; 52:35:10. The nitrogen content in the scale increased at the same rate that the 
oxygen and yttrium content decreased. Due to the alignment of the electron beam, it was difficult to determine the actual thickness of any silicon oxynitride layer that may have formed at the scale-substrate interface. Due to the extremely slow etch rate of silicon oxynitride in HF as previous studies have found $[10,20]$, this layer would act as an effective etch stop. Therefore, a coupon oxidized in air at $1300^{\circ} \mathrm{C}$ and etched in concentrated $\mathrm{HF}$ for approximately two minutes to remove the outer scale. Figure 11 shows an ESCA depth profile of an oxidized and HF etched coupon which revealed the presence of an oxynitride layer. The surface concentration of the coupon corresponds to a nitrogen rich oxynitride $46: 45: 8$ ratio of Si:N:O. This oxynitride layer is extremely thin (approximately $60 \AA$ ) based on the fact that only two minutes were needed to sputter through it. An accurate assessment of thickness of the oxynitride layer proved difficult, since the oxide, oxynitride, and substrate sputter at different rates. It is also possible that some of the oxynitride may have been etched, which adds further uncertainty to the measurement. Therefore, this oxynitride layer may be considerably thicker than $60 \AA$. 


\section{DISCUSSION}

When $\mathrm{Si}_{3} \mathrm{~N}_{4}$ is exposed to oxidizing ambients at high temperatures, an outer scale of silica is formed on the surface. The formation of this silica scale occurs by one of two oxidation mechanisms, according to the recent literature. The first oxidation mechanism involves the reaction of oxygen with $\mathrm{Si}_{3} \mathrm{~N}_{4}$ to form $\mathrm{SiO}_{2}$. giving off nitrogen gas as a product according to equation (1). This reaction is a one step process in which the $\mathrm{Si}_{3} \mathrm{~N}_{4}$ substrate is directly oxidized to form $\mathrm{SiO}_{2}$.

A second oxidation mechanism involves the formation of an intermediate silicon oxynitride phase, as illustrated by the sequential reactions below. The first reaction is the oxidation of the $\mathrm{Si}_{3} \mathrm{~N}_{4}$ to a silicon oxynitride phase by the reaction:

$$
3 \mathrm{O}_{2}+4 \mathrm{Si}_{3} \mathrm{~N}_{4}-->6 \mathrm{Si}_{2} \mathrm{ON}_{2}+2 \mathrm{~N}_{2}
$$

The silicon oxynitride phase then reacts with oxygen to produce $\mathrm{SiO}_{2}$ and nitrogen gas:

$$
3 \mathrm{O}_{2}+2 \mathrm{Si}_{2} \mathrm{ON}_{2}->4 \mathrm{SiO}_{2}+2 \mathrm{~N}_{2}
$$

The stoichiometry of this layer does vary and is best represented as $\mathrm{SiO}_{\mathrm{x}} \mathrm{N}_{\mathrm{y}}$ or $\mathrm{Si}_{x} \mathrm{O}_{y} \mathrm{~N}_{z}[10,18,20]$. Furthermore this silicon oxynitride layer was found to be more structurally dense than the $\mathrm{SiO}_{2}$ layer leading to the conclusion that diffusion of molecular oxygen through this dense oxynitride layer is the rate limiting step for the oxidation of CVD $\mathrm{Si}_{3} \mathrm{~N}_{4}[10]$. This could not be confirmed by our results on NT154, since it was difficult to determine the exact thickness of this layer. However, it is sufficient to say that such a layer exists in the scale at the oxide-substrate interface.

For HPSN ceramics, it is the generally agreed that the outward diffusion of the cation species to the external scale is the rate limiting step in the overall 
oxidation process. The oxidation of higher purity forms of silicon nitride suggests that the inward diffusion of oxygen through the oxide scale is the rate limiting step. Since our hot isostatically pressed $\mathrm{Si}_{3} \mathrm{~N}_{4}$ coupons contains approximately $4 \mathrm{wt} \% \mathrm{Y}_{2} \mathrm{O}_{3}$ it was anticipated that the rate limiting step would be the outward diffusion of yttrium along the grain boundaries in the nitride into the external oxide scale. However, observations during the initial phases of oxidation of this silicon nitride suggests that the behavior was more complicated than this.

Oxide growth rate hot isostatically pressed $\mathrm{Si}_{3} \mathrm{~N}_{4}$ was dependent on both temperature and oxygen partial pressure. High temperature oxidation in dry oxygen showed classic parabolic rate kinetics as seen in Figure 3, which indicates a diffusion controlled growth mechanism. However logarithmic rate kinetics were observed when these same coupons were oxidized at an oxygen partial pressure of $0.20 \mathrm{~atm}$ over the same temperature range.

This logarithmic rate behavior has been previously observed for this material [21]. The insert in Figure 6 shows that in the first 5-10 minutes of oxidation, very rapid oxidation of the $\mathrm{Si}_{3} \mathrm{~N}_{4}$ occurred. During the early stages of oxidation it is suspected that a very thin, porous, non-protective film of $\mathrm{SiO}_{2}$ forms on the surface of the nitride, as previously observed for silicon [22]. This allows the oxidant to remain in contact with the silicon nitride during the early stages of oxidation in dry air and thus, results in rapid initial growth. At higher oxygen partial pressures, it is believed that a dense, coherent, oxide scale is formed by the coalescence of this scale and creates an effective diffusion barrier. The growth kinetics change over much more quickly to parabolic rate behavior when the oxygen partial pressure in the furnace atmosphere is increased. Continued oxidation in the dry oxygen ambient showed a steady weight gain, while reduced oxygen partial pressures quickly reached a limiting 
weight gain. A previous study [21] on the oxidation behavior of NT154 attributed the non-parabolic rate behavior to the preferential oxidation within the grain boundaries. This preferential oxidation induced compressive stresses in the bulk grains and reduced lattice spacing, which retarded oxygen permeability in the grain boundary phase. This explanation does yield a viable mechanism for our oxidation studies at reduced oxygen partial pressures, but does not explain the observed parabolic rate kinetics for these oxidation studies performed in dry oxygen ambients.

Another possible explanation for the large difference in rate behavior observed under reduced oxygen partial pressure conditions, is the formation of a nitrogen rich oxynitride phase at the scale-substrate interface. Previous studies [10] found the oxynitride layer to be more structurally dense than the silica scale. At a high oxygen partial pressure, it is also more thermodynamically favorable for oxygen to react with the silicon oxynitride layer. This would inherently create a thinner oxynitride phase. At reduced oxygen partial pressures, this oxynitride may slow down the outward diffusion of nitrogen and thus, stabilize a nitrogen rich oxynitride phase. Thereafter, oxygen would diffuse to the oxynitride-substrate interface where it would react to form additional oxynitride and thus, thicken this oxynitride layer. This explanation does coincide with our observations, however, it was extremely difficult to characterize the oxynitride layer. Other studies of a silicon oxynitride intermediate phase found the oxide layer to consist of graded compositions making it difficult to determine the exact thickness of the layer $[20,23]$. Evidence of a thin, nitrogen rich, silicon oxynitride layer is evident from the ESCA depth profile in Figure 12. However, the etching performed in this study may have removed some of the $\mathrm{SiO}_{x} \mathrm{~N}_{y}$, making an accurate assessment of the layer difficult. Therefore, further evaluation of the oxynitride layer is necessary 
before its role in the oxidation process can be determined.

The oxide scale formed on the $\mathrm{Si}_{3} \mathrm{~N}_{4}$ coupons consisted of both silica and yttrium silicate and corresponds to oxide scales typically found on a $\mathrm{Si}_{3} \mathrm{~N}_{4}$ ceramics fabricated with various oxide densification aids. Specimens oxidized in pure oxygen showed a continual increase in intensity of the (101) $\alpha$ cristobalite peak with increasing oxidation temperature, as shown in Figures 7 and 8 . There is also a corresponding increase in the (101) $\alpha$-cristobalite peak intensity with increasing oxygen partial pressure (Figure 9). It appears that the presence of oxygen in the scale increases the stability of the cristobalite phase. This assumption is supported by the fact that the oxidation of a coupon at $1400^{\circ} \mathrm{C}$ in dry oxygen had greater crystallinity and a lower weight gain than $\mathrm{Si}_{3} \mathrm{~N}_{4}$ coupons oxidized at $1400^{\circ} \mathrm{C}$ in dry air. The crystallization of the $\mathrm{SiO}_{2}$ in the scale may also be partially responsible for the growth kinetics observed. It is suspected that the $\alpha$-cristobalite phase does not form an effective diffusion barrier relative to that of an amorphous oxide. Literature values of the oxygen diffusivity [24] have found the diffusion of oxygen through amorphous $\mathrm{SiO}_{2}$ to be approximately two orders of magnitude greater that crystalline $\mathrm{SiO}_{2}$ due to its lower density. However, it is more difficult to create a coherent scale of crystalline $\mathrm{SiO}_{2}$ on the substrate since the crystallization of this scale results in substantial microcracking. The micrograph in Figure 10 shows how the volume change promotes cracks in the scale, thereby creating short circuit diffusion paths for the ingress of oxygen through the scale. In the case of a totally amorphous scale a more continuous coating with less breaks and fissures would reduce the extent of these short circuit paths.

Therefore, oxidation in dry oxygen may have resulted in more rapid transport due to the transformation of the glassy phase to cristobalite. This most likely created a less protective oxide scale at temperatures below $1400^{\circ} \mathrm{C}$. At 
reduced oxygen partial pressures, however, the glassy phase did not transform to $\beta$-cristobalite as readily since ample oxygen was not present in the gas phase to stabilize the $\beta$-cristobalite structure. This could have significantly reduced the diffusion of oxygen to the substrate by providing a more effective diffusion barrier. It is also apparent that the oxidation temperature contributes heavily to the extent of crystallinity of the oxide scale, as illustrated in Figures 7 and 8.

The formation of the silicate phases is observed occurs via a solid state reaction of the $\mathrm{SiO}_{2}$ scale with the sintering aid. The silicate phases formed in the oxide scale were dependent on the oxidation temperature; $\beta-\mathrm{Y}_{2} \mathrm{Si}_{2} \mathrm{O}_{7}$ and $\mathrm{Y}_{4} \mathrm{Si}_{3} \mathrm{O}_{12}$ were observed at temperatures above $1400^{\circ} \mathrm{C}$, while $\alpha$ and $\delta-\mathrm{Y}_{2} \mathrm{Si}_{2} \mathrm{O}_{7}$ were observed at all temperatures. The $\alpha$ and $\delta-Y_{2} \mathrm{Si}_{2} \mathrm{O}_{7}$ XRD peak intensities were very weak and appeared mainly as background in the spectra. In previous studies $[1,6,7,8]$ it was observed that the silicate phases were more prevalent at increasing temperatures. This observation, along with others lead us to the conclusion that the diffusion of the cation impurities in the bulk material was not the rate determining step in this form of $\mathrm{Si}_{3} \mathrm{~N}_{4}$. Since we did not see an increase in the amount of silicate phase in the scale (over the temperature range $1100^{\circ}-1400^{\circ} \mathrm{C}$ ), we believe that the formation of this phase did not affect the rate kinetics. The very intense $\mathrm{Y}_{4} \mathrm{Si}_{3} \mathrm{O}_{12}$ peak observed at $1500^{\circ} \mathrm{C}$, along with the growth of yttrium silicate crystallites shown in the micrograph of Figure 10 , seem to support the conclusion that the diffusion of the sintering aid along the grain boundaries was enhanced at high temperatures. It is evident that at these higher temperatures $\left(>1500^{\circ} \mathrm{C}\right)$, the oxidation mechanism and rate limiting step has changed. 


\section{CONCLUSIONS}

The oxidation of hot isostatically pressed $\mathrm{Si}_{3} \mathrm{~N}_{4}$ in dry oxygen follows a parabolic growth law with an activation energy of $297 \mathrm{~kJ} / \mathrm{mol}$. The resulting oxide scale consisted largely of $\alpha$-cristobalite and amorphous $\mathrm{SiO}_{2}$ with a small amount of yttrium silicate. However, the oxidation of hot isostatically pressed $\mathrm{Si}_{3} \mathrm{~N}_{4}$ in reduced oxygen partial pressures resulted in a logarithmic growth law at temperatures $<1400^{\circ} \mathrm{C}$ and a parabolic rate law at temperatures $\geq 1400^{\circ} \mathrm{C}$. The logarithmic rate behavior observed at low temperatures consisted of an initial rapid oxidation followed by a very slow increase in oxide growth. XRD analysis of the oxidized hot isostatically pressed $\mathrm{Si}_{3} \mathrm{~N}_{4}$ showed a decrease in crystallinity of the $\alpha$-cristobalite phase present in the oxide scale as the oxygen partial pressure and oxidation temperature was reduced. ESCA analysis of the oxide scale formed by the oxidation of hot isostatically pressed $\mathrm{Si}_{3} \mathrm{~N}_{4}$ in dry air showed the presence of a thin, nitrogen-rich silicon oxynitride layer at the scalesubstrate interface.

No single oxidation mechanism that has been considered in this investigation can fully explain the observed oxidation kinetics over the entire range of temperatures and oxygen partial pressures studied. However, we believe that one or more of the following mechanisms may play a role in the overall oxidation process.

(1) Oxidation in dry oxygen resulted in the rapid formation of a thin oxide layer whose subsequent growth was controlled by the diffusion of oxygen through this layer. Oxidation in reduced oxygen partial pressures resulted in a porous oxide layer that allowed rapid oxidation of the hot isostatically pressed $\mathrm{Si}_{3} \mathrm{~N}_{4}$ substrate until complete coverage of an oxide film was achieved. Thereafter, this coherent oxide layer provided a barrier to further oxidation and yielded the 
observed logarithmic growth.

(2) The formation of a dense, oxidation resistant silicon oxynitride layer in reduced oxygen partial pressures was observed. This oxynitride layer impeded further oxidation under these more reducing conditions by forming an effective diffusion barrier. This oxynitride phase may have been stabilized by the higher nitrogen partial pressures associated with oxidation under these more reducing conditions.

(3) Oxidations performed at higher oxygen partial pressures and temperatures resulted in the formation of a more crystalline oxide scale, as indicated by SEM and XRD analysis. Crystalline or partially crystalline oxide scales are not as protective as amorphous oxide scales since grain boundary or interphase boundary transport is usually much more rapid than bulk transport. 


\section{LITERATURE CITED}

[1] Singhal, S. C."Thermodynamics and Kinetics of Oxidation of Hot-Pressed Silicon Nitride.", Journal of Materials Science, 11, 500-509, 1976.

[2] Tripp, W. C.; and Graham, H. C."Oxidation of $\mathrm{Si}_{3} \mathrm{~N}_{4}$ in the Range $1300^{\circ}$ to $1500^{\circ} \mathrm{C}$.", Journal of the American Ceramic Society, Vol. 5 9, No. 9-10, 399-403, 1976.

[3] Kiehle, A. J.; Heung, L. K.; Gielisse, P. J.; and Rockett, T. J."Oxidation Behavior of Hot-Pressed $\mathrm{Si}_{3} \mathrm{~N}_{4}$ ", Journal of the American Ceramic Society, Vol. 58, No. 1-2, 17-20, 1975.

[4] Vaughn, W. L. and Machs, H. G."Active-to-Passive Transition in the Oxidation of Silicon Carbide and Silicon Nitride in Air.", Journal of the American Ceramic Society, Vol. 73 [6], 1540-1543, 1990.

[5] Clarke, D. R.; and Lange, F. F."Oxidation of $\mathrm{Si}_{3} \mathrm{~N}_{4}$ Alloys: Relation to Phase Equilibria in the System $\mathrm{Si}_{3} \mathrm{~N}_{4}-\mathrm{SiO}_{2}-\mathrm{MgO}$.", Journal of the American Ceramic Society, Vol. 6 3, No. 9-10, 586-593, 1980.

[6] Cubicciotti, D.; and Lau, K. H."Kinetics of Oxidation of Hot-Pressed Silicon Nitride Containing Magnesia.", Journal of the American Ceramic Society, Vol. 61 , No. 11-12, 512-517, 1978.

[7] Babini, G. N.; Bellosi, A.; and Vincenzini, P.“A Diffusion Model for the Oxidation of Hot Pressed $\mathrm{Si}_{3} \mathrm{~N}_{4}-\mathrm{Y}_{2} \mathrm{O}_{3}-\mathrm{SiO}_{2}$ Materials.", Journal of Materials Science, 1 9, 1029-1042, 1984.

[8] Mieskowski, D. M.; and Sanders, W. A."Oxidation of Silicon Nitride Sintered with Rare-Earth Oxide Additions.", Journal of the American Ceramic Society, Vol. 68 [7], C-160-C-163, 1985.

[9] Falk, L. K. L.; and Engstrom, E. U."Elemental Concentration Profiles in an Oxidized Silicon Nitride Material.", Journal of the American Ceramic Society, Vol. 74 [9], 2286-2292, 1991.

[10] Du, H.; Tressler, R. E.; Spear, K. E.; and Pantano, C. G."Oxidation Studies of Crystalline CVD Silicon Nitride.", Journal of the Electrochemical Society, Vol. 136, No. 5, 1527-1536, 1989.

[11] Ogbuji, L. U. J. T.; and Smialek, J. L."Evidence from Transmission Electron Microscopy for an Oxynitride Layer in Oxidized $\mathrm{Si}_{3} \mathrm{~N}_{4}$.", Journal of the Electrochemical Society, Vol. 138, No. 10, L51-L56, 1991.

[12] Hirai, T.; Niihara, K. and Goto, T."Oxidation of CVD $\mathrm{Si}_{3} \mathrm{~N}_{4}$ at $1550^{\circ}$ to $1650^{\circ} \mathrm{C}$.", Journal of the American Ceramic Society, Vol. 63 , No 7-8, 419-424, 
[13] Choi, D. J.; Fischbach, D. B.; and Scott, W. D.“Oxidation of ChemicallyVapor-Deposited Silicon Nitride and Single-Crystal Silicon.", Journal of the American Ceramic Society, Vol. 7 2, No. 7, 1118-1123, 1989.

[14] Du, H.; Tressler, R. E.; and Spear, K. E., "Thermodynamics of the Si-N-O System and Kinetic Modeling of Oxidation of $\mathrm{Si}_{3} \mathrm{~N}_{4}$.", Journal of the Electrochemical Society, Vol. 136, No. 11, 3210-3215, 1989.

[15] Gregory, O. J.; and Richman, M. H.“Thermal Oxidation of Sputter-Coated Reaction-Bonded Silicon Nitride.", Journal of the American Ceramic Society, Vol. 67 , No. 5, 335-340, 1984.

[16] Haggerty, J. S.; Lightfoot, A.; Ritter, J. E.; Gennari, P. A.; and Nair, S. V."Oxidation and Fracture Strength of High-Purity Reaction-Bonded Silicon Nitride.", Journal of the American Ceramic Society, Vol. 72 [9], 1675-79, 1989.

[17] Cranmer, D. C.; Hockey, B. J.; and Wiederhorn, S. M."Creep and Creep Rupture of HIP'ed $\mathrm{Si}_{3} \mathrm{~N}_{4}$.", Ceramic Engineering and Science Proceedings, 12 [9-10], 1862-1872, 1991.

[18] Fourrier, A.; Bosseboeuf, A.; Bouchier, D.; and Gautherin, G."Thermal Oxidation in Wet Oxygen Reactive Ion-Beam Sputter-Deposited Silicon Nitride Films.", Journal of the Electrochemical Society, Vol. 138, No. 4, 1084-1089, 1991.

[19] X-Ray diffraction card file \# 22-994.

[20] Loewenstein, L. M.; and Tipton, C. M."Chemical Etching of Thermally Oxidized Silicon Nitride: Comparison of Wet and Dry Etching Methods.", Journal of the Electrochemical Society, Vol. 138, No. 5, 1389-1394, 1991.

[21] Strangeman, T. E.; and Fox D. S."Strength Retention of NT154 Silicon Nitride Exposed to High-Temperature Oxidation and Hot Corrosion Environments", Presented at the 184th Meeting of The Electrochemical Society, New Orleans, LA, October 12, 1993.

[22] Ghandhi, S. K., VLSI Fabrication Principles, New York, John Wiley \& Sons, Inc., pp. 462-463, 1994.

[23] Du, H.; Houser, C. A.; Tressler, R. E.; Spear, K. E.; and Pantano, C. G. "Isotopic Studies of Oxidation of $\mathrm{Si}_{3} \mathrm{~N}_{4}$ and Si using SIMS.", Journal of the Electrochemical Society, Vol. 137, No. 2, 741-742, 1990.

[24] Kofstad, P. High Temperature Corrosion, Elsevier Science Publishing Co., New York, pp. 123, 1988. 


\section{FIGURE CAPTIONS}

Figure 1. ESCA depth profile of an as-received HIP'ed silicon nitride coupon.

Figure 2. Experimental setup used for high temperature oxidation runs.

Figure 3. Weight change versus time curves for HIP'ed silicon nitride coupons oxidized in dry oxygen at 1 atm pressure.

Figure 4. Parabolic oxidation curves for HIP'ed silicon nitride coupons oxidized in dry oxygen at $1 \mathrm{~atm}$ pressure.

Figure 5. Parabolic rate constants for HIP'ed silicon nitride coupons oxidized in dry oxygen at 1atm pressure as a function of reciprocal temperature.

Figure 6. Weight change versus time curves for HIP'ed silicon nitride coupons oxidized in dry air at $1 \mathrm{~atm}$ pressure.

Figure 7. XRD peak intensity of (101) $\alpha$-cristobalite relative to (200) $\beta$ - $\mathrm{Si}_{3} \mathrm{~N}_{4}$ for HIP'ed silicon nitride coupons oxidized at various temperatures in dry oxygen.

Figure 8. XRD peak intensity of (101) $\alpha$-cristobalite relative to (200) $\beta-\mathrm{Si}_{3} \mathrm{~N}_{4}$ for HIP'ed silicon nitride coupons oxidized at various temperatures in dry air.

Figure 9. XRD peak intensity of (101) $\alpha$-cristobalite relative to (200) $\beta-\mathrm{Si}_{3} \mathrm{~N}_{4}$ for HIP'ed silicon nitride coupons oxidized under various oxygen partial pressures at $1400^{\circ} \mathrm{C}$.

Figure 10. SEM micrograph of a HIP'ed silicon nitride coupon oxidized in dry oxygen at $1300^{\circ} \mathrm{C}$.

Figure 11. SEM micrograph of a HIP'ed silicon nitride coupon oxidized in dry oxygen at $1500^{\circ} \mathrm{C}$.

Figure 12. ESCA depth profile of a HIP'ed silicon nitride coupon oxidized at $1300^{\circ} \mathrm{C}$ in dry air and etched in HF. 


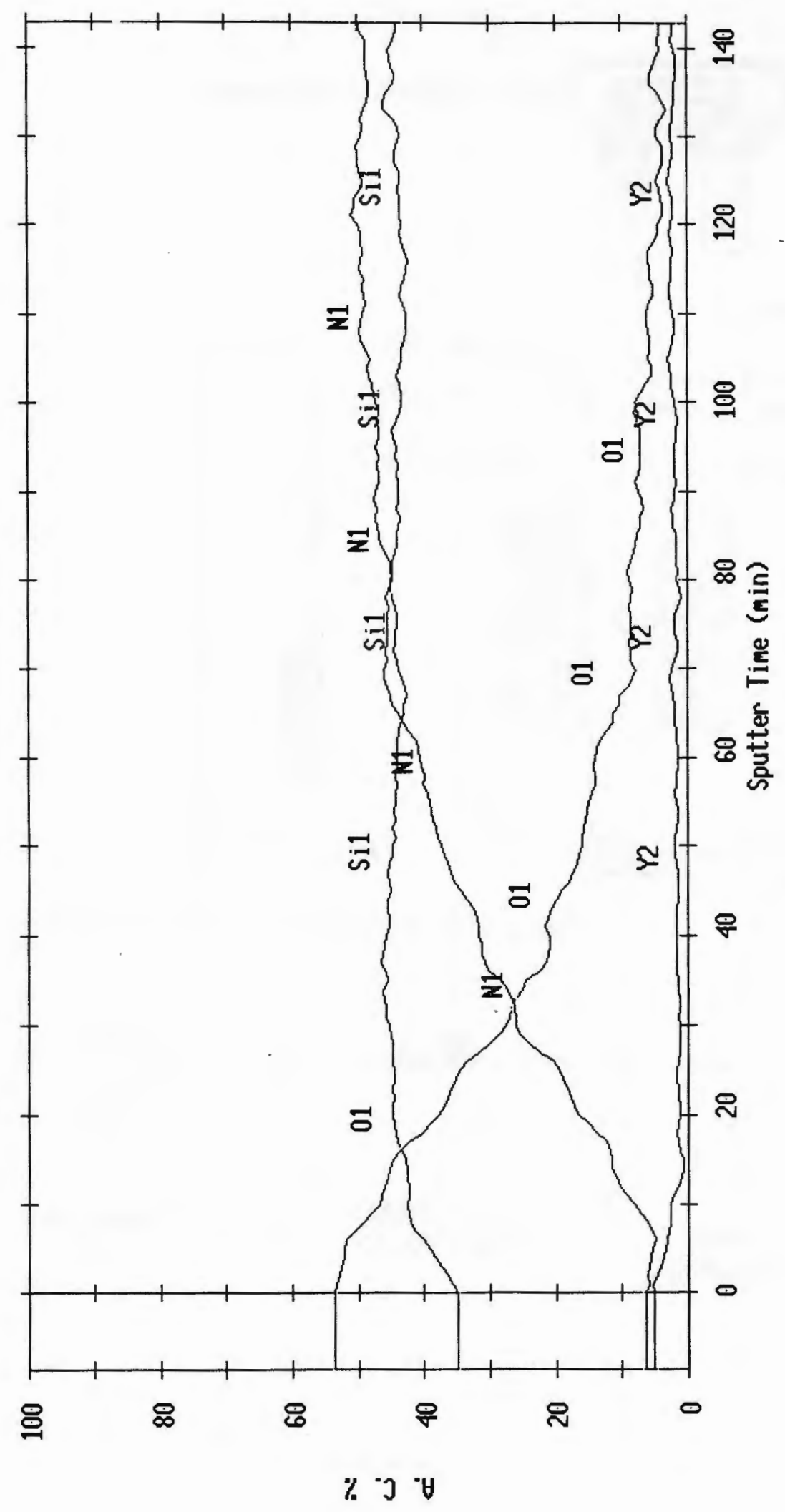

Figure 1 


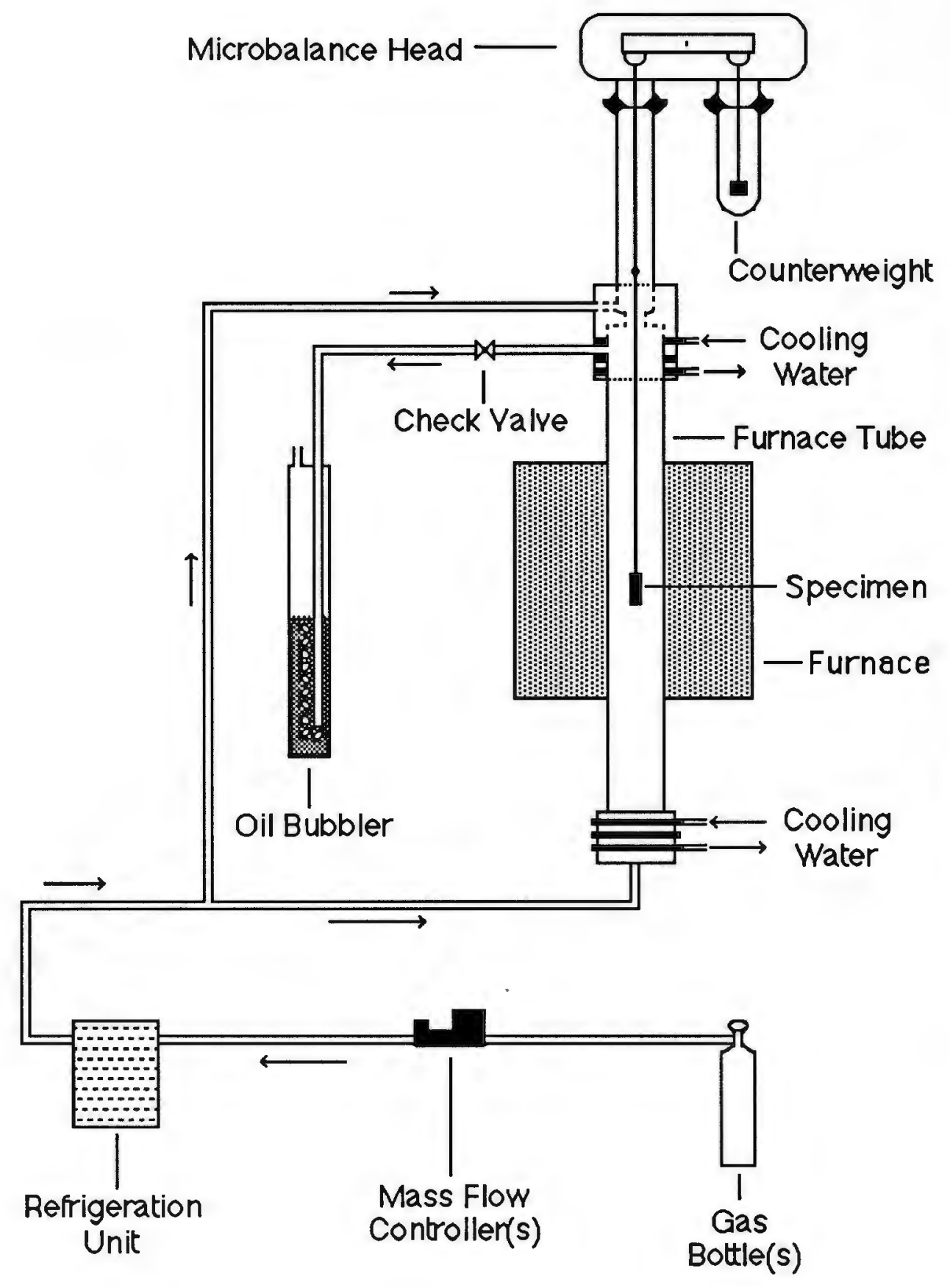

Figure 2 


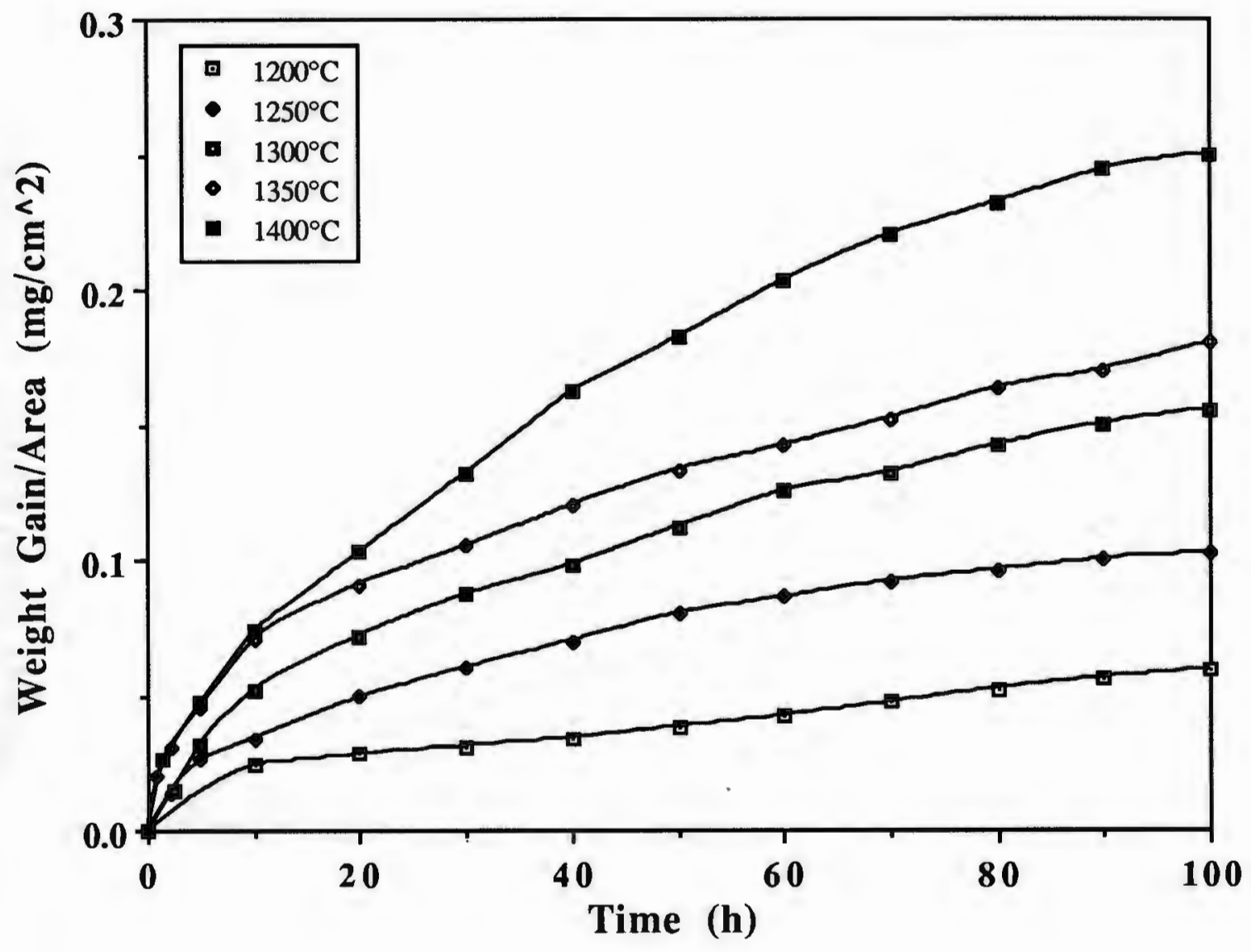

Figure 3 


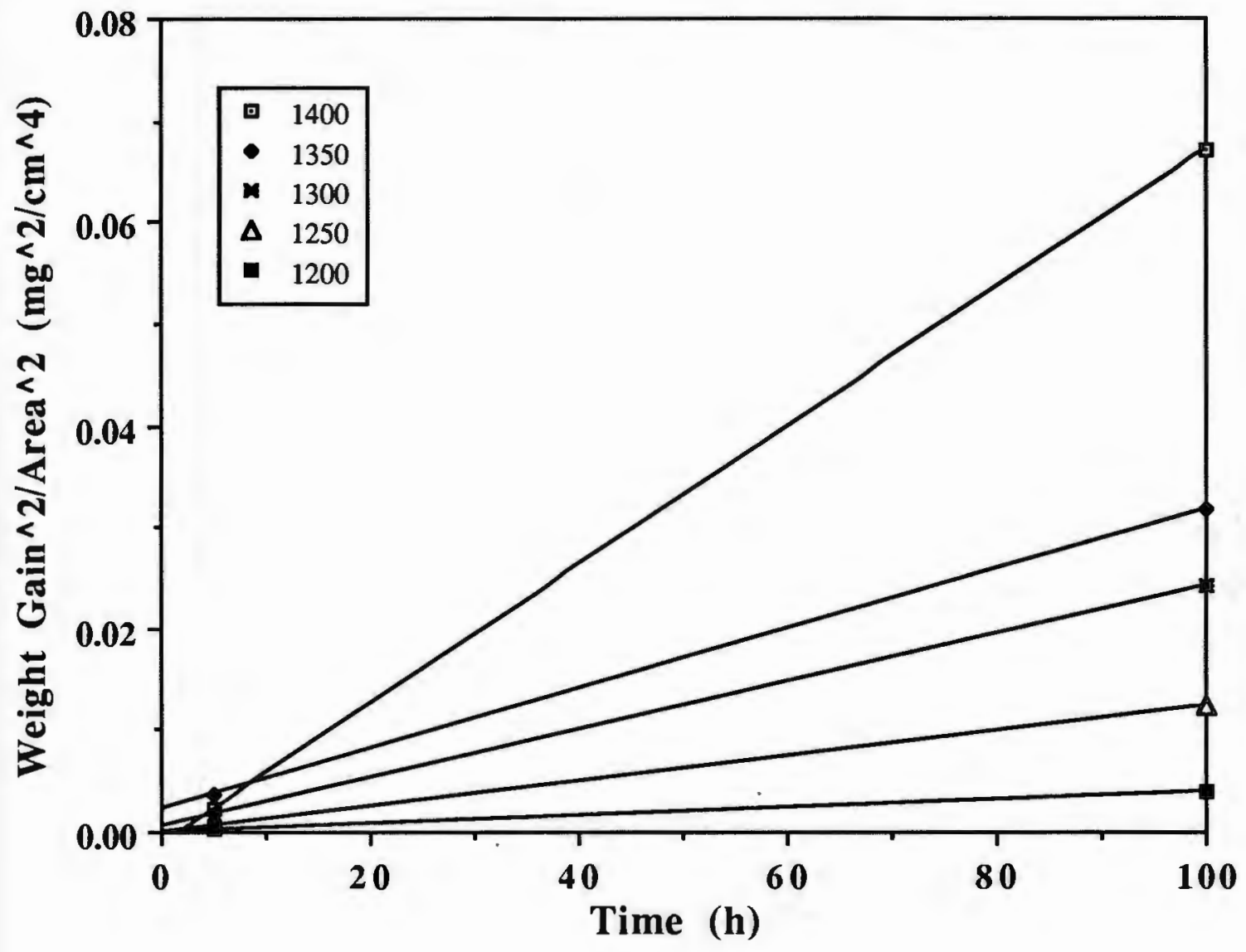

Figure 4 


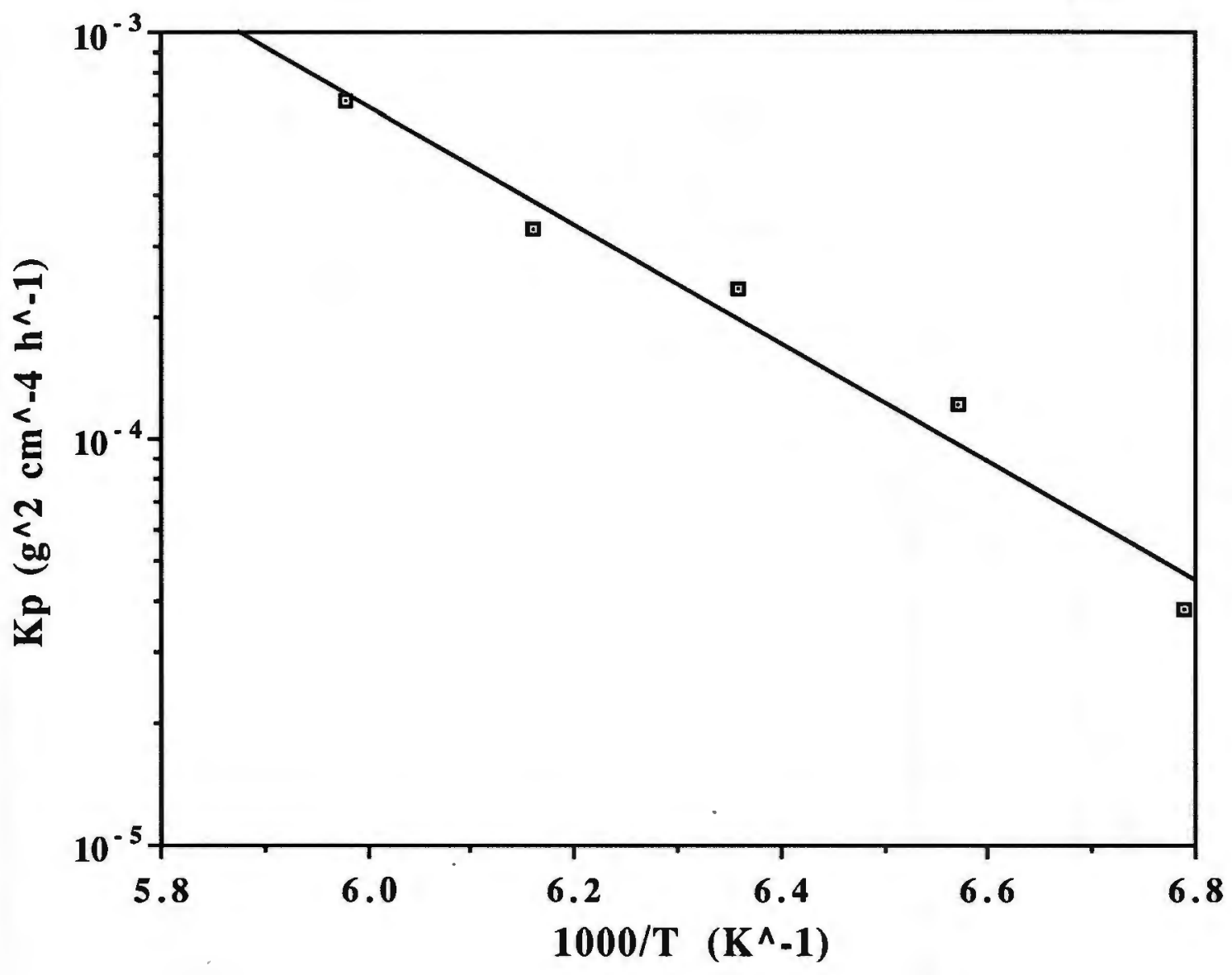

Figure 5 


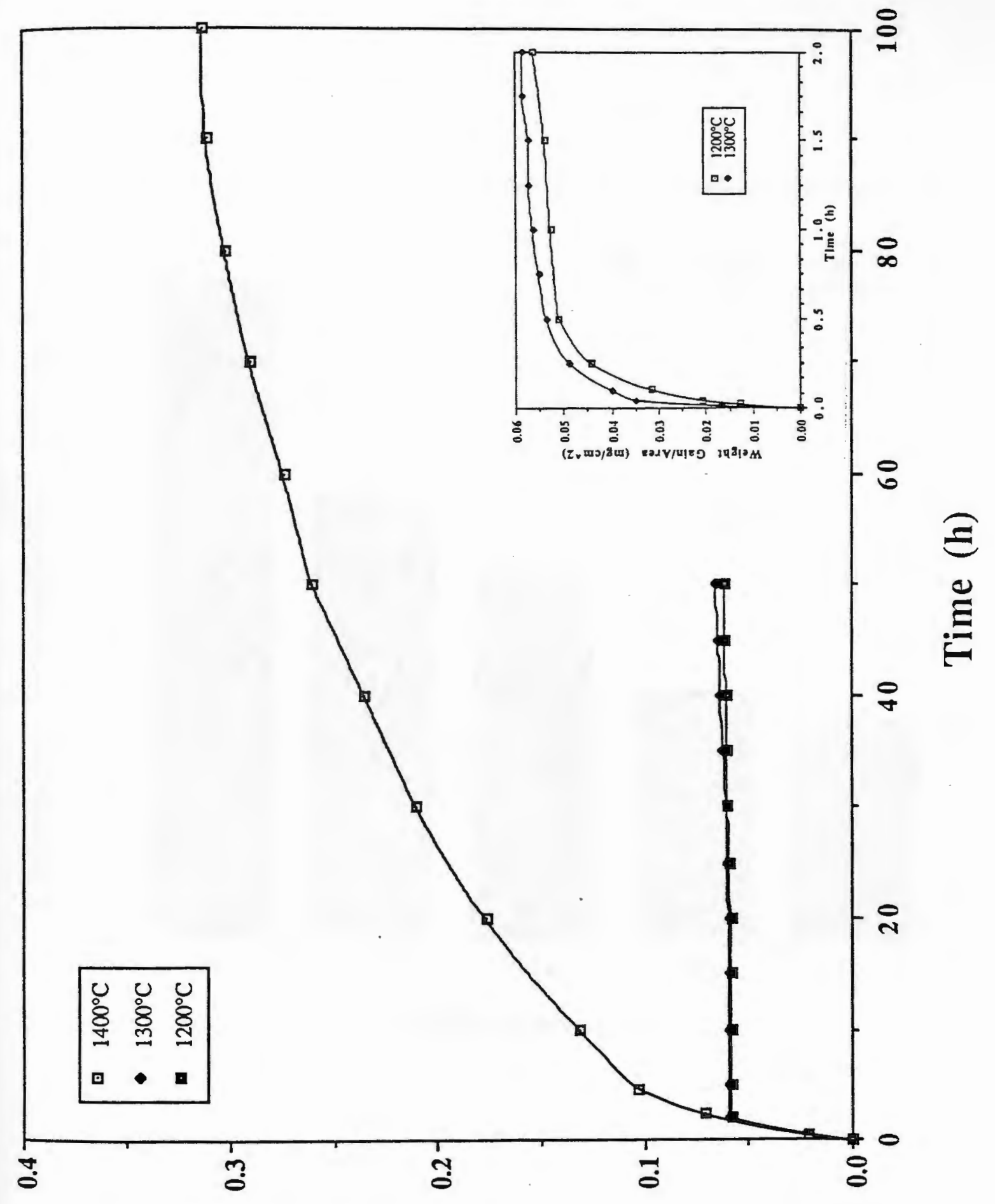

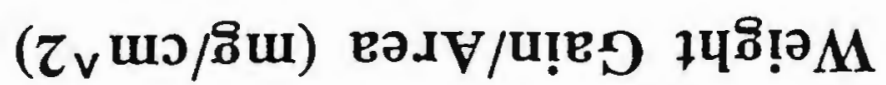

Figure 6 


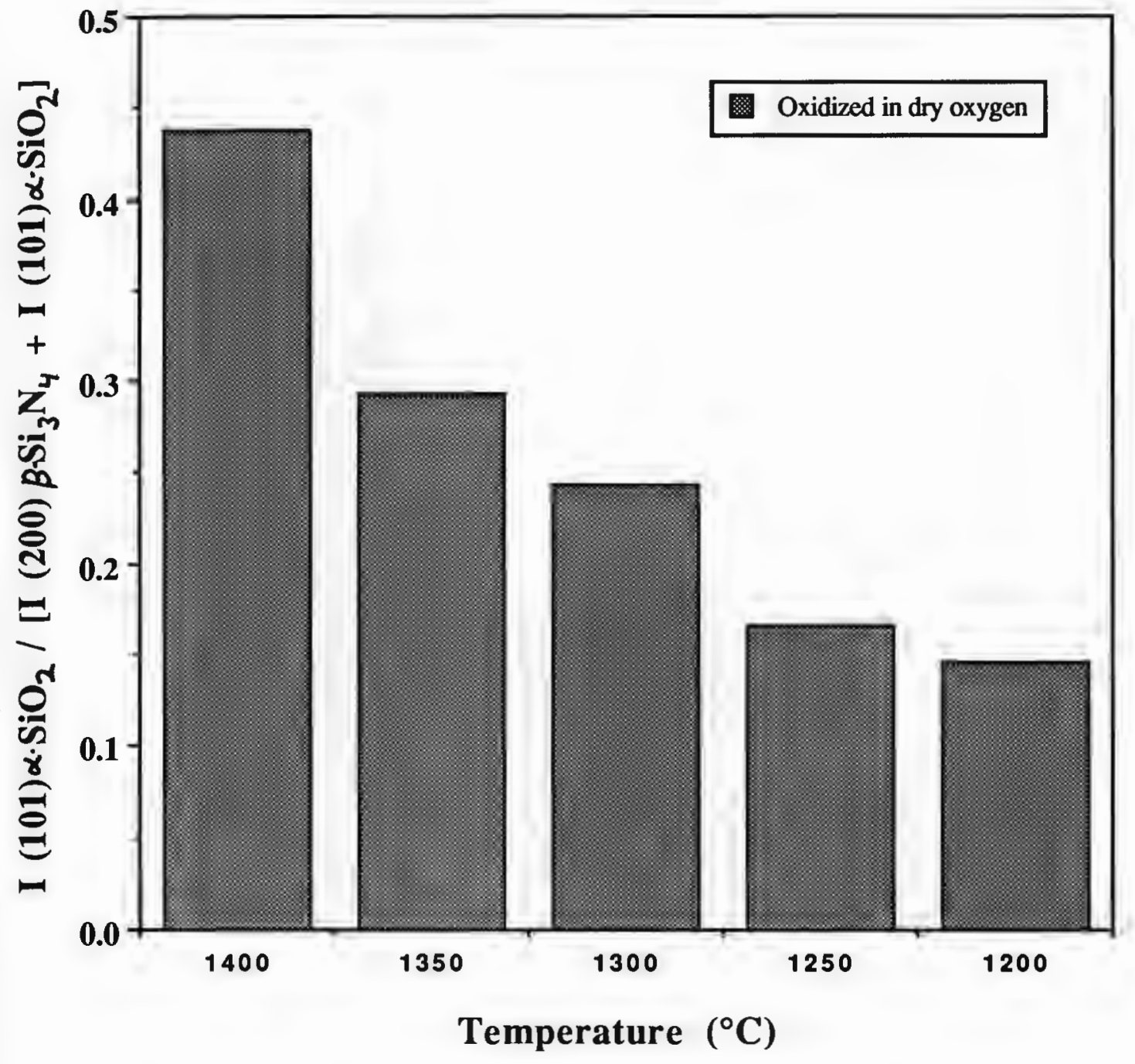

Figure 7 


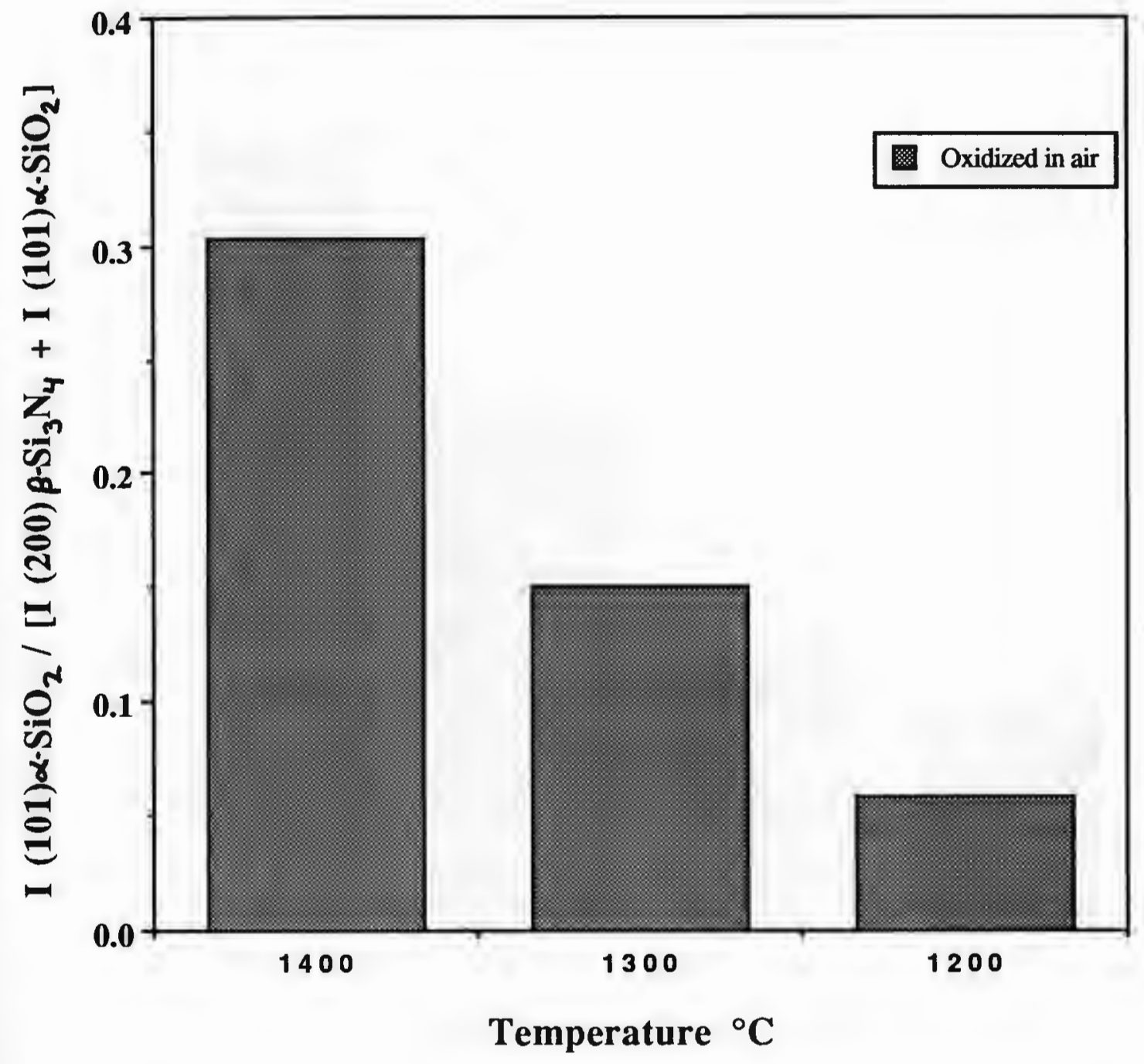

Figure 8 


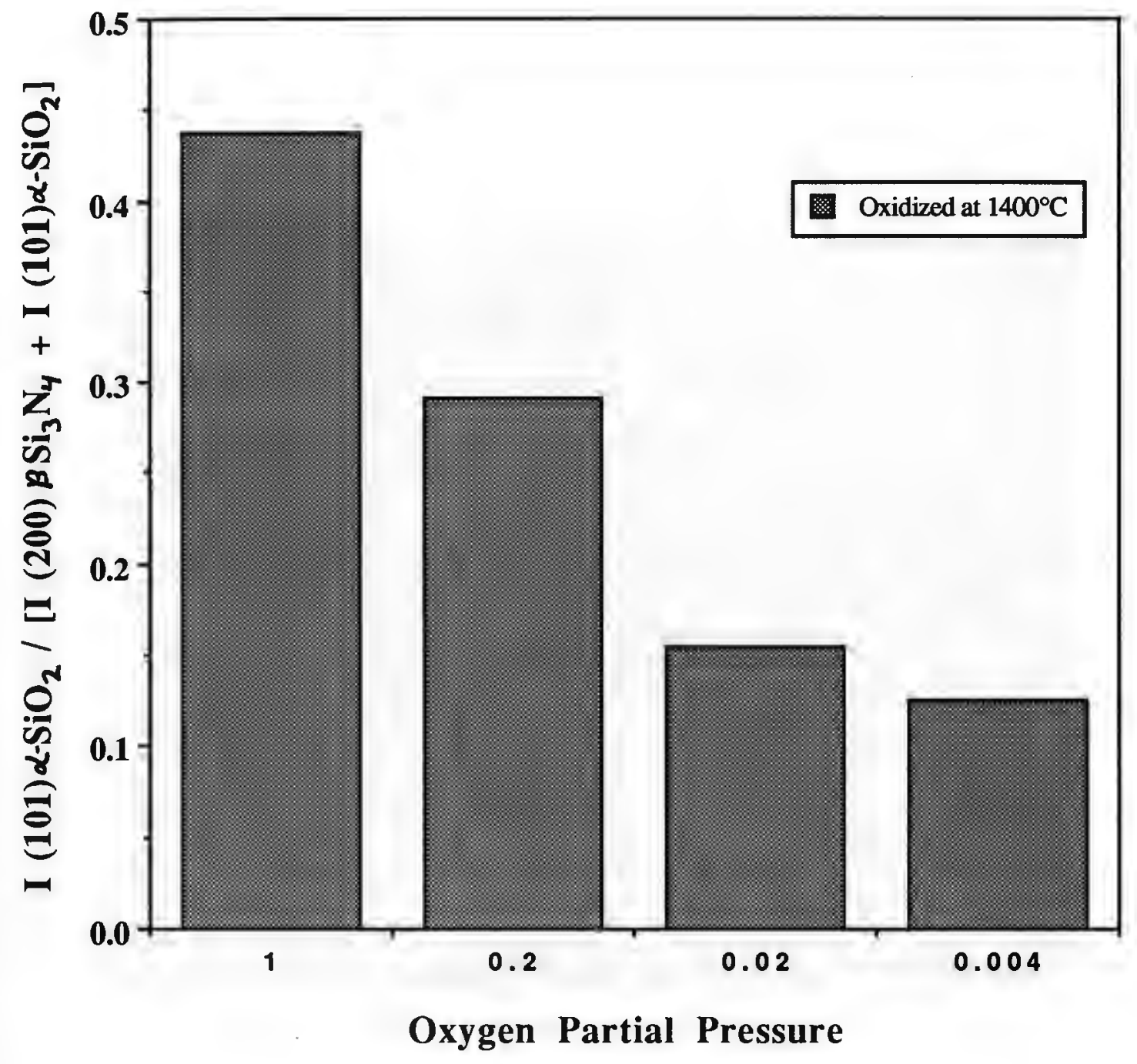

Figure 9 


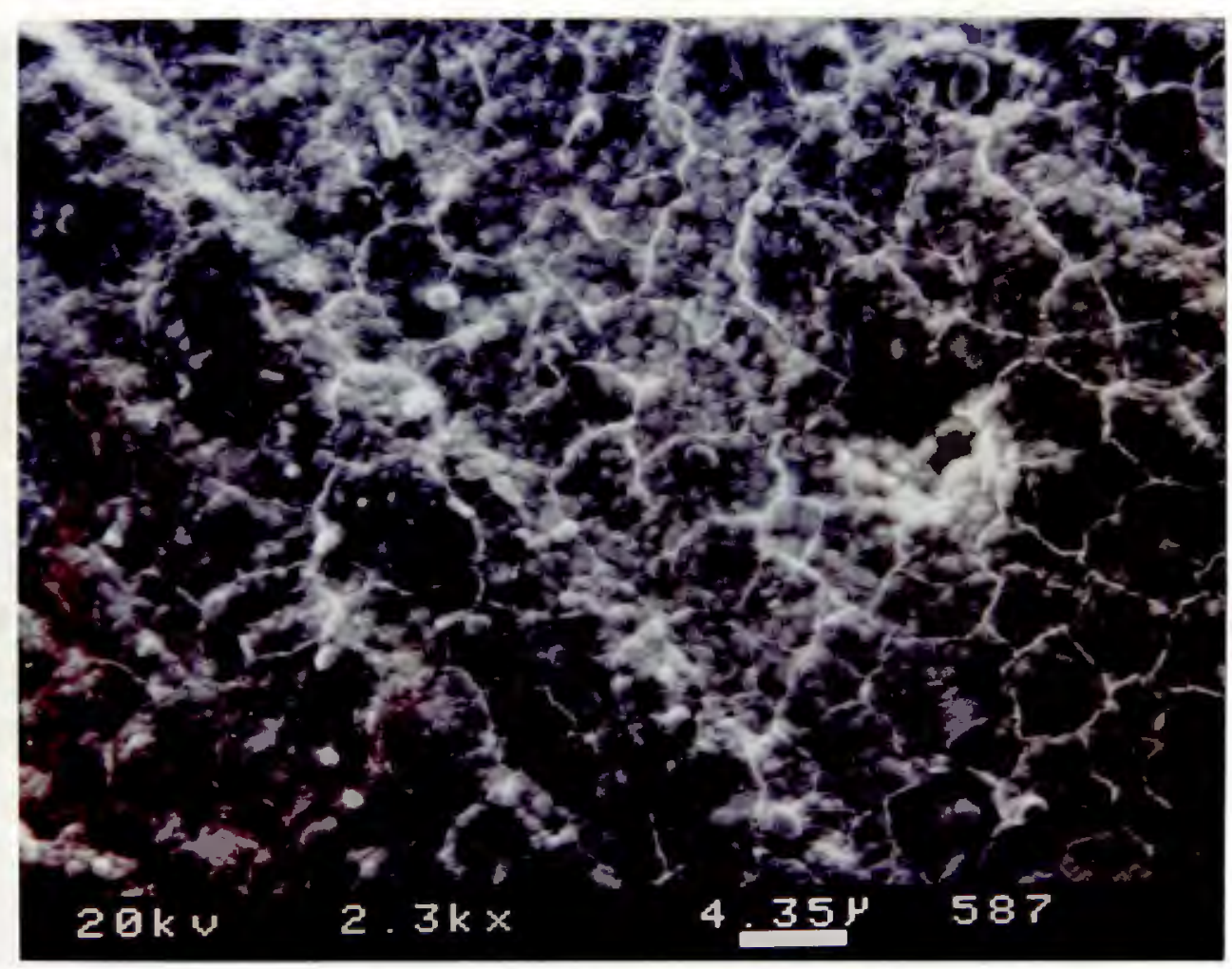

Figure 10 


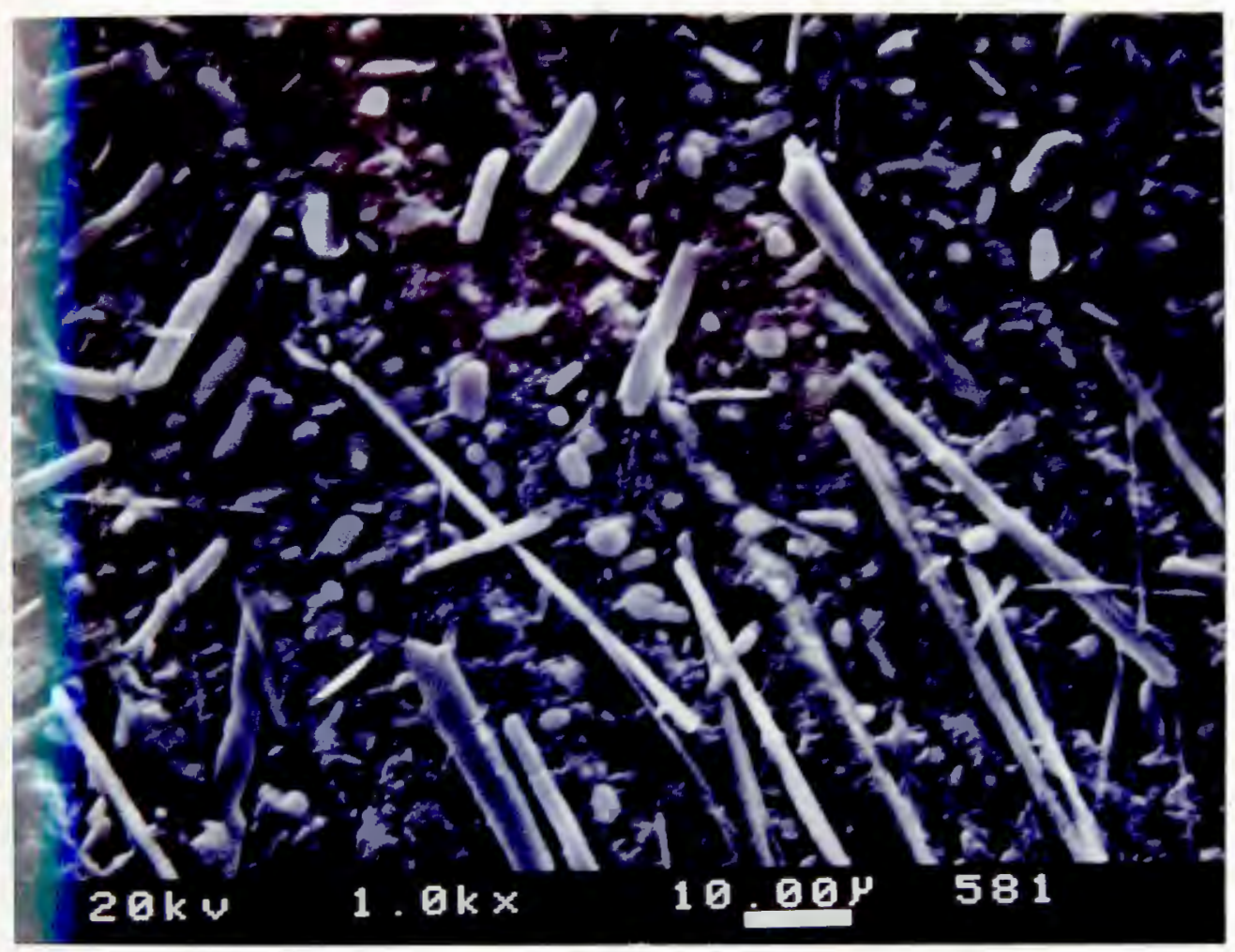

Figure 11 


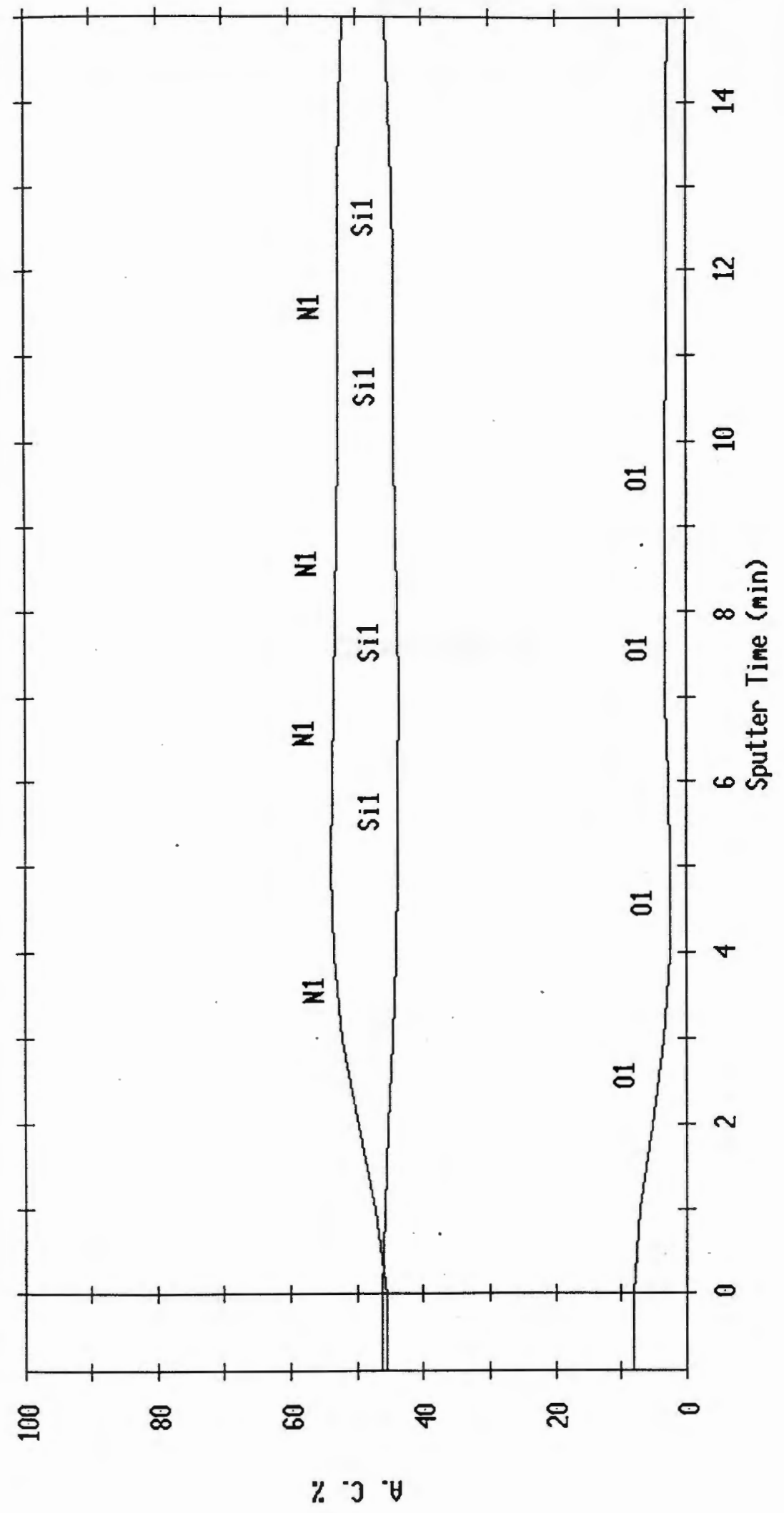

Figure 12 
CHAPTER III 


\section{Abstract}

With the introduction of newly developed, high strength, ceramic materials in gas turbine engines, there is a subsequent increase in efficiency and thrust-to-weight ratio since operating temperatures can be be significantly increased. Conventional temperature measurement techniques, such as embedded wire thermocouples, are not feasible due to the difficulty in machining ceramics the serious structural problems that can result. Surface mount technology is the only alternative to accurately measure the surface temperature of these new ceramic jet engine components. A thin film thermocouple system has been effectively fabricated on $\mathrm{Si}_{3} \mathrm{~N}_{4}$ substrates. The thermocouple consists of $1 \mu \mathrm{m} \mathrm{Pt}$ and Pt:10Rh sensor elements deposited onto the $\mathrm{Si}_{3} \mathrm{~N}_{4}$ substrate by if sputtering. Lead wires are bonded using parallel gap welding and an $\mathrm{Al}_{2} \mathrm{O}_{3}$ overcoat is sputtered over the entire pattern to prevent high temperature oxidation of the sensor elements. Fabricated sensors are then tested in a high temperature, controlled atmosphere, furnace where a variety of temperature gradients can be applied to the sensor pattern. Scanning electron microscopy of failed sensor patterns revealed that emf drift and sensor failure was due to the oxidation of rhodium and the thermal sintering of the metal films. Aluminum oxide overcoats were found to successfully counteract both of these effects. 


\section{INTRODUCTION}

The development of gas turbine engines based on advanced ceramics has been extensively investigated over the last two decades. Lighter weight engine designs based on ceramics can significantly improve engine performance, in terms of improved fuel efficiency and reduced maintenance. Ceramic based engines are capable of higher temperature operation and thus, higher fuel efficiencies. To evaluate ceramic engine designs, it is necessary to accurately determine the surface temperature of these ceramic components during operation. Thin film thermocouples (TFTC's) provide a reliable means of surface temperature measurement without compromising engine performance or operation.

Considerable gas and heat path distortion can be encountered with embedded wire thermocouples, making accurate, reliable temperature measurement difficult. TFTC's are attractive here from the viewpoint that they are non-intrusive and have much lower thermal masses than conventional wire thermocouples. These thin film sensors exhibit much faster response times (and smaller thermal time constants). In addition, since these sensors are only a few micrometers thick they provide a better indication of the true surface temperature, which is frequently required for modeling purposes, particularly when complex cooling schemes are employed.

Hot isostatically pressed $\mathrm{Si}_{3} \mathrm{~N}_{4}$ (NT154) was used as the ceramic substrate for the TFTC studies, since it is a leading candidate material for use in gas turbine engine applications. This is due to its strength retention at high temperature $\left(400 \mathrm{MPa}\right.$ at $\left.1300^{\circ} \mathrm{C}\right)$ combined with excellent oxidation and creep resistance at temperatures below $1300^{\circ} \mathrm{C}$ [1]. However, NT154 oxidizes in air ambients at temperatures above $1300^{\circ} \mathrm{C}$ and can react readily 
with $\mathrm{Pt}$ under reducing conditions at these temperatures to form platinum silicides. Therefore, a stable oxide layer was formed on the silicon nitride substrates to minimize adverse reactions with the thermocouple elements and provide a stable surface for these sensor elements at temperatures greater than $1300^{\circ} \mathrm{C}$. 


\section{EXPERIMENTAL}

As-received bars of NT154 measuring $0.64 \mathrm{~cm} \times 0.32 \mathrm{~cm} \times 10.16 \mathrm{~cm}$, were diamond ground' to an RMS surface roughness of $0.25 \mu \mathrm{m}(10 \mu \mathrm{in})$. These test bars were oxidized at $1300^{\circ} \mathrm{C}$ in air for 100 hours to produce a relatively thick outer scale of silica and a thin inner scale of silicon oxynitride. The test bars were then etched in concentrated HF (48-50\%) to remove the bulk $\mathrm{SiO}_{2}$ scale that formed, thereby exposing the underlying oxynitride layer, which also acted as an etch stop. The presence of a silicon oxynitride $\left(\mathrm{Si}_{2} \mathrm{ON}_{2}\right)$ layer was confirmed by $\mathrm{ESCA}$, as shown in Figure 1. This figure shows an ESCA profile of a silicon nitride surface that was etched in HF after 100 hours of exposure to air at $1300^{\circ} \mathrm{C}$. This oxynitride layer is approximately $60 \AA$ thick and has a surface concentration that corresponds to a nonstoichiometric $\mathrm{Si}_{2} \mathrm{ON}_{2}$. Both metal and oxide sputtered films adhere well to this oxynitride.

The NT154 substrates were initially cleaned by sonicating in acetone followed by methanol, deionized water rinses, and blown dry in nitrogen. Aluminum oxide was then sputtered (5000 $\AA$ ) over the entire surface to form an effective diffusion barrier and prevent the interaction of the $\mathrm{Pt}$ sensor elements with the $\mathrm{Si}_{3} \mathrm{~N}_{4}$ substrate. The $\mathrm{Pt}$ and $\mathrm{Pt}: 10 \mathrm{Rh}$ sensor elements were patterned on the ceramic substrates by sputtering through copper-beryllium shadow masks that were chemically machined to the exact dimensions of the sensor elements (the patterning of the curved ceramic blades are performed in a different manner and are explained further in Appendix B). The thin film sensors consisted of $200 \mu \mathrm{m}$ wide lines with bond pads measuring $400 \mu \mathrm{m}$ across. In addition, the sensor pattern had $1 \mu \mathrm{m}$ thick elements and $3 \mu \mathrm{m}$ thick

\footnotetext{
'Bomas Machine Specialties, Somerville, MA
} 
bond pads. The bond pads were thickened from 1 to $3 \mu \mathrm{m}$ to promote bonding of the $76 \mu \mathrm{m}$ lead wires.

All of the thin films were prepared by if sputtering in an MRC model 822 sputtering system equipped with a load lock and substrate heating. High purity $(99.9 \%)$ platinum and platinum:10rhodium targets $(12.7 \mathrm{~cm}$ in diameter) and semiconductor grade argon were used to deposit the thin film sensor elements. Prior to sputtering, the system was evacuated to a background pressure of $5 \times 10^{-7}$ torr at which point argon gas was leaked into the system to establish a gas pressure of 8 mtorr. Intermittent in-situ heating cycles were employed without breaking vacuum at $300^{\circ} \mathrm{C}$ for $10 \mathrm{~min}$. This was done to promote the outdiffusion of trapped argon, which is incorporated into the metal films during deposition. At elevated temperatures, the coalescence and sudden release of the trapped argon in the metallic films can induce blistering and ultimately result in failure of the thin film. No high temperature annealing step was performed after fabrication.

Lead wire attachment was accomplished via thermocompression welding. Cantilever loaded solid $\mathrm{Al}_{2} \mathrm{O}_{3}$ bars, were placed over the test coupons to generate a compressive force between the thin film bond pads and the $76 \mu \mathrm{m}$ diameter lead wires. One specimen had lead wires bonded to the lead film by parallel gap welding. Appendix $\mathrm{C}$ contains the procedures and optimal bonding parameters used for parallel gap welding. After attachment, a $1.6 \mu \mathrm{m}$ thick $\mathrm{Al}_{2} \mathrm{O}_{3}$ layer was sputtered over this particular sensor to provide protection to the $\mathrm{Pt}$ and $\mathrm{Pt}: 10 \mathrm{Rh}$ thin films.

EMF signals from the TFTC as well as the hot and cold reference thermocouples were recorded using Strawberry Tree software. The drift rate, estimated from the drift in temperature ( $\left.T_{r e f}-T_{t f}\right)$ per unit time was used as a 
measure of device stability. Reference wire thermocouples were used to verify that there was virtually no change in furnace temperature during the tests. Tests were performed in both oxidizing and inert gas atmospheres. The inert atmosphere was maintained by passing dry nitrogen gas through a $\mathrm{P}_{2} \mathrm{O}_{5}$ getter, followed by a titanium getter at $500^{\circ} \mathrm{C}$ to remove residual water and oxygen that may be present in the gas. Sensors were tested in a Deltech high temperature furnace with a 7 inch hot zone. The furnace was ramped up at a rate of $3^{\circ} \mathrm{C} / \mathrm{min}$ to the desired temperature and held for a specified soak time. The lifetime of the device corresponded to the time to catastrophic failure of the metal films. Temperature gradients between $0-600^{\circ} \mathrm{C}$ were established along the length of the test bars and scanning electron microscopy (ISI SX40A SEM) was utilized for all microstructural analysis. 


\section{RESULTS}

Figure 2 shows the results of TFTC's tested under different oxidizing conditions. The thin film sensors tested here did not have a protective overcoat, and consequently, they experienced significant drift, the rates of which depended on the atmosphere and imposed temperature gradient $(\Delta T)$. The sensors tested in air ambients, with a $300^{\circ} \mathrm{C} \Delta \mathrm{T}$ established between the bond pad and the TFTC junction exhibited a drift rate of $5.0^{\circ} \mathrm{C} / \mathrm{hr}$, which remained at this level after ramping to higher temperatures. The sensors tested in nitrogen ambients with a $300^{\circ} \mathrm{C} \Delta \mathrm{T}$, had drift rates of only $1.2^{\circ} \mathrm{C} / \mathrm{hr}$ and $1.5^{\circ} \mathrm{C} / \mathrm{hr}$ at low and high temperatures, respectively. However, the lifetimes of these thin film sensors were similar to those tested in air, with each device failing after approximately $31 \mathrm{~h}$. This suggested that oxidation was not the only mechanism responsible for failure of the devices.

Microstructural analysis suggested that transport of metal via surface diffusion from the edge of the TFTC lines can affect both electrical conductivity and adhesion [2,3,4]. Morphological changes in the films were commensurate with the imposed $\Delta \mathrm{T}$, which provided the driving force for mass transport in the thermocouple elements. A sensor was tested using a significantly larger $\Delta T$, to determine the extent of this effect on drift rate and lifetime. These sensors, tested in air using a $600^{\circ} \mathrm{C} \Delta \mathrm{T}$, experienced drift rates of $5.5^{\circ} \mathrm{C} / \mathrm{hr}$ and $13.8^{\circ} \mathrm{C} / \mathrm{hr}$ at low and high temperatures respectively and failure of this sensors occurred after only $20 \mathrm{~h}$.

Scanning electron micrographs of the platinum films tested under oxidizing conditions with a $300^{\circ} \mathrm{C}$ gradient showed extensive thermal sintering (Figure 3). Little difference between the microstructures of the platinum and 
platinum:10rhodium thin films was observed. Both films exhibited extensive recrystallization and pore growth, with the contiguous regions (or platinum lands) showing considerable faceting similar to microstructures developed as a result of vapor phase transport $[2,3,4]$.

To determine if the composition of the platinum:10rhodium thermoelement is changing due to oxidation, an ESCA depth profile was performed on a $1 \mu \mathrm{m}$ platinum:10rhodium film that was exposed to air for $1 \mathrm{~h}$ at $1000^{\circ} \mathrm{C}$. This depth profile is shown in Figure 4. An oxygen and rhodium rich layer was observed on the surface of the alloy, which was depleted of platinum. At a depth of approximately $600 \AA$, a bulk ratio of $93: 7(\mathrm{Pt}: \mathrm{Rh})$ was observed. It appears that the selective oxidation of platinum resulted in both $\mathrm{Pt}$ and Rh concentration gradients in the film. Specifically, Pt was depleted in the surface regions of the alloy while Rh was enriched in the surface regions. This can lead to a significant variation in junction chemistry and thus, emf output. Previous studies studies on the oxidation of platinum and rhodium indicated a mass loss directly proportional to oxygen pressure, with larger losses due to greater volatility associated with platinum oxides compared to rhodium oxides at the temperatures investigated [5].

An SEM micrograph of a platinum:10rhodium thin film after exposure to nitrogen gas at elevated temperature is shown in Figure 5. This film exhibits complete recrystallization, with very little porosity and an average grain size $4.7 \mu \mathrm{m}$. The platinum thin film had a similar microstructure, with slightly greater porosity (Figure 6). The solid solution strengthening effect of the rhodium in the alloy prevented extensive grain growth and the formation of slip bands that were evident in the pure platinum films. Striations (or slip bands) within the grains are the result of plastic deformation due to both bubble formation and the impingement of grains at boundaries and triple 
points. The platinum thin films had an average grain size of $15.0 \mu \mathrm{m}$.

SEM micrographs of the thin film sensor tested with a large temperature gradient showed significant amounts of metal transport within the patterned metal lines. Specifically, Figure 7 shows a failure site where the metal film has undergone extensive sintering and the metal line has actually receded from its original location. Transport of the metal from the outer edge of the line towards the center of the line resulted in a pile up of material in the center of the line. From these observations, it was apparent that both the formation of volatile oxides and surface induced mass transport were responsible for the changes in electrical properties, sensor drift and eventual failure of the device.

After investigating these sources of drift, thin film sensors were fabricated with $\mathrm{Al}_{2} \mathrm{O}_{3}$ overcoats in an attempt to minimize this degradation. Figure 8 shows the measured temperature of an overcoated sensor, relative to that a reference wire thermocouple. The output of the TFTC and reference wire thermocouple were almost identical, as shown by the deviation of the TFTC from the reference thermocouple after annealing. There was no measurable drift in the signal at temperatures of $1000,1100,1200$, and $1300^{\circ} \mathrm{C}$. In addition, the lifetime of these overcoated sensors was extended beyond those prepared without overcoats. Microstructural analysis of the thin film sensor elements showed little porosity within the metal film and no evidence of thermal sintering (Figure 9). Although these films showed some blistering along the edge of lines where step coverage was poor, the majority of the film experienced little degradation. 


\section{DISCUSSION}

The results to date indicate that there are two possible sources of emf drift; oxidation of the precious metal films and thinning of the metal lines by mass transport. The corresponding decrease in drift rate with lower oxygen partial pressures is consistent with the hypothesis that volatile platinum and rhodium oxides were forming and the metal lines were thinning as a result of this oxidation. Studies have shown that both platinum and rhodium are unstable in oxidizing ambients and form a volatile oxide species $\left(\mathrm{PtO}_{2}\right.$ and $\mathrm{RhO}_{2}$ gas) at elevated temperatures [5]. This can change the local concentration of metal in the film and affect the emf signal by forming a dissimilar metal junction of considerably different composition. The continual loss of rhodium and platinum (differential loss) generated an emf at the junction that was considerably different from that of the type $S$ thermocouple junction originally formed. Other researchers have used relatively thick films $(2-20 \mu \mathrm{m})$, in an attempt to minimize this differential loss of metal [6-14]. However, more Ar gas can be trapped in the as-deposited films and thus, lead to a greater density of blisters after higher temperature exposure. When the metal films are exposed to high temperatures, trapped argon gas within the film can coalesce to form bubbles. These bubbles can rupture and cause ultimate failure of the metal lines. In addition, thicker sensor elements can make it more difficult to produce a conformal, protective overcoat due to poor step coverage at the edges of the thin films.

High temperature exposure of unannealed thin film lines produced sintered microstructures, as shown in Figure 3. This thermal sintering behavior of the films can be explained on the basis of conventional sintering models. For example, platinum crystallites grow via the incorporation of 
platinum atoms from the surrounding amorphous matrix, leaving behind a thin membrane or pore as shown in Figure 3. Effectively, the material withdraws to attain the equilibrium shape characteristic of these particles in which metalsubstrate and metal-gas interfacial energies are approximately equal [4]. These microstructures are typical of a non-wetting material and the facets evident in the micrograph suggest that surface driven mass transfer has occurred, similar to that formed when material is transported through a vapor phase. This will increase the thin film resistivity and ultimately affect the voltage signal generated. Dewetting of the platinum films leads to a receding contact line and pile up of material in the center of the metal line due to the non-wetting behavior of these platinum base materials on oxide substrates. Figure 7 clearly shows the extent of this behavior and the associated mass transfer. This non-wetting phenomenon is driven by the reduction in surface free energy. This observation is similar to other mass transfer induced failure mechanisms such as electromigration, which is frequently observed in aluminum lines used for interconnects in integrated circuits. The large temperature gradient along the test bar and high average temperatures tend to accelerate this behavior and promote failure.

Figures 5 and 6 show a reduction in porosity and thermal sintering for thin films tested in nitrogen. Here, thermal sintering takes place via an Ostwald ripening process or coalescence of crystallites [2], when the film is made up almost entirely of small crystallites.

Overcoats of high purity alumina can effectively reduce degradation due to oxidation and thermal sintering. The SEM micrograph of a $1.6 \mu \mathrm{m}$ alumina overcoat (Figure 9) minimized both surface transport of platinum and vaporization of the precious metals as oxides. The overcoat reduced the extent to which these processes dominate by forming an effective diffusion 
barrier. Here, the only evidence of blistering was around the edges of the metal lines. Since this area of the $\mathrm{Al}_{2} \mathrm{O}_{3}$ overcoat has the poorest coverage, it was more prone to blistering. This evidence supports the hypothesis that a short circuit diffusion path was formed for the out-diffusion of trapped argon in the metal film. Gas migration was restricted along the interphase boundary to locally thin regions of the overcoat. The locally thin overcoat ruptured when sufficient pressure in these bubbles had developed. Although the overcoat did not completely eliminate the problems described above, it did minimize the adverse effects of sintering and oxidation. 


\section{CONCLUSIONS}

Thin film thermocouples have been fabricated with lifetimes up to 50 hours at $1300^{\circ} \mathrm{C}$ with no measurable drift at temperature. However, the accuracy of the TFTC was affected by two different degradation processes: (1) the formation of volatile metal oxides and associated compositional changes at the TFTC junction and (2) the surface driven mass transport of the precious metal films via thermal sintering. Aluminum oxide overcoats have been successfully employed to reduce the extent of degradation by these processes and thus improve TFTC performance. 


\section{LITERATURE CITED}

[1] Cranmer, D. C.; Hockey, B. J.; and Wiederhorn, S. M.“Creep and Creep Rupture of HIP'ed $\mathrm{Si}_{3} \mathrm{~N}_{4}$.", Ceramic Engineering and Science Proceedings, 12 [9-10], 1862-1872, 1991.

[2] Wu, N. L.; and Phillips, J."Reaction-Enhanced Sintering of Platinum Thin Films during Ethylene Oxidation.", Journal of Applied Physics, 59 (3), Feb 1986.

[3] Gimpl, M. L.; McMaster, A. D.; and Fuschillo, N."Amorphous Oxide Layers on Gold and Nickel Films Observed by Electron Microscopy.", Journal of Applied Physics. 35 (12), Dec 1964.

[4] Presland, A. E. B.; Price, G. L.; and Trimm, D. L."Kinetics of Hillock and Island Formation During Annealing of Thin Silver Films.", Progress in Surface Science, 3, 63, 1972.

[5] Alcock, C. B.; and Hooper, G. W., "Thermodynamics of the gaseous oxides of the platinum-group metals", Proceeding of the Royal Society of London, 254 A, pp.551, 1960.

[6] Prakash, S.; Budhani, R. C.; and Bunshah, R. F."Development of Thin Film Temperature Sensors for High Performance Turbo-Jet Engines.", Materials Research Bulletin, Vol. 2 3, 187-195, 1988.

[7] Grant, H. P.; and Przybyszewski, J. S.; and Claing, R. G."Turbine Blade Temperature Measurements Using Thin Film Temperature Sensors - Phase II.", NASA Lewis Research Center report CR-165201. PWA-5604-31, 1981.

[8] Bennethum, W. H.; and Sherwood, L. T."Sensors for Ceramic Components in Advanced Propulsion Systems.", NASA Lewis Research Center report CR$180900,1988$.

[9] Atkinson, W. H.; Cyr M. A.; and Strange, R. R."Development of Sensors for Ceramic Components in Advanced Propulsion Systems.", NASA Lewis Research Center report CR-182111. PWA-6113-12, 1988.

[10] Budhani, R. C.; Prakash, S.; and Bunshah, R. F."Thin Film Temperature Sensors for Gas Turbine Engines: Problems and Prospects.", Journal of Vacuum Science and Technology, 2609-2617, Nov/Dec 1986.

[11] Grant, H. P.; and Przybyszewski, J. S."Thin Film Temperature Sensors Phase I.", NASA Lewis Research Center report CR-159782. PWA-5526-31, 1980.

[12] Grant, H. P.; and Przybyszewski, J. S.; and Claing, R. G.; and Anderson, W. 
L."Thin Film Temperature Sensors Phase III.", NASA Lewis Research Center report CR-165476. PWA-5708-26, 1990.

[13] Kreider, K. G."Thin Film Thermocouples for Internal Combustion Engines.", Journal of Vacuum Science and Technology Vol. 4, No. 6, 2618-2623, Nov/Dec 1986.

[14] Holanda, R."Development of thin film thermocouples on ceramic materials for advanced propulsion system application.", NASA technical memorandum 106017, April 28-May 2, 1992. 


\section{FIGURE CAPTIONS}

Figure 1. ESCA depth profile of a silicon nitride coupon that was oxidized in air at $1300^{\circ} \mathrm{C}$ for $100 \mathrm{~h}$ and then etched in concentrated HF.

Figure 2. Drift of thin film thermocouples fabricated on silicon nitride and tested in various atmospheres without overcoats.

Figure 3. SEM micrograph of a sputtered $\mathrm{Pt}: 10 \mathrm{Rh}$ film heat treated in air at $1300^{\circ} \mathrm{C}$.

Figure 4. ESCA depth profile of a Pt:10Rh film after $1 \mathrm{~h}$ exposure in air at $1000^{\circ} \mathrm{C}$.

Figure 5. SEM micrograph of a sputtered $\mathrm{Pt}: 10 \mathrm{Rh}$ film heat treated in nitrogen at $1300^{\circ} \mathrm{C}$.

Figure 6. SEM micrograph of a sputtered $\mathrm{Pt}$ film heat treated in nitrogen at $1300^{\circ} \mathrm{C}$.

Figure 7. SEM micrograph of a sputtered Pt film heat treated in air with an imposed $600^{\circ} \mathrm{C}$ temperature gradient. Note the edges of the film have receded from the original position.

Figure 8. Drift of a thin film thermocouple fabricated with a sputtered $\mathrm{Al}_{2} \mathrm{O}_{3}$ overcoat. The deviation of the thin film thermocouple from a reference (wire) thermocouple provides a basis of comparison between the emf outputs.

Figure 9. SEM micrograph of a Pt:10Rh thermocouple element fabricated with a $1.6 \mu \mathrm{m} \mathrm{Al} \mathrm{O}_{3}$ overcoat. Note extensive blistering around edge of the metal pattern where the step coverage is poor. 


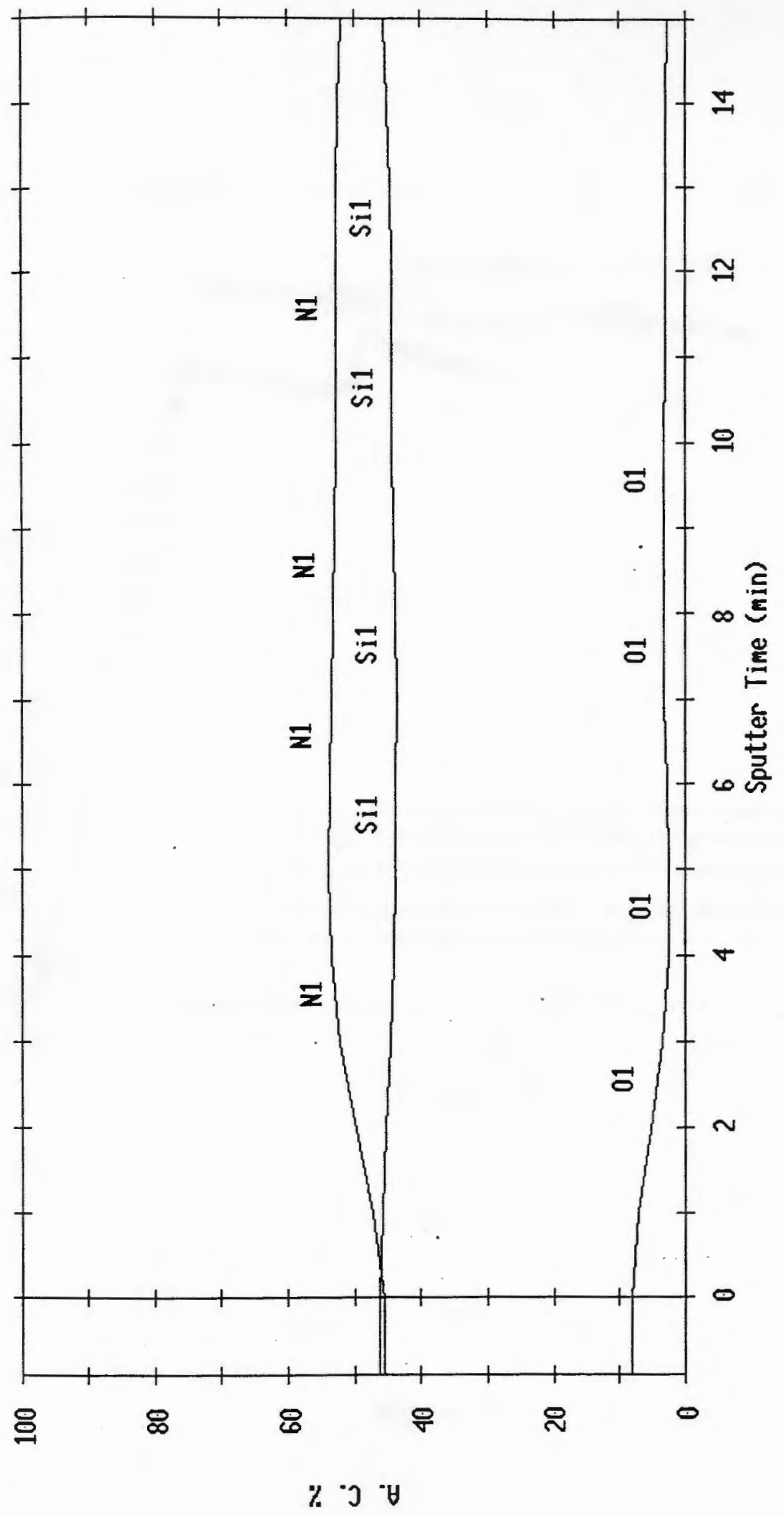

Figure 1 


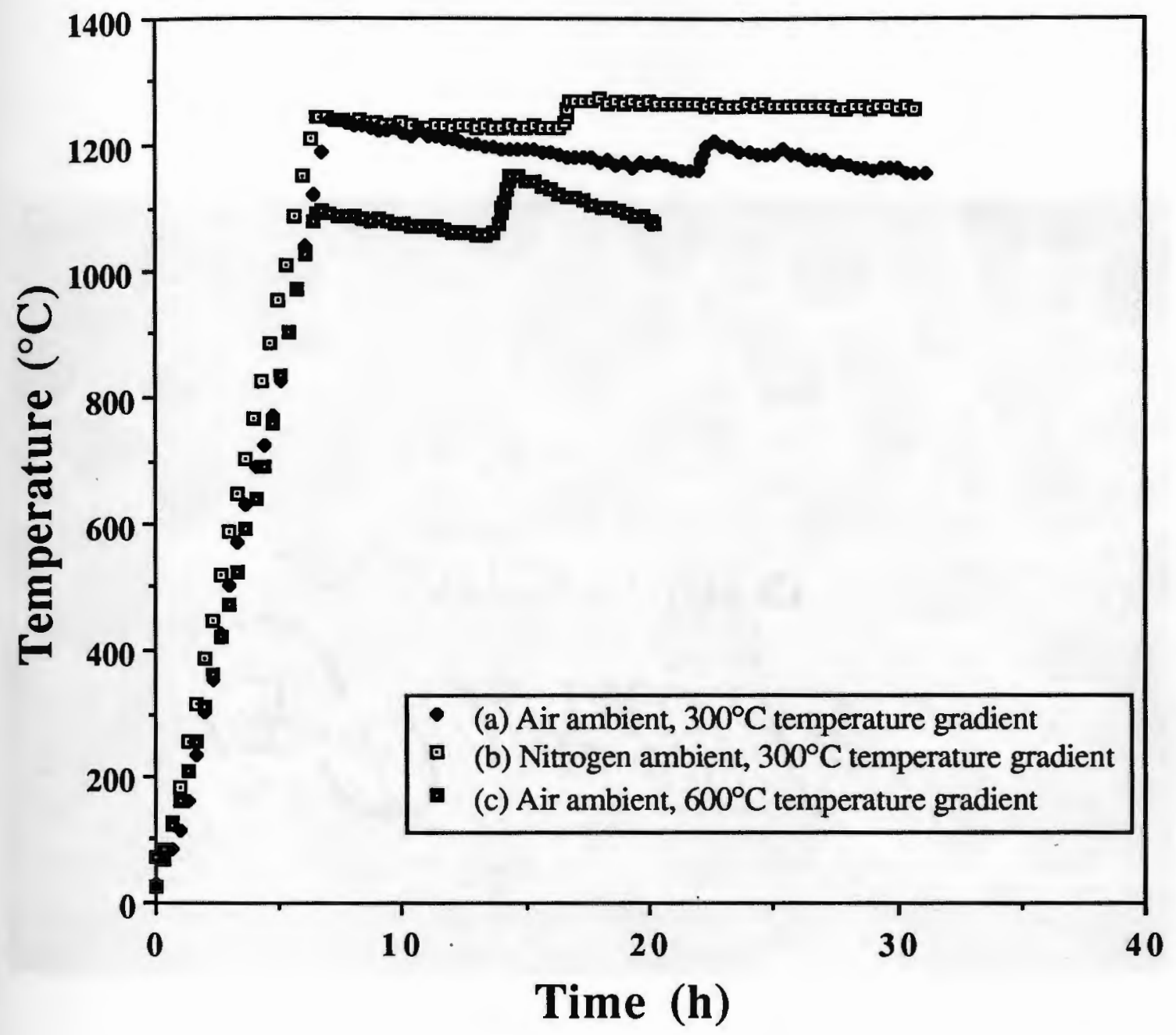

Figure 2 


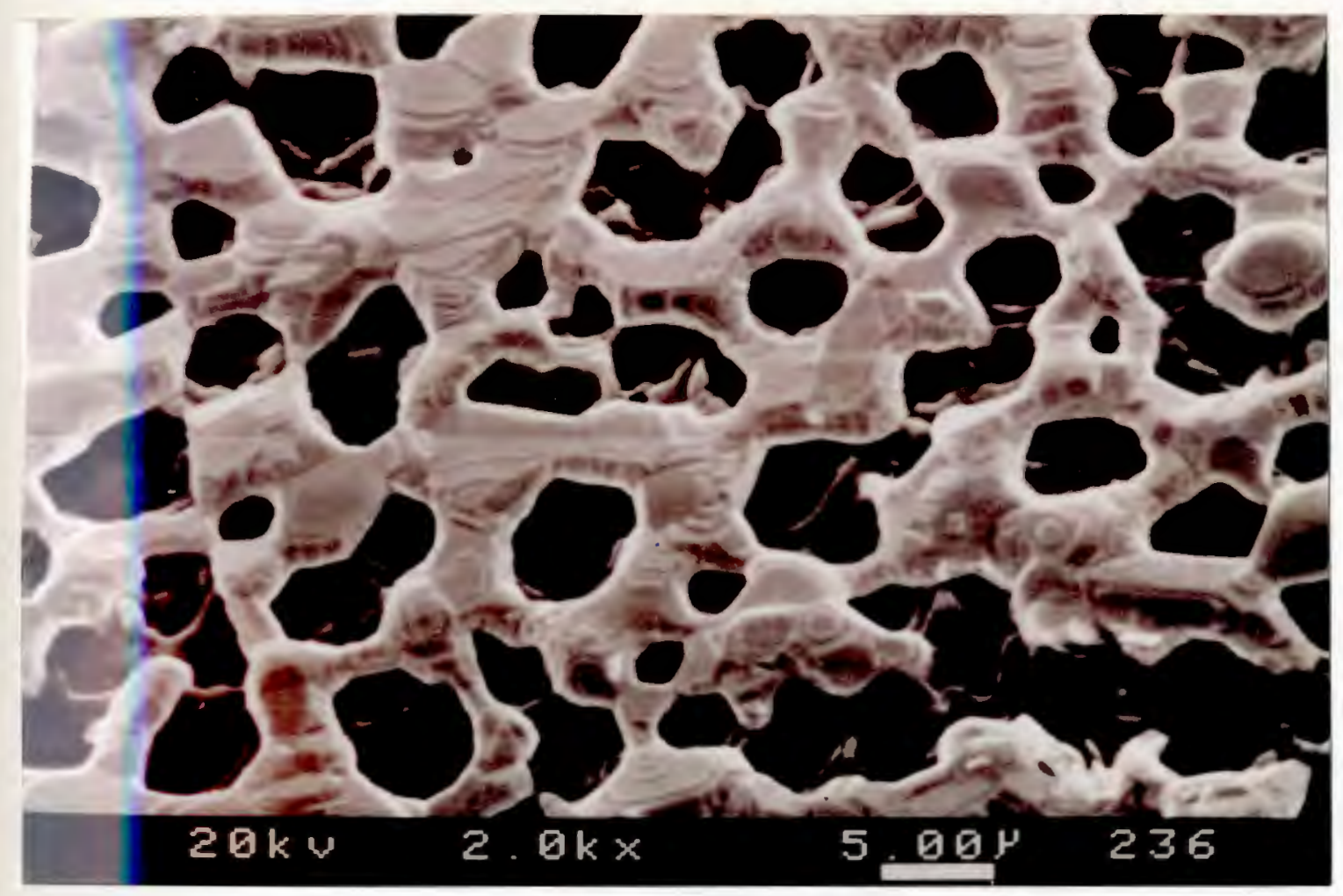

Figure 3 


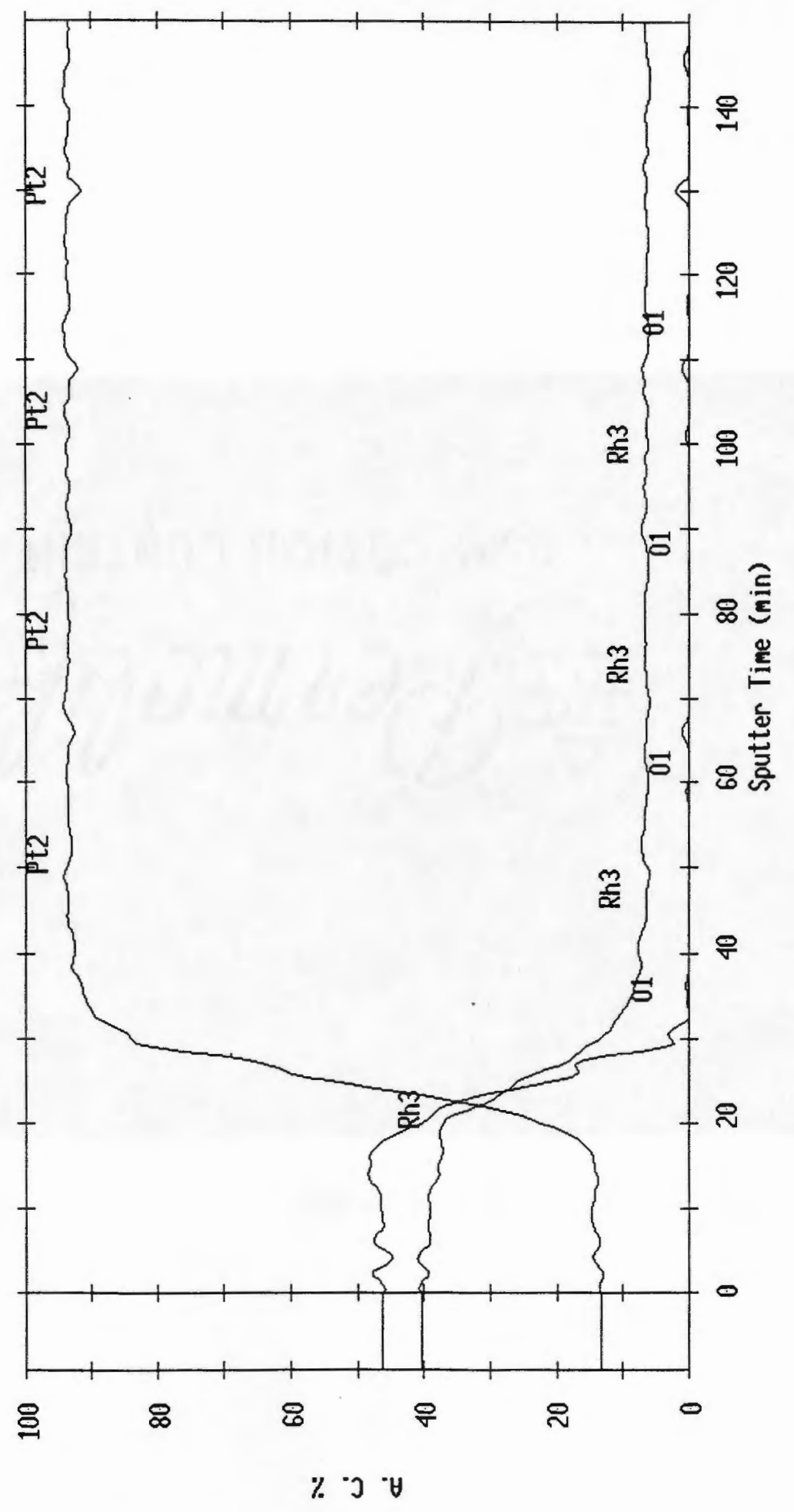

Figure 4 


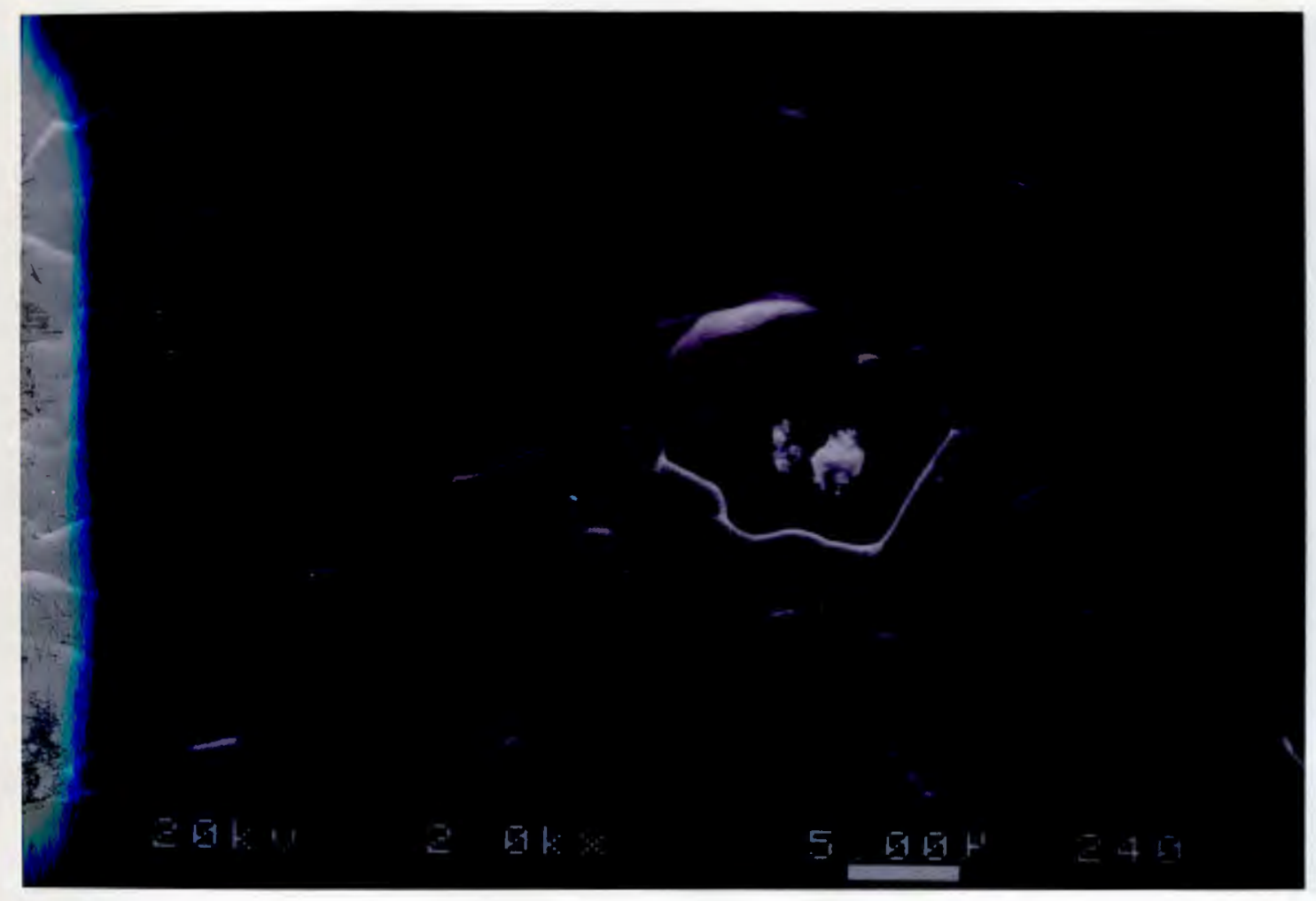

Figure 5 


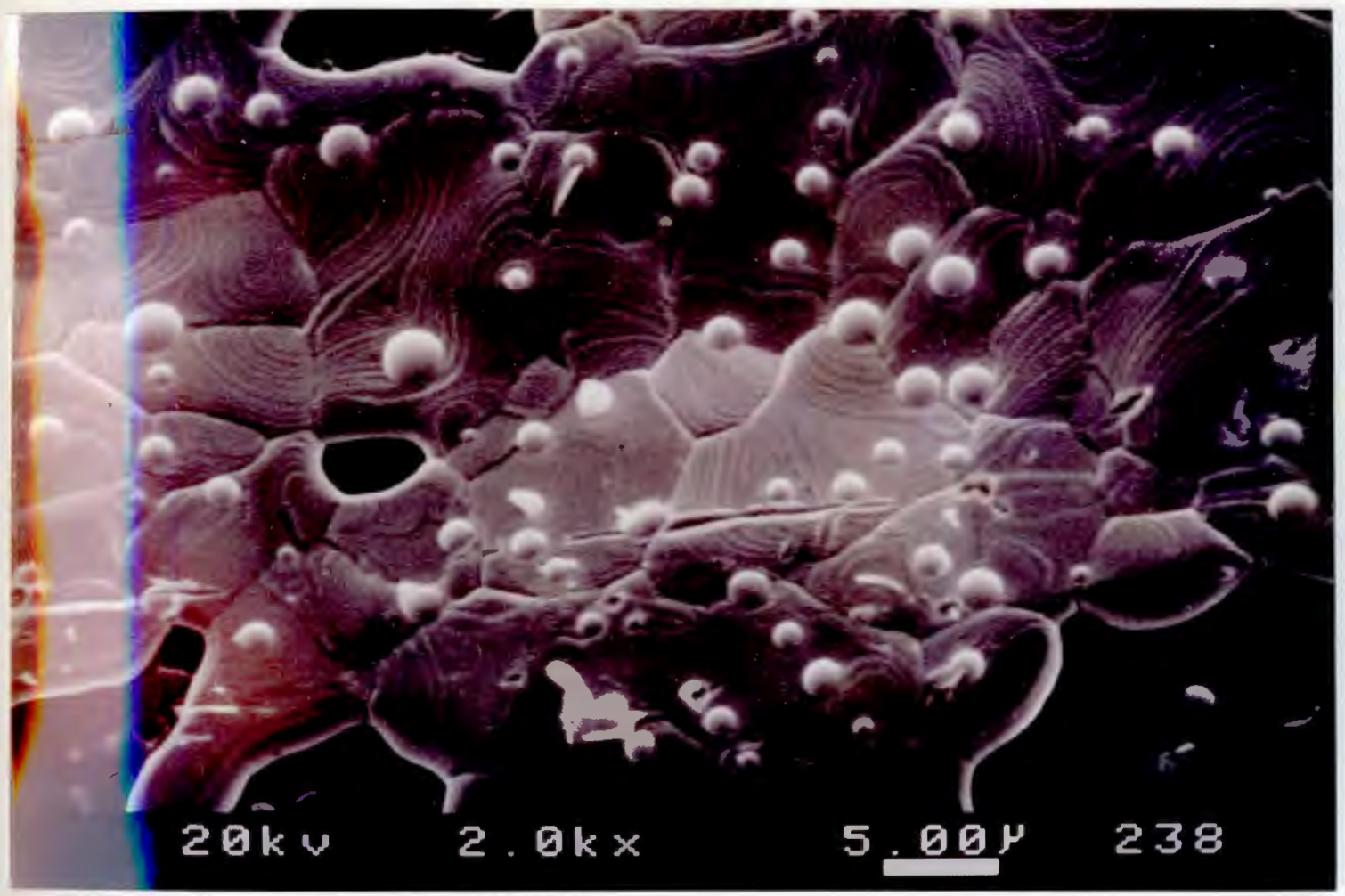

Figure 6 


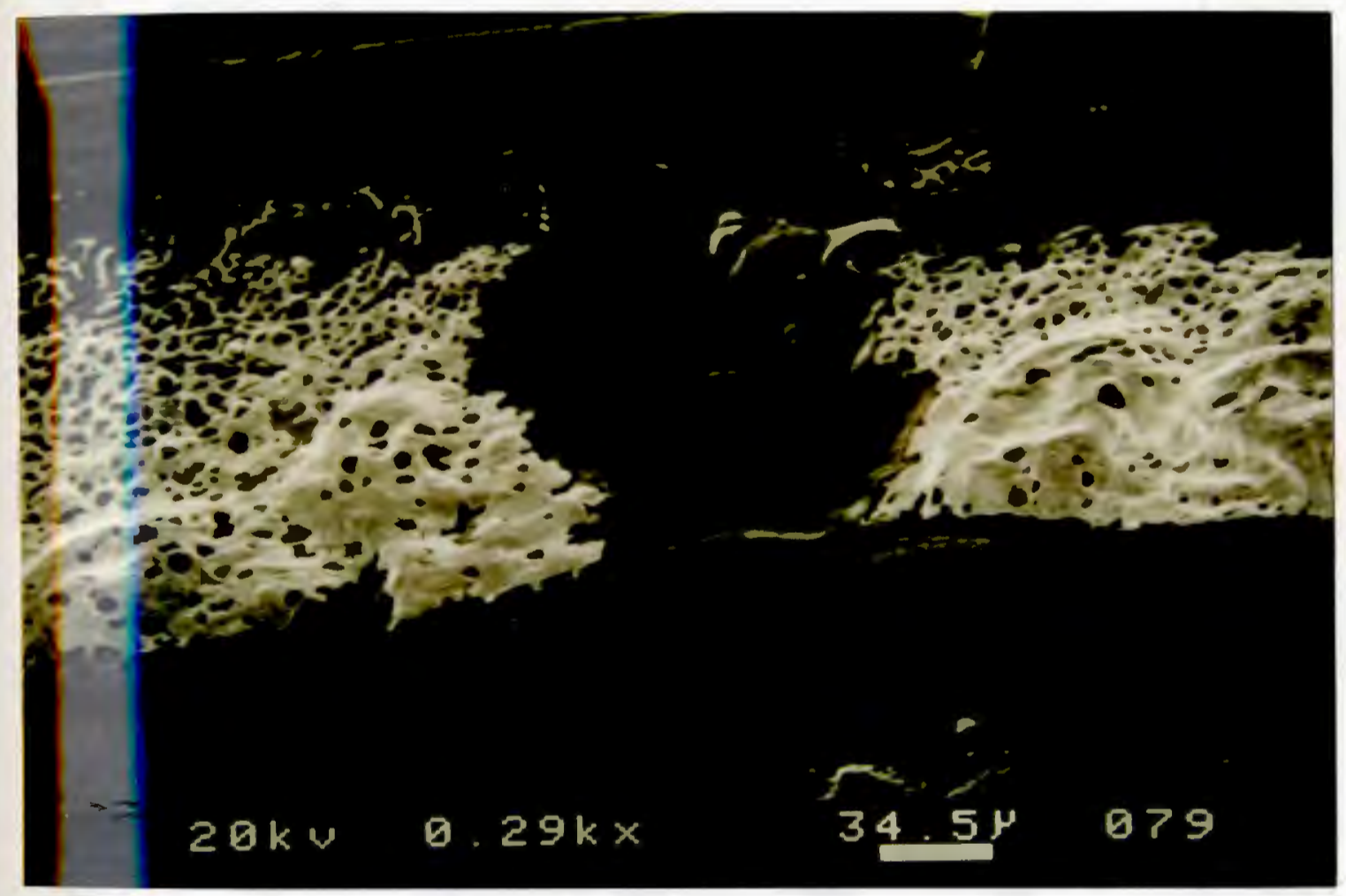

Figure 7 


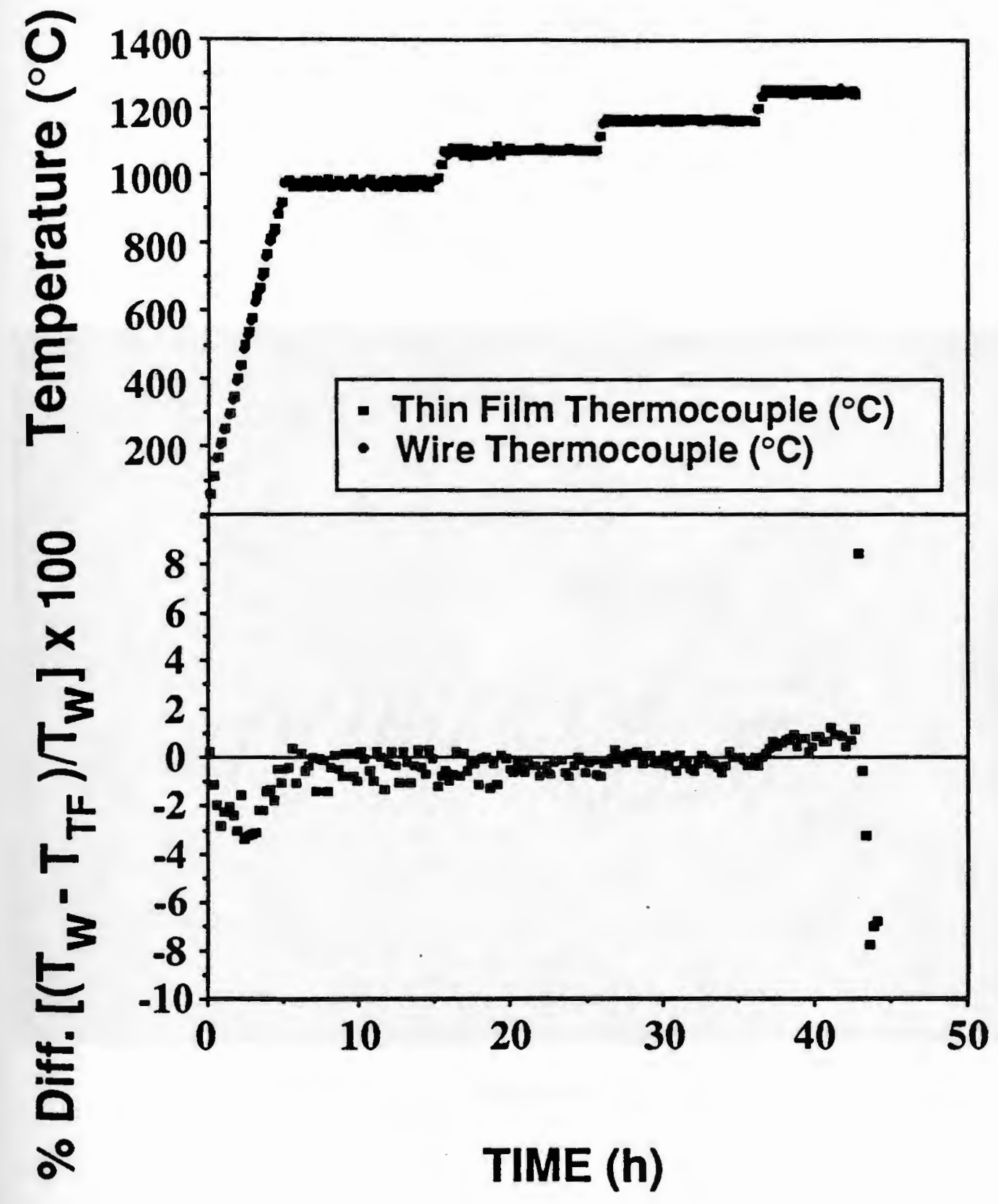

Figure 8 


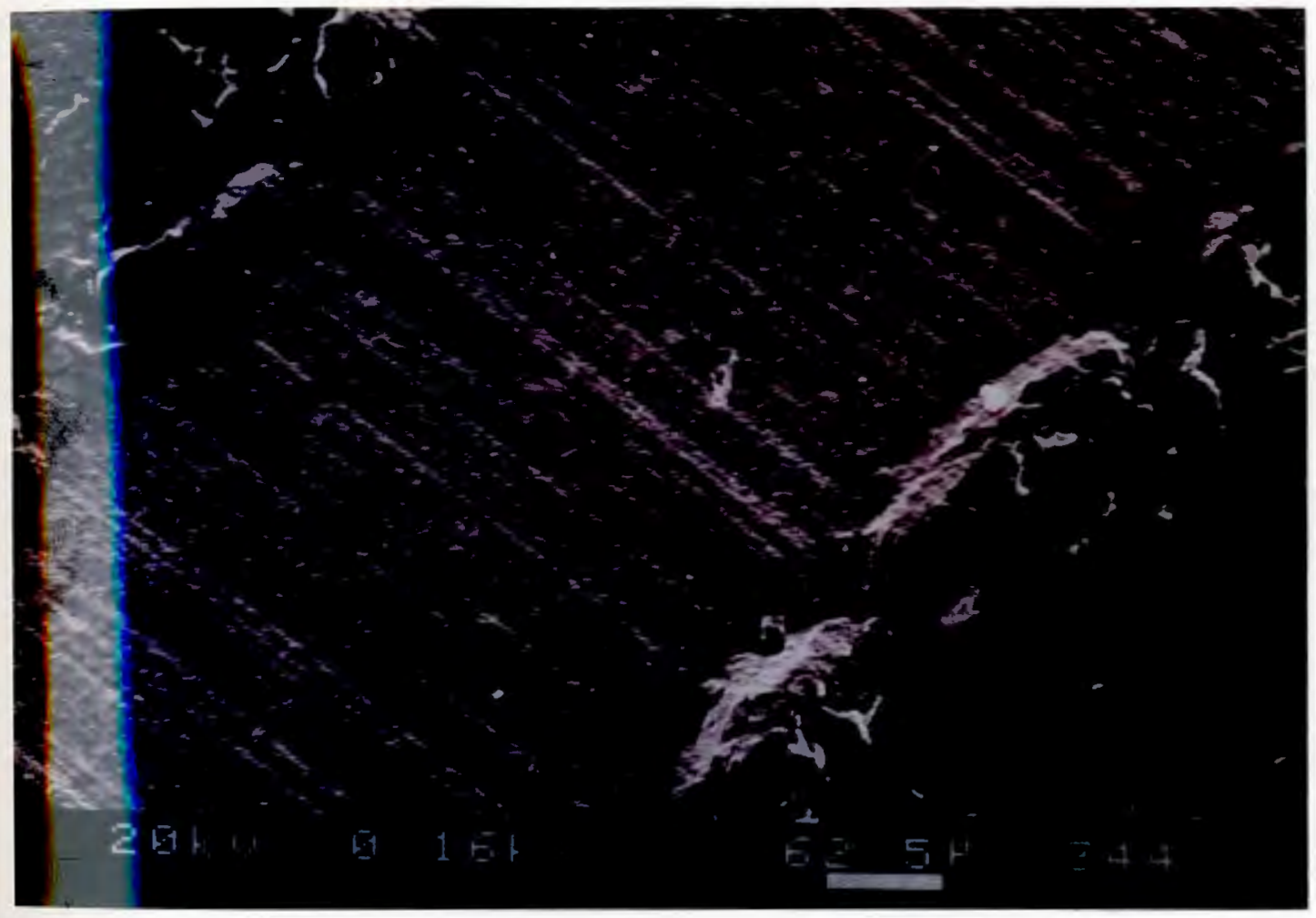

Figure 9 
Appendix A 


\subsection{Physical Vapor Deposition}

The thin film thermocouples being developed in this study are multilayered vapor deposited devices. Not only are the thermocouple legs deposited by sputtering, but an insulating layer, to electrically isolate the device from the metal components, a bond coat layer, to allow for adequate adhesion of the dielectric layer and an overcoat, to protect the device, have to be sputtered deposited onto each component. Due to the wide variety of materials that must be deposited and the need for very dense film, sputtering is a more practical method for this work than the two other forms of thin film deposition: vacuum evaporation and chemical vapor deposition.

Sputtering is an ejection of atoms from a target due to the bombardment of this target by ions. The process is a result of the transfer of momentum from the bombarding ions to the ejected atoms during collision. This transfer of momentum is analogous to the cue ball hitting the rack of balls in a game of billiards. Of these atoms a certain percentage will be deposited onto the particular substrate that is to be coated.

A typical schematic of a sputtering system is shown in Figure 1. This system is actually contained in a high vacuum chamber. The chamber is first evacuated then argon gas is introduced. Argon is generally used since it is an inert gas that has a fairly high mass to allow for a high sputtering yield since the process is dependent upon the transfer of momentum and is relatively cheap. One component not represented in Figure 1 is a tungsten filament which is used to initiate the sputtering process. Electrons are emitted from the filament and then collide with the argon atoms, thereby ionizing some of the gas atoms creating a plasma. The ions are then accelerated toward the target, since it is biased negatively with respect to the plasma, the biasing is generated by an external power supply. Four different outcomes may result when an ion impacts 
the target material. The possibilities are that a target atom may be sputter ejected, the ion may also become implanted in the target or reflected as a neutral, the ion impact may result in an alteration of the target surface, or finally a secondary electron may be ejected. Of these four possibilities only the ejection of a target atom or a secondary electron are helpful to the sputtering process. Of the target atoms that are ejected only a certain percentage of these atoms will come to rest on the substrate where they can condense. The secondary electrons that are ejected maintain the plasma by creating additional ions when they collide with argon atoms.

The mobility of the cations in the plasma is much slower than the mobility of the electrons; therefore, cations accumulate at the surface of the target creating what is known as a dark space. It is across this dark space the entire voltage between the target and plasma is dropped. When a secondary electron is ejected from the target it is accelerated across the dark space before it makes an ionizing collision. For this reason, the ground shield (Figure 1) is used so no sputtering will occur from the sides or back of the target since this material would be wasted. This shield must be kept within the dark space region to insure no ion bombardments will occur in this area.

\subsubsection{RF Sputtering}

In the previous explanation of sputtering the target was negatively biased resulting in the accumulation of ions at the surface of the target. However, if the target is an insulator, the positive charge can not be neutralized, thereby resulting in the accumulation of charge at the surface of the target. If an alternating current is applied instead, energy could be transmitted into the plasma through the form of displacement current through the insulator. If this $A C$ supply was of a low frequency almost the entire applied voltage would be 
dropped across the insulator. Therefore, the ions that do arrive at the surface of the target would not have obtained a sufficient energy to result in sputtering. Therefore, it is necessary to use a frequency in excess of 50-100 kilohertz. Due to Federal Communication Commission regulations the lowest frequency that can be used is 13.56 megahertz; this frequency is within the range known as radio frequency or $\mathrm{rf}$.

In order to accomplish rf sputtering the target must be bonded to a metal backing plate that acts as an electrode. When an rf power supply is used and an alternating voltage is applied to the electrode, the target is alternately bombarded by ions then electrons. At these high frequencies the ions can not keep up with the changes in the electric field; therefore, very few of the ions can reach the target in one cycle. For this reason ions pile up immediately in front of the target which is very similar to the Crookes dark space generated in dc sputtering. Since the ions have a much lower mobility than the electrons, an insufficient number of ions arrive at the target during the negative half-cycle to neutralize the electrons that arrive during the positive cycle. This results in the target acquiring a substantial negative charge at the surface which results in a self biasing of the target .

Another significant difference between of and dc sputtering is that $\mathrm{rf}$ sputtering can be performed at much lower pressures. This is due to the fact that if discharge is much more efficient in producing ions and electrons within the gas and is not solely dependent upon the ejection of secondary electrons from the target to sustain a glow discharge. This occurs since electrons are able to oscillate in an rf field thereby absorbing energy until it is able to make an ionizing collision. By operating at lower pressures, fewer sputtered atoms will be scattered since there are fewer atoms to collide with. 


\subsubsection{Bias Sputtering}

Two inherent problems associated with sputtering are detrimental to the success of this work. First, sputtering is for the most part a line of sight deposition process. For example, if a material were sputtered onto a sample that had slots machined into it, the side walls of these slots would have hardly any material deposited onto them. Secondly, gases, whether inert or reactive, may be incorporated into the films as they are deposited. This is harmful to the process when extremely pure or dense films are required. One process, known as bias sputtering, can help to alleviate both of these problems.

Bias sputtering is performed in a similar manner to standard sputtering except that a negative potential is also supplied to the substrate. This results in sputtering of the substrate surface since it will also be bombarded with ions. As long as the target voltage is greater than the substrate voltage a net deposition will occur. Generally the voltage applied to the substrate is significantly smaller than that supplied to the target. The ions that bombard the substrate result in selective removal of loosely bound or absorbed impurities.

If a substrate contains surfaces only partially or indirectly exposed to the target, the deposition of the target material over the substrate will vary. As shown in the work of Seeman, if a substrate has grooves machined into the surface, the grooves can be coated as long as some portion of the groove can be deposited by line of sight. The portion coated by line of sight then acts as a secondary target to coat the sidewalls of the slot through bias sputtering (see Figure 2). Continued biasing generally results in a leveling of the deposited film.

One extremely important result of bias sputtering that has not been mentioned yet is that improved adhesion is quite often obtained. This is a result of cleaning the surface of the substrate in the preliminary stage of sputtering. 
Since there is little to no deposited material on the substrate, ionic bombardment would result in the sputter ejection of the substrate material. This exposes fresh material and cleans the substrate surface. This operation is similar to sputter etching. In etching, a negative bias is applied to the substrate, but no bias is applied to the target; therefore, the substrate acts as the cathode. In order to prevent the contamination of the target material, a movable shutter is placed between the substrate and target during etching. 


\section{FIGURE CAPTIONS}

Figure 1. Schematic of a typical sputtering system.

Figure 2. Affect of bias sputtering onto samples with trenches machined into the surface of the substrate. 


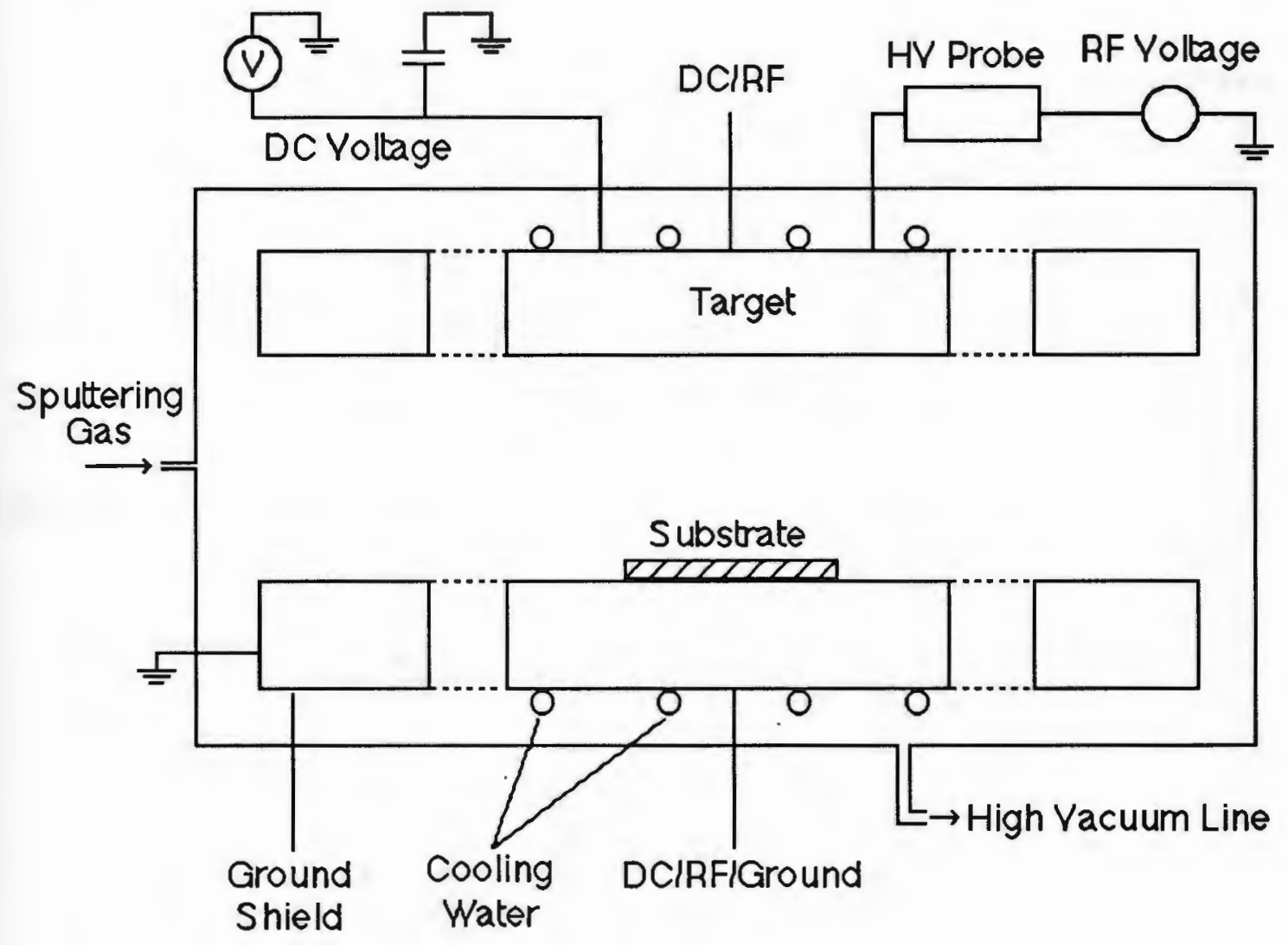

Figure 1 
Appendix B 


\section{Patterning of Curved Ceramic Blades}

The patterning sequence used to pattern the NT154 stator blades is shown in Figures 1 through 4. The patterning sequence is as follows: One side of a NT154 stator blade is immersed in an epoxy solution to form a mold that will replicate the curved surface. The epoxy mold is allowed to harden and is then cut down the middle in order form a split mold so that it can be removed from the blade. The resulting mold and blade are shown in Figure 1. Heavy duty aluminum foil is then formed around the blade by first loosely placing the aluminum foil around the blade and then forcing the aluminum against the blade with the epoxy mold (Figure 2). Prior to this step the thermocouple legs are cut out of the foil (Figure 3). The formed aluminum is then removed and super glue is placed on those areas of the blade not occupied by the sensor elements. The aluminum mask is then applied to the blade and bonded. The pattern can then be transferred to the blade. After sensor deposition, the aluminum foil can be removed by heating above $300^{\circ} \mathrm{C}$ to completely decompose and ash the super glue. Little or no residue is left on the blade after the ashing process. The final result is a sputtered stator blade that can be seen in Figure 4. 


\section{FIGURE CAPTIONS}

Figure 1. Stator blade with split epoxy mold.

Figure 2. Epoxy mold positioning on stator blade.

Figure 3. Aluminum mask formed on stator blade without adhesive.

Figure 4. Sputtered metal pattern on stator blade. 


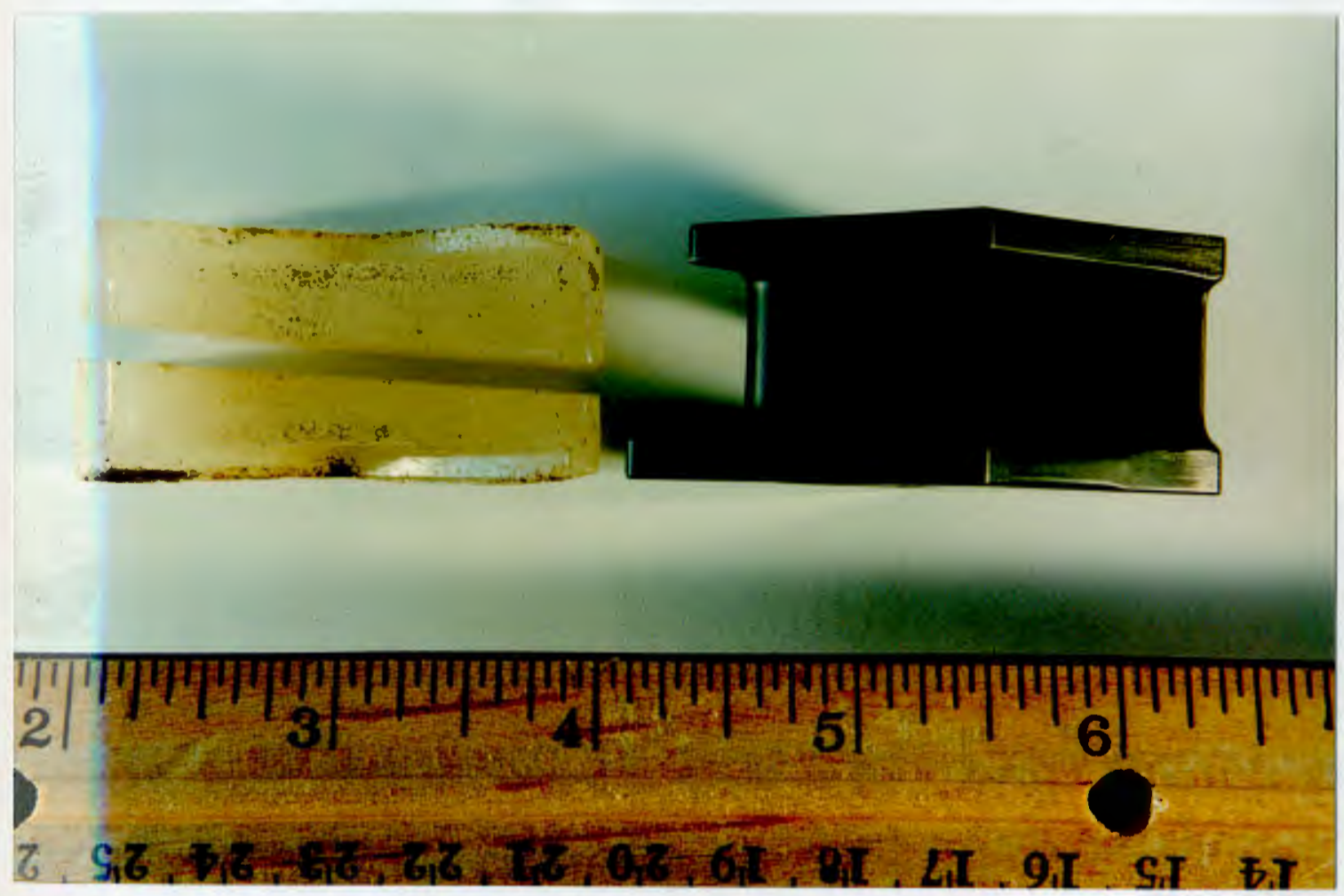

Figure 1 


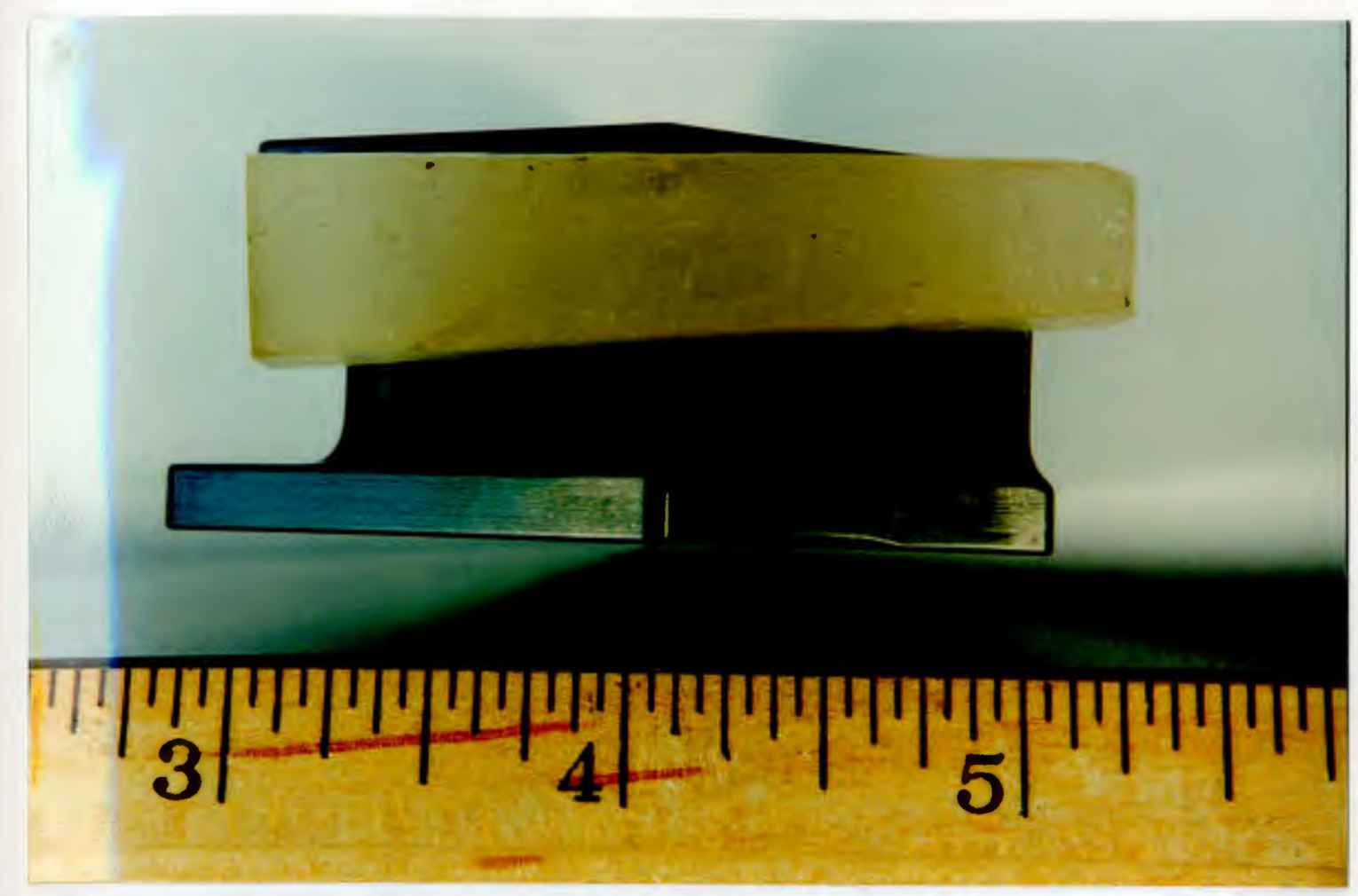

Figure 2a

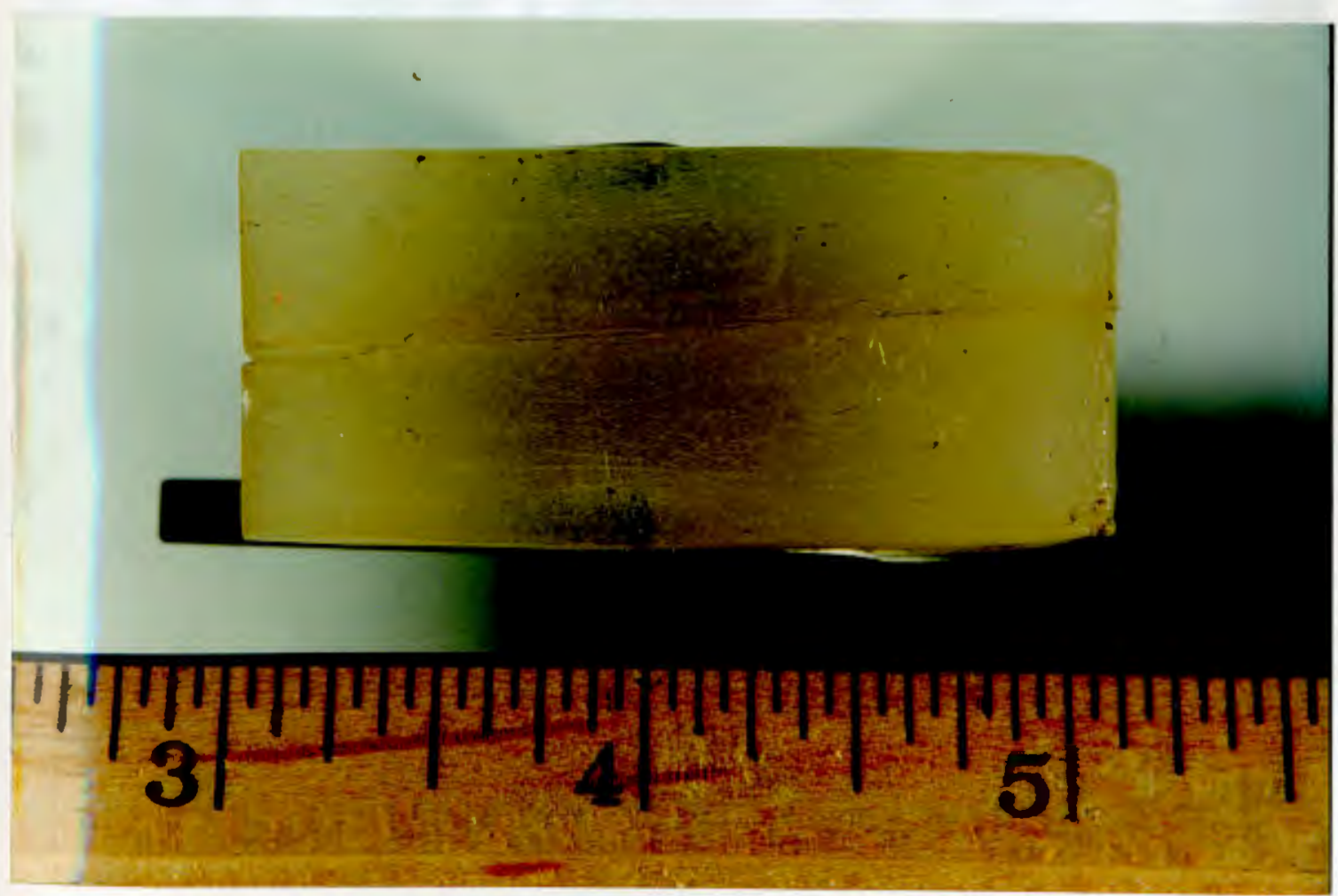

Figure $2 b$ 


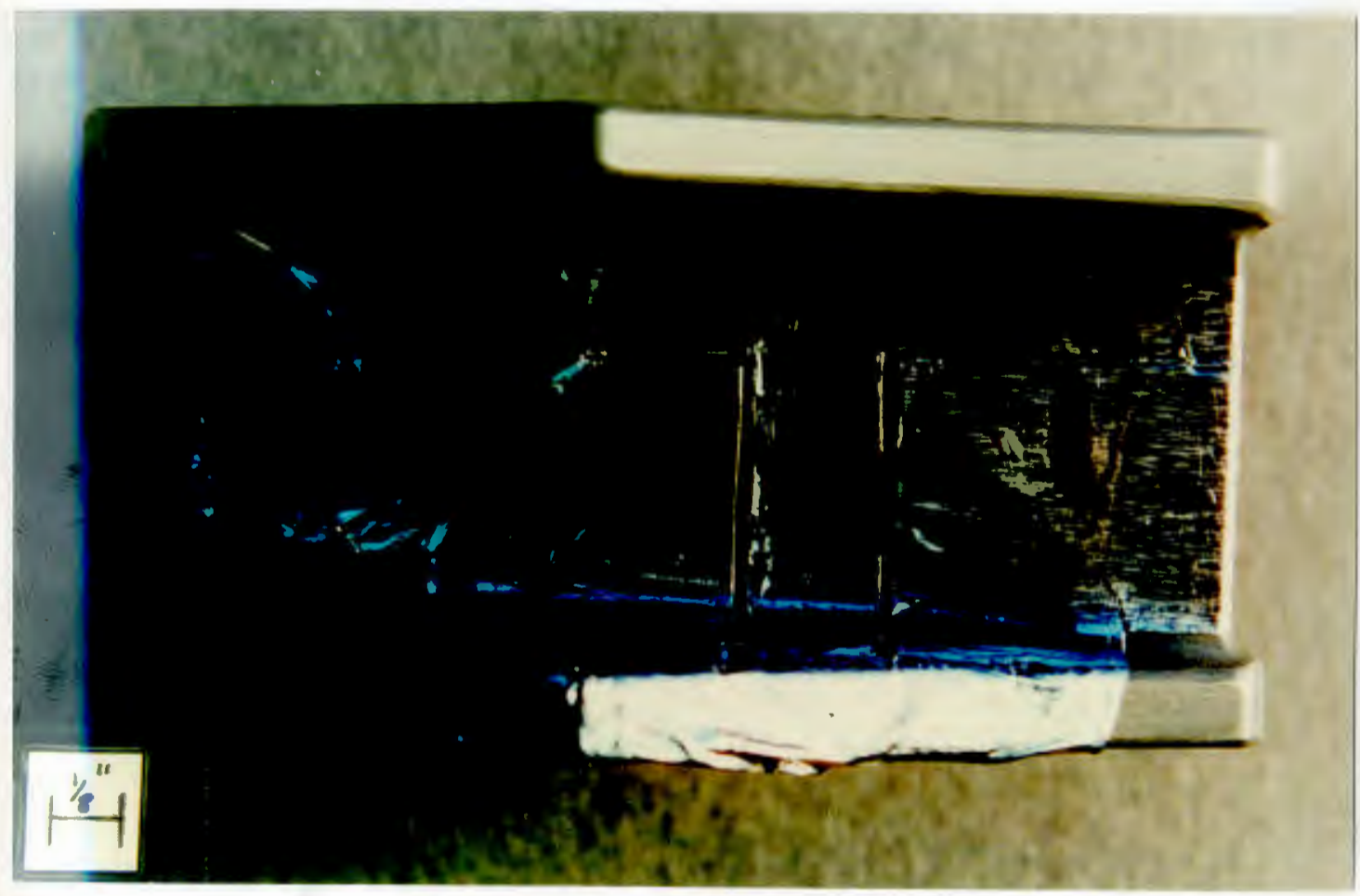

Figure 3 


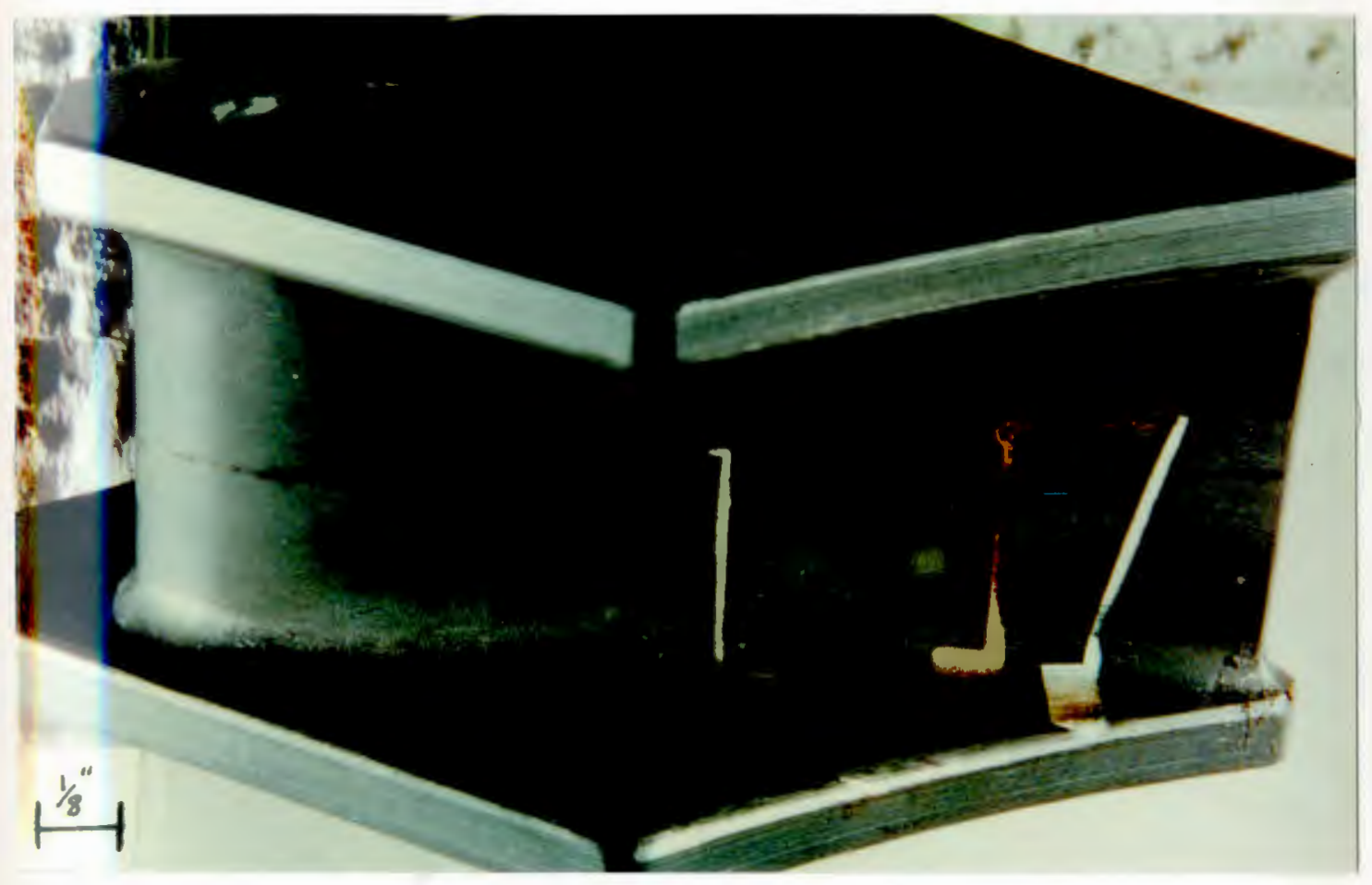

Figure 4 
Appendix C 


\section{Lead Wire Attachment by Parallel Gap Welding}

\subsection{Introduction}

Parallel gap welding was chosen for lead wire attachment to sensor films on the ceramic substrates. Other methods such a ultrasonic welding, oven brazing, flame-spray metallic coatings, and conductive pastes were not chosen since previous studies have found them to be unreliable and time consuming [1]. Thermocompression bonding was found to have promise for easily formed noble metals, such as gold, platinum, and rhodium. However, this method is quite time consuming and adequate fixturing was not available [2,3].

The advantages of parallel-gap welding process for thin-film-to-lead connections are: (1) the instantaneous formation of the bond; (2) no extraneous material is added into the thermocouple circuit; and (3) the ability of the weld to withstand a temperatures as high as the metals in the thin film thermocouple itself.

The welding equipment consisted of a Unitek, Unibond 2 (Model \# 1-19101). Before the welding tests coupons were sputtered with the appropriate precious metal, the $\mathrm{Si}_{3} \mathrm{~N}_{4}$ substrates were first oxidized at $1300^{\circ} \mathrm{C}$ in air for 100 hours. This was followed by a concentrated HF etch (49\%) to planarize the surface. Precious metal films were then sputtered in argon gas at $8 \mathrm{mTorr}$ and $200 \mathrm{~W}$. Pt and Pt:10Rh wire, 0.003" (76 $\mu \mathrm{m})$ diameter, were flattened prior to wire bonding (Figure 1) to prevent rolling and increase the contact area (interfacial area) between the wire and the precious metal film. Thereafter, a methanol wash and a nitrogen blow dry was used to remove any oils or impurities prior to wire bonding.

Prior to Pt metal deposition, a $1000 \AA$ layer of $\mathrm{Al}_{2} \mathrm{O}_{3}$ was presputtered for 
adhesion purposes followed by a $4 \mu \mathrm{m}$ thick film of Pt. Since Pt:10Rh already has acceptable adhesion properties, a presputtered layer of $\mathrm{Al}_{2} \mathrm{O}_{3}$ was unnecessary. Again, a $4 \mu \mathrm{m}$ thick Pt:10Rh film is sputtered. A thickness of $4 \mu \mathrm{m}$ was chosen for both $\mathrm{Pt}$ and $\mathrm{Pt}: 10 \mathrm{Rh}$ films since they had the best strength properties and any destructive blistering was minimized.

After lead wires were attached, a pull test was performed perpendicular to the metal film with measured weights to determine the bond strength in $\left(\mathrm{Ib}_{\mathrm{f}} / \mathrm{in}^{2}\right)$.

\subsection{Platinum Lead Wire Attachment}

The welding tip used was a constant gap, 0.004", Unitip electrode (model \# UTM224C). This tip gave excellent welds when first used. However, over time (approximately 700 welds), the strengths of the bonds decreased. Excessive polishing decrease the welding tips effectiveness, probably by rounding the tip. Earlier welding tests were able to support much more weight than the later tests, using identical welding parameters. The loss of effectiveness from the same welding tip over a large number of welds concurs with previous studies. ${ }^{3}$ Despite this, strong welds were still obtained with an older tip.

The optimal parameters used for Pt wire bonding with a new electrode tip were as follows: mode-voltage + current; applied force-900 g ; pulse duration-27 ms.

The optimal parameters used for Pt wire bonding with a heavily used electrode were: mode-voltage + current; applied force-550 g ; pulse duration-70 ms.

The applied voltage was observed to have the largest influence on the 
weld strength. Sections 2.1 and 2.2 discuss the welding voltages used.

\subsection{Platinum weld parameters and SEM micrographs}

Figure 2 shows an SEM micrograph of a low voltage ( 0.50 volts) weld of a Pt wire to a Pt film that used a new electrode tip. From this micrograph, a fusion zone on the wire cannot be seen. However, a slight heat affected zone is visible on the Pt film around the weld tip compression area. This weld had poor strength, since little fusion of the wire was observed. When a pull test was attempted on these bonds, the wire easily pulled away from the film, and therefore it was determined that no real join was formed between the wire and the film.

Figure 3 shows SEM micrographs of another Pt wire welded at a voltage of 0.55 volts using a new electrode tip. A fusion zone can be clearly seen on the wire, with slight wetting of the film. Strengths were greatly enhanced by using this higher voltage setting. The increase in strength was attributed to the large contact area between the wire and film. Although there is some deformation of the wire at this setting, the welds are still considered good since there is no dielectric layer whose integrity can be compromised, as would be the case in metal engine components.

Figure 4 shows SEM micrographs of yet another Pt wire welded at a voltage of 0.60 volts using a new electrode tip. This setting destroyed both the wire and the film and seriously compromised the strength (no reproducible strengths were recorded). The weld shown in Figure 4 was one of a few, at 0.60 volts and above, that did not stick to the electrode tips, since a majority of these welds did stick. The welds formed at this setting caused too much damage to the film, wire, and the electrodes. 
Figure 5 shows an SEM micrograph of six Pt wires welded at various voltages between $0.65-0.85$ volts (a voltage of less than 0.65 volts could not create any weld) from a tip that had been used over 700 times. With the exception of the second wire from the top (which has a heat affected zone around the weld points) all the wires appear to have been welded using identical parameters.

Figure 6 shows SEM micrographs of Pt wire welded using 0.65 and 0.70 volts with an older electrode tip. No fusion zone or heat affected zone can be seen, only the compression regions from the weld tip. Figure 7 shows SEM micrographs of $\mathrm{Pt}$ wire welded with a 0.85 volt setting, that also used an older electrode tip. A slight heat affected zone can be seen on the low magnification micrograph, which indicates there is some wire-film interaction present. However, there is no fusion zone present, only a slight necking of the wire between the electrode tip contact points.

\subsection{Platinum weld strengths}

Welds formed using voltages $<0.50$ and $>0.60$ volts and a new electrode tip did not have pull tests performed on them due to their poor quality. However, a normalized strength of $8200 \mathrm{lb} / \mathrm{in}^{2}$ at 0.55 volts was observed to give the best results from all welds.

Figure 8 shows how the film strength varies with applied voltage when a tip has been used over 700 times and was cleaned with $\mathrm{Al}_{2} \mathrm{O}_{3}$ polishing disks repeatedly. It is apparent that strength decrease drastically with over usage. The plot here shows that the best voltage employed for a heavily used tip was 0.70 volts. However, this parameter can vary slightly and still give similar results. It is apparent that this tip was not well suited for heavy use. 


\subsection{Platinum:10Rhodium Lead Wire Attachment}

Attachment of Pt:10Rh lead wires required different weld parameters compared to those used for $\mathrm{Pt}$. The optimal parameters used for the $\mathrm{Pt}: 10 \mathrm{Rh}$ wire bonding are as follows: mode-voltage; applied force-800 g; pulse duration-25 ms. The welding tip was a variable gap Unibond electrode (model \# EU2030M). Various gaps were tested and a 0.007 " gap was found to give the best results. Larger gaps (>0.010") severed the wires, whereas smaller gaps (<0.004") do not produce an adequate adhesion area. Again the applied voltage was found to have the most influence on the weld strength. Sections 3.1 and 3.2 further discusses the welding voltages used.

In addition to the weld parameters being different, the Pt:10Rh films had to be annealed prior to bonding. The film was heated to $1200^{\circ} \mathrm{C}$ for 1 hour to relieve incorporated stresses and relax the films. To further aid in bonding the wire, a large $A C$ current was passed through it to remove any organics and oils on the wire surface. In an attempt to further enhance welding, an aqua regia wet etch of the wire and film was utilized to remove any oxides and other impurities that may be present on the surface. However, this additional etching step showed no significant increase in welding strength.

\subsection{Platinum:10Rhodium weld parameters and SEM} micrographs

Figure 9 is a SEM micrograph of a weld formed using 1.1 volt setting. It was apparent that little or no fusion occurred in the wire. This weld was insufficient to carry a load since there was little diffusion between the wire and 
the film.

Figure 10 has SEM micrographs of welds that used 1.3 volts. The fusion zone can be clearly seen on the wire. This weld voltage was found to give good strengths and does not compromise the wire or film strength. With this weld, however, there was only a small amount of contact area between the film and the wire and thus slightly lower strengths based on this may be anticipated.

Figure 11 shows SEM micrographs of welds formed at 1.5 volts. This setting caused considerable flowing of the Pt:10Rh wire, but had the best strength. This large increase in contact area correspondingly produced the excellent strength.

Figure 12 shows SEM micrographs of welds formed at 1.7 volts. The micrographs show how the wire dewetted from the substrate due to the damage done on the film. The film damage from this voltage can also be seen in Figure 12 (Note that the area inside the blown out wire is not the Pt:10Rh film, but the charging from the $\mathrm{Si}_{3} \mathrm{~N}_{4}$ substrate).

\subsection{Platinum:10Rhodium weld strengths}

The pull test described in the introduction was also done for Pt:10Rh weldments. The plot of weld strength-vs-applied voltage is shown in Figure 13. Although 1.7 volts showed good weld strengths, the SEM micrographs show that excessive damage was done in the process. In the long run, this damage may effect the emf data and output of the sensor. From these results it was determined that the 1.5 volt setting was the best for $\mathrm{Pt}: 10 \mathrm{Rh}$ lead wire attachment. 


\section{LITERATURE CITED}

[1] Grant, H. P.; and Przybyszewski, J. S.; Anderson, W. L.; and Claing, R. G., "Thin film strain gage development program final report", NASA contract report 174707, Dec. 1983.

[2] Grant, H., and Przybyszewski, J., "Thin film temperature sensor - Phase 1", NASA contract report 159782, 1980.

[3] Holanda, R.; Kim, W. S.; Pencil, E.; Groth, M.; and Danzey, G. A., "Attachment of lead wires to thin film thermocouples mounted on high temperature materials using the parallel gap welding process", NASA technical memorandum 102442, May 1990. 


\section{FIGURE CAPTIONS}

Figure 1a. SEM micrograph of a flattened lead wire prior to welding (low magnification).

Figure 1b. SEM micrograph of a flattened lead wire prior to welding (high magnification).

Figure 2a. SEM micrograph of a $0.003 " \mathrm{Pt}$ wire bonded to a $4 \mu \mathrm{m} \mathrm{Pt}$ film with a voltage setting of $0.50 \mathrm{~V}$ using a new electrode tip (low magnification).

Figure 2b. SEM micrograph of a $0.003 " \mathrm{Pt}$ wire bonded to a $4 \mu \mathrm{m}$ Pt film with a voltage setting of $0.50 \mathrm{~V}$ using a new electrode tip (high magnification).

Figure 3a. SEM micrograph of a $0.003 " \mathrm{Pt}$ wire bonded to a $4 \mu \mathrm{m}$ Pt film with a voltage setting of $0.55 \mathrm{~V}$ using a new electrode tip (low magnification).

Figure 3b. SEM micrograph of a $0.003 "$ Pt wire bonded to a $4 \mu \mathrm{m}$ Pt film with a voltage setting of $0.55 \mathrm{~V}$ using a new electrode tip (high magnification).

Figure 4a. SEM micrograph of a $0.003 " \mathrm{Pt}$ wire bonded to a $4 \mu \mathrm{m}$ Pt film with a voltage setting of $0.60 \mathrm{~V}$ using a new electrode tip (low magnification).

Figure 4b. SEM micrograph of a 0.003 " Pt wire bonded to a $4 \mu \mathrm{m}$ Pt film with a voltage setting of $0.60 \mathrm{~V}$ using a new electrode tip (high magnification).

Figure 5. SEM micrograph of Pt wires welded at various voltages using a worn electrode tip. Top wire - various settings; second from top $-0.85 \mathrm{~V}$; third from top $-0.80 \mathrm{~V}$; fourth from top $-0.75 \mathrm{~V}$; second from bottom $-0.70 \mathrm{~V}$; bottom $-0.65 \mathrm{~V}$.

Figure 6a. SEM micrograph of a 0.003 " Pt wire bonded to a $4 \mu \mathrm{m}$ Pt film using a worn electrode tip at a voltage setting of $0.65 \mathrm{~V}$.

Figure 6b. SEM micrograph of a $0.003 " \mathrm{Pt}$ wire bonded to a $4 \mu \mathrm{m}$ Pt film using a worn electrode tip at a voltage setting of $0.70 \mathrm{~V}$.

Figure 7a. SEM micrograph of a $0.003^{\prime \prime} \mathrm{Pt}$ wire bonded to a $4 \mu \mathrm{m}$ Pt film using a worn electrode tip with an applied voltage of $0.85 \mathrm{~V}$ (low magnification).

Figure $7 \mathrm{~b}$. SEM micrograph of a $0.003^{\prime \prime} \mathrm{Pt}$ wire bonded to a $4 \mu \mathrm{m}$ Pt film using a worn electrode tip with an applied voltage of $0.85 \mathrm{~V}$ (high magnification).

Figure 8. Platinum weld strengths as a function of applied voltage that used a worn electrode tip. (film thickness $=4 \mu \mathrm{m}$ ). 
Figure 9. SEM micrograph of a $0.003 " \mathrm{Pt}: 10 \mathrm{Rh}$ wire bonded to a $4 \mu \mathrm{m} \mathrm{Pt:10Rh}$ film with a voltage setting of 1.1V. (Note that some recrystallization of the wire has occurred and grain boundaries are now visible most likely due to thermal etching in the vicinity of the heat affected zone).

Figure 10a. SEM micrograph of a $0.003 " \mathrm{Pt}: 10 \mathrm{Rh}$ wire bonded to a $4 \mu \mathrm{m}$ $\mathrm{Pt}: 10 \mathrm{Rh}$ film with a voltage setting of $1.3 \mathrm{~V}$. (Note the columnar grains in the liquid to solid fusion zone).

Figure 10b. SEM micrograph of a $0.003^{\prime \prime} P t: 10 R h$ wire bonded to a $4 \mu \mathrm{m}$ $\mathrm{Pt}: 10 \mathrm{Rh}$ film with a voltage setting of $1.3 \mathrm{~V}$. (Note the columnar grains in the liquid to solid fusion zone).

Figure 11 a. SEM micrograph of a $0.003 " \mathrm{Pt}: 10 \mathrm{Rh}$ wire bonded to a $4 \mu \mathrm{m}$ Pt:10Rh film with a voltage setting of $1.5 \mathrm{~V}$.

Figure $11 \mathrm{~b}$. SEM micrograph of a $0.003^{\prime \prime} \mathrm{Pt}: 10 \mathrm{Rh}$ wire bonded to a $4 \mu \mathrm{m}$ Pt:10Rh film with a voltage setting of $1.5 \mathrm{~V}$.

Figure 12a. SEM micrograph of a $0.003 "$ Pt:10Rh wire bonded to a $4 \mu \mathrm{m}$ Pt:10Rh film with a voltage setting of $1.7 \mathrm{~V}$. (Note the area inside the deformed wire is the charging of the $\mathrm{Si}_{3} \mathrm{~N}_{4}$ substrate and not the film).

Figure 12b. SEM micrograph of a $0.003 "$ Pt:10Rh wire bonded to a $4 \mu \mathrm{m}$ $\mathrm{Pt}: 10 \mathrm{Rh}$ film with a voltage setting of $1.7 \mathrm{~V}$. (Note the area inside the deformed wire is the charging of the $\mathrm{Si}_{3} \mathrm{~N}_{4}$ substrate and not the film).

Figure 13. Pt:10Rh weld strengths as a function of applied voltage. (film thickness $=4 \mu \mathrm{m}$ ). 


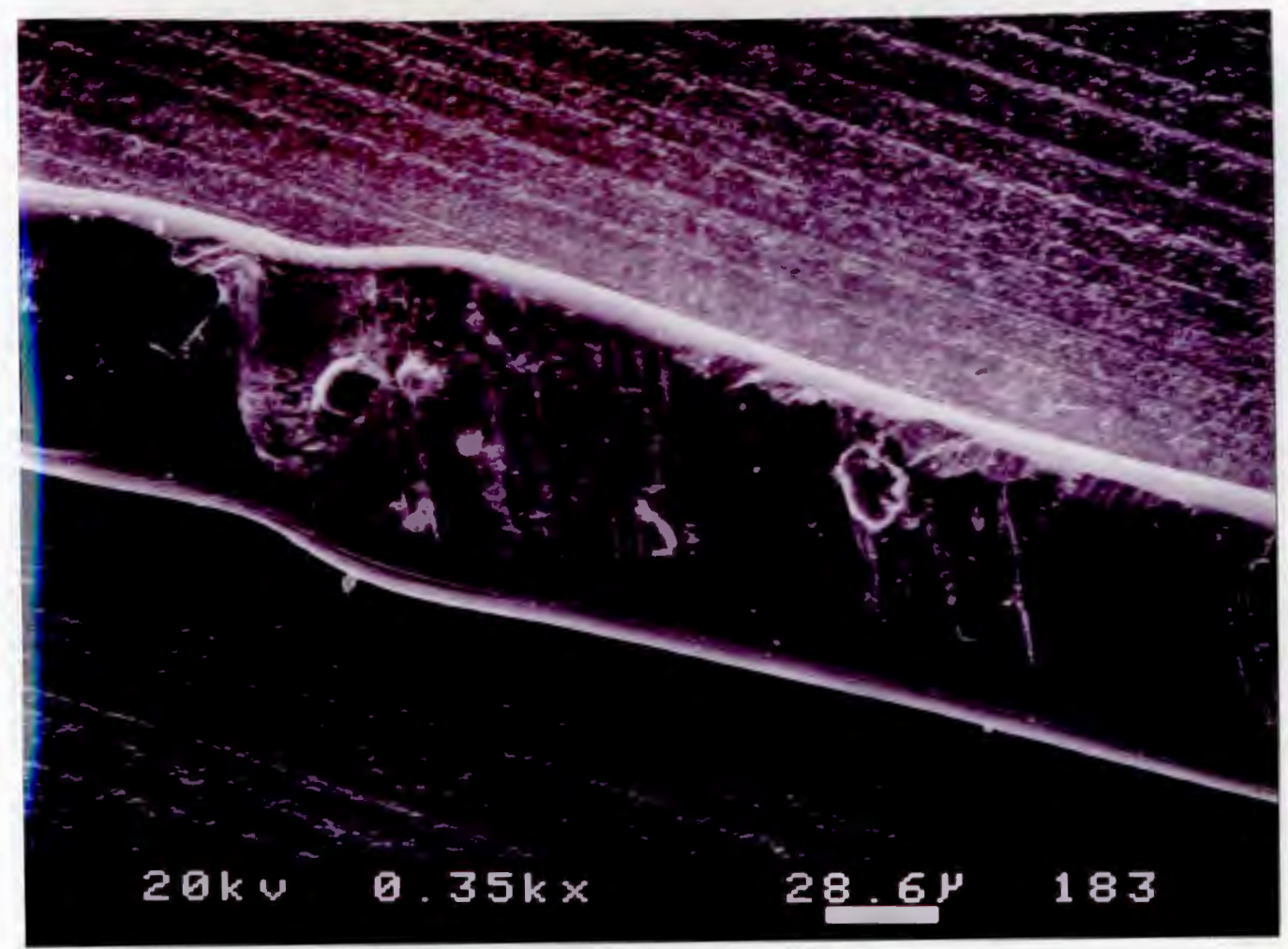

Figure $1 \mathrm{a}$

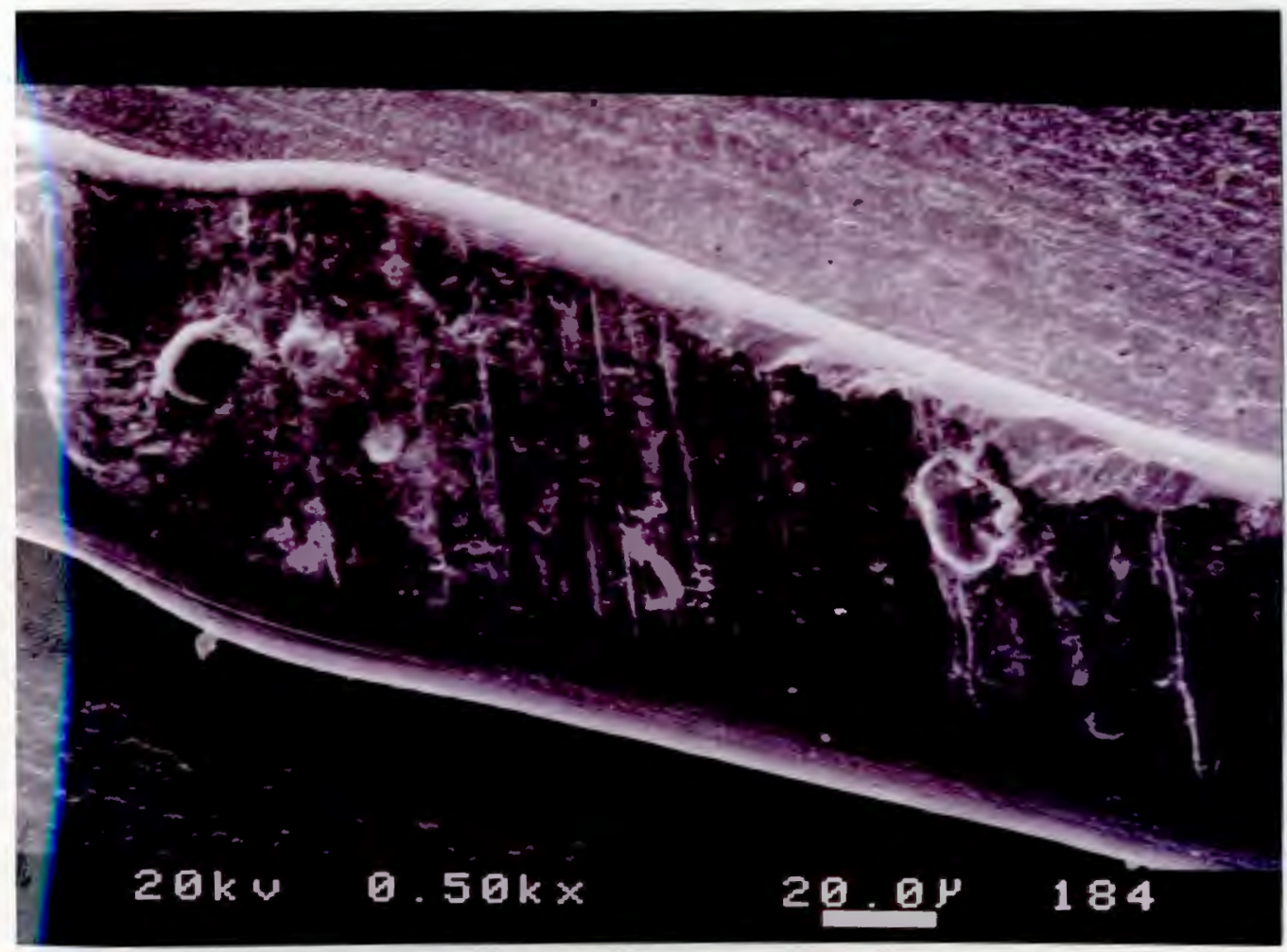

Figure 1b 


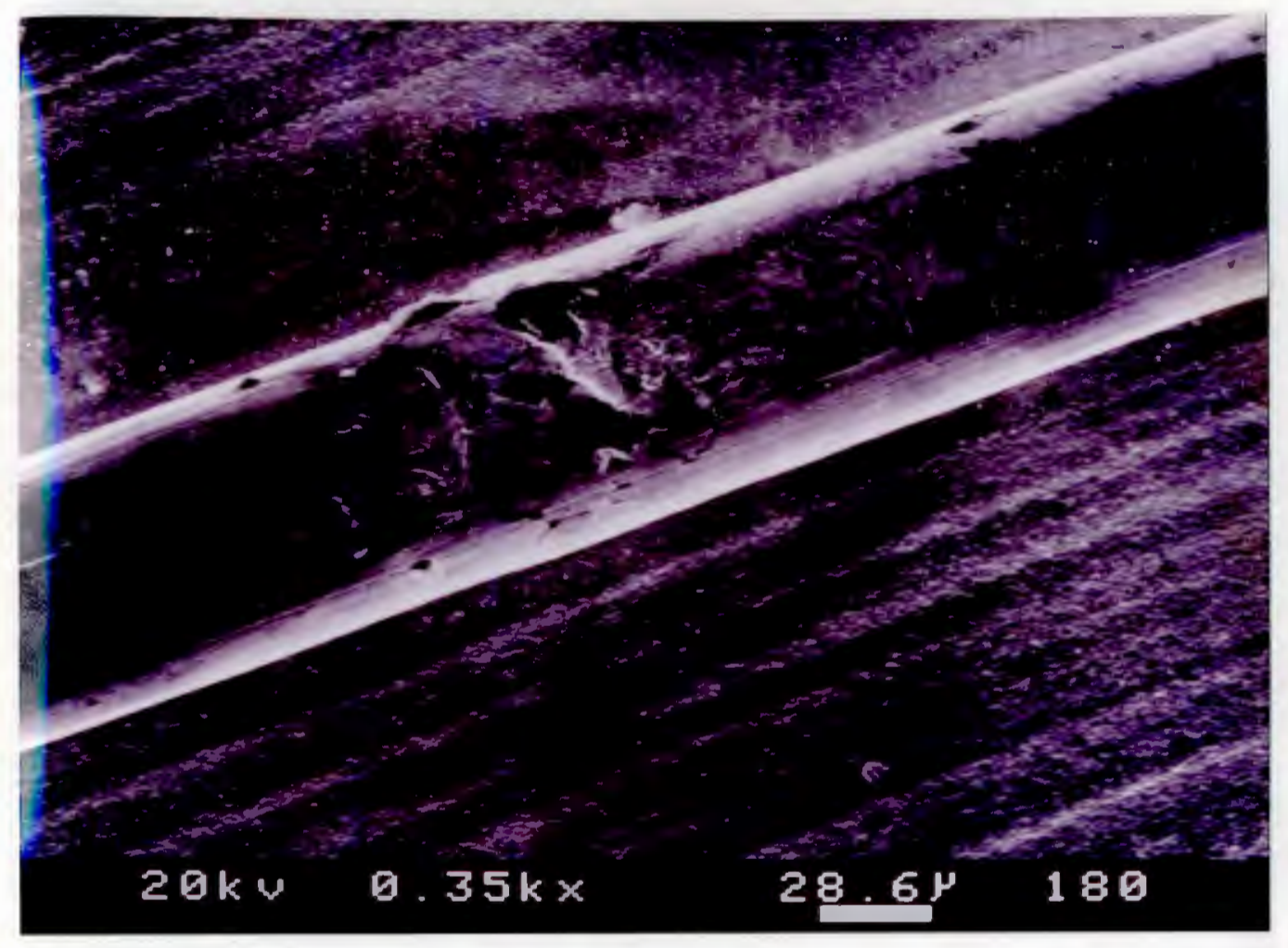

Figure 2a

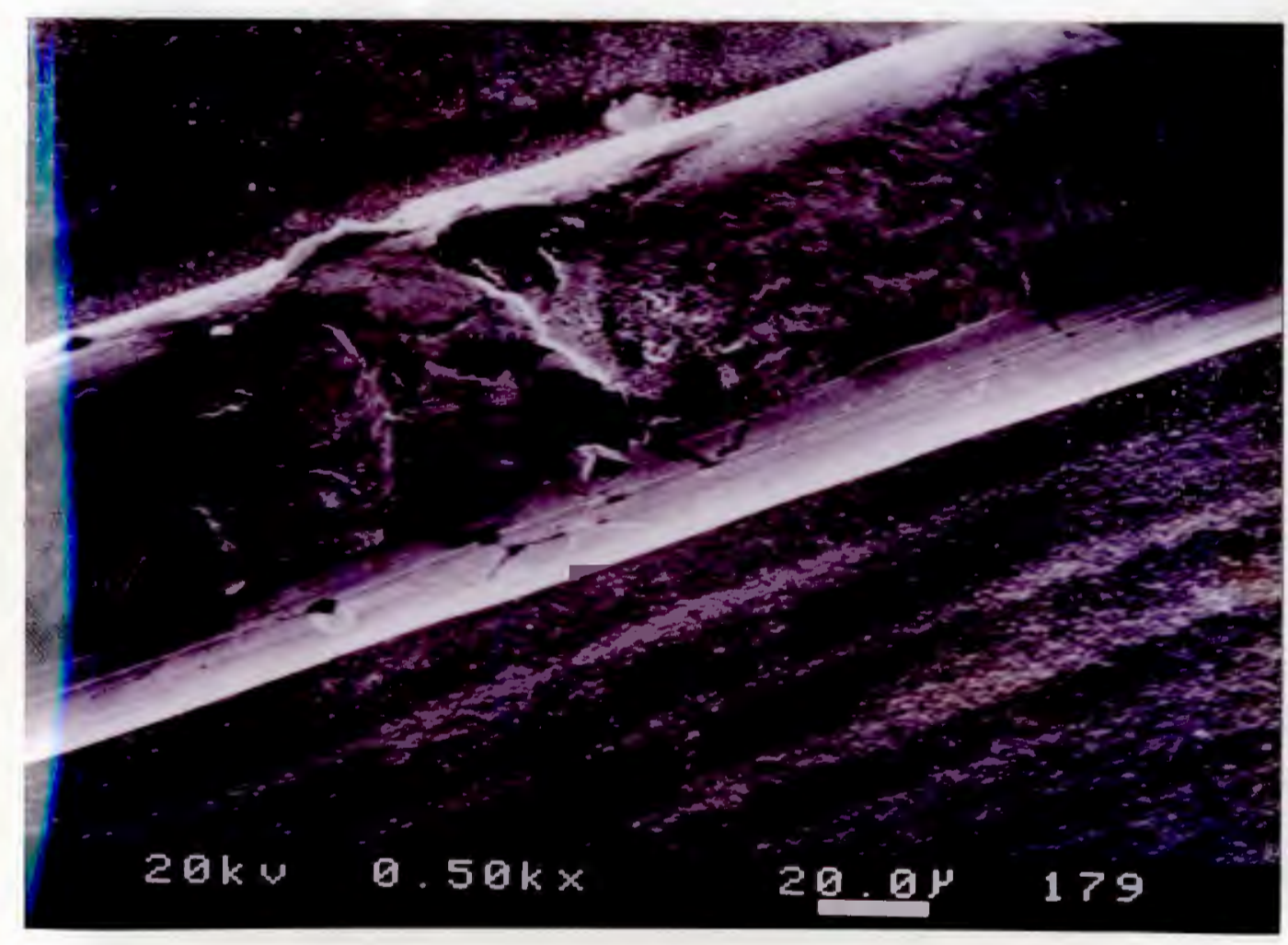

Figure $2 b$ 


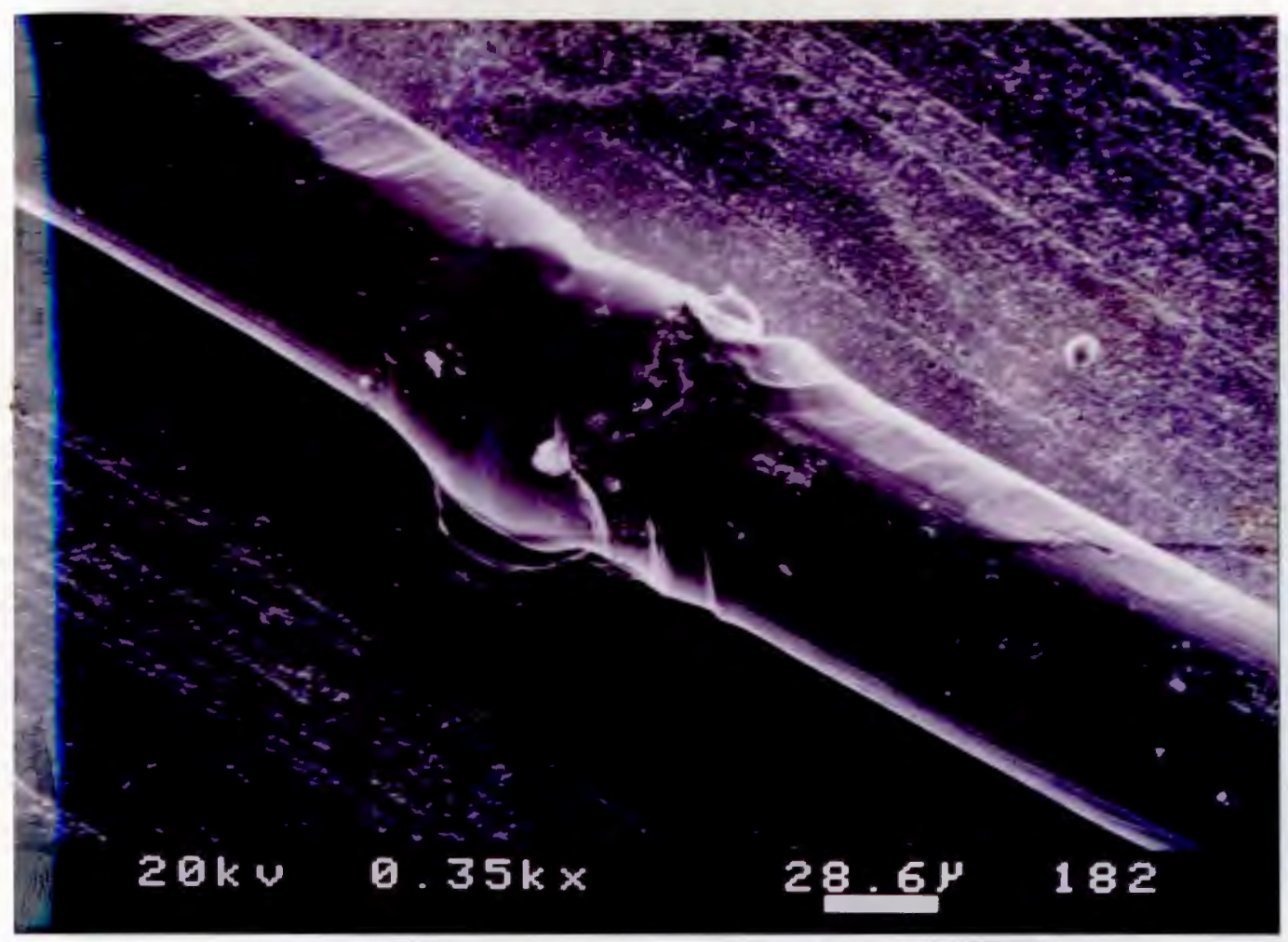

Figure $3 a$

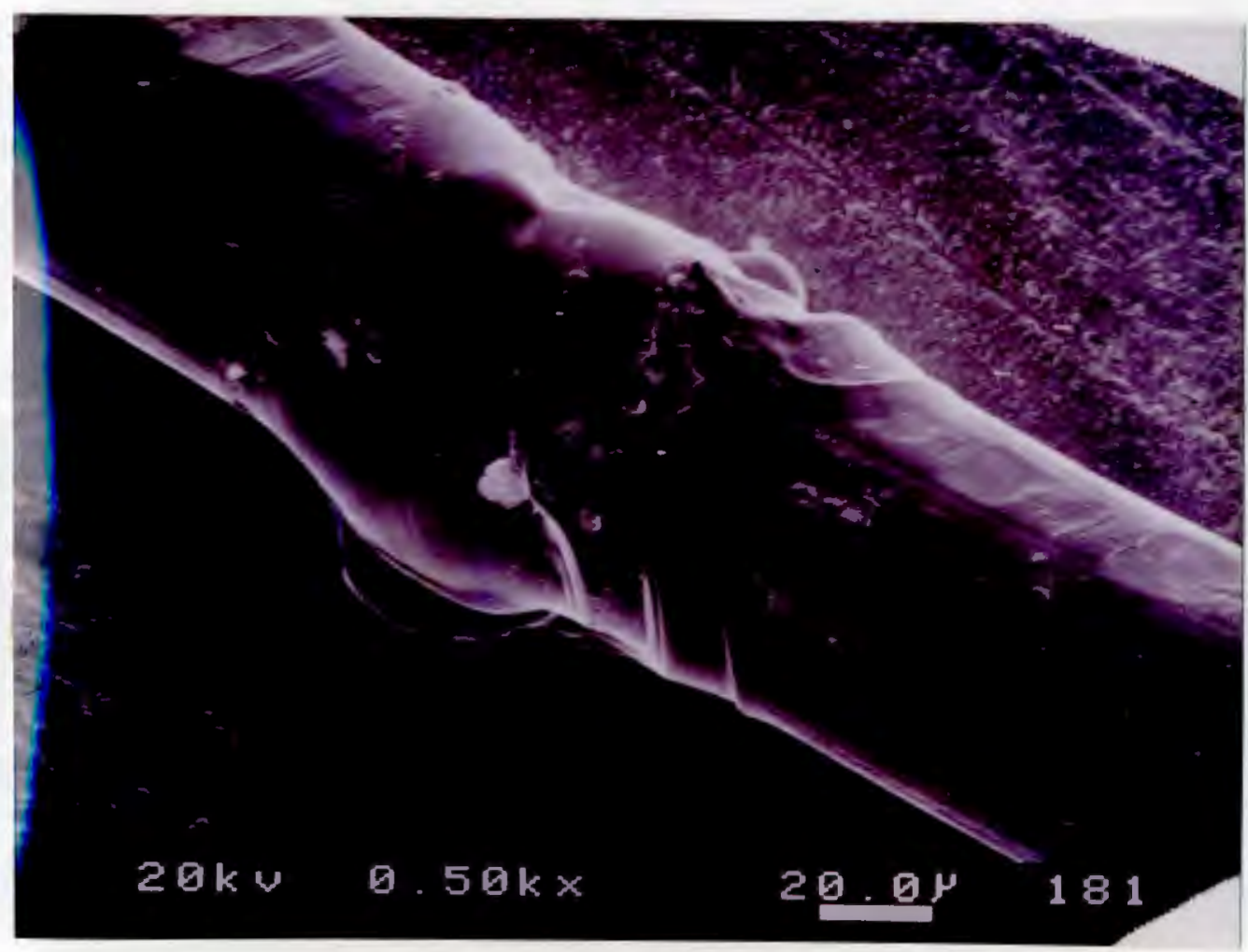

Figure $3 b$ 


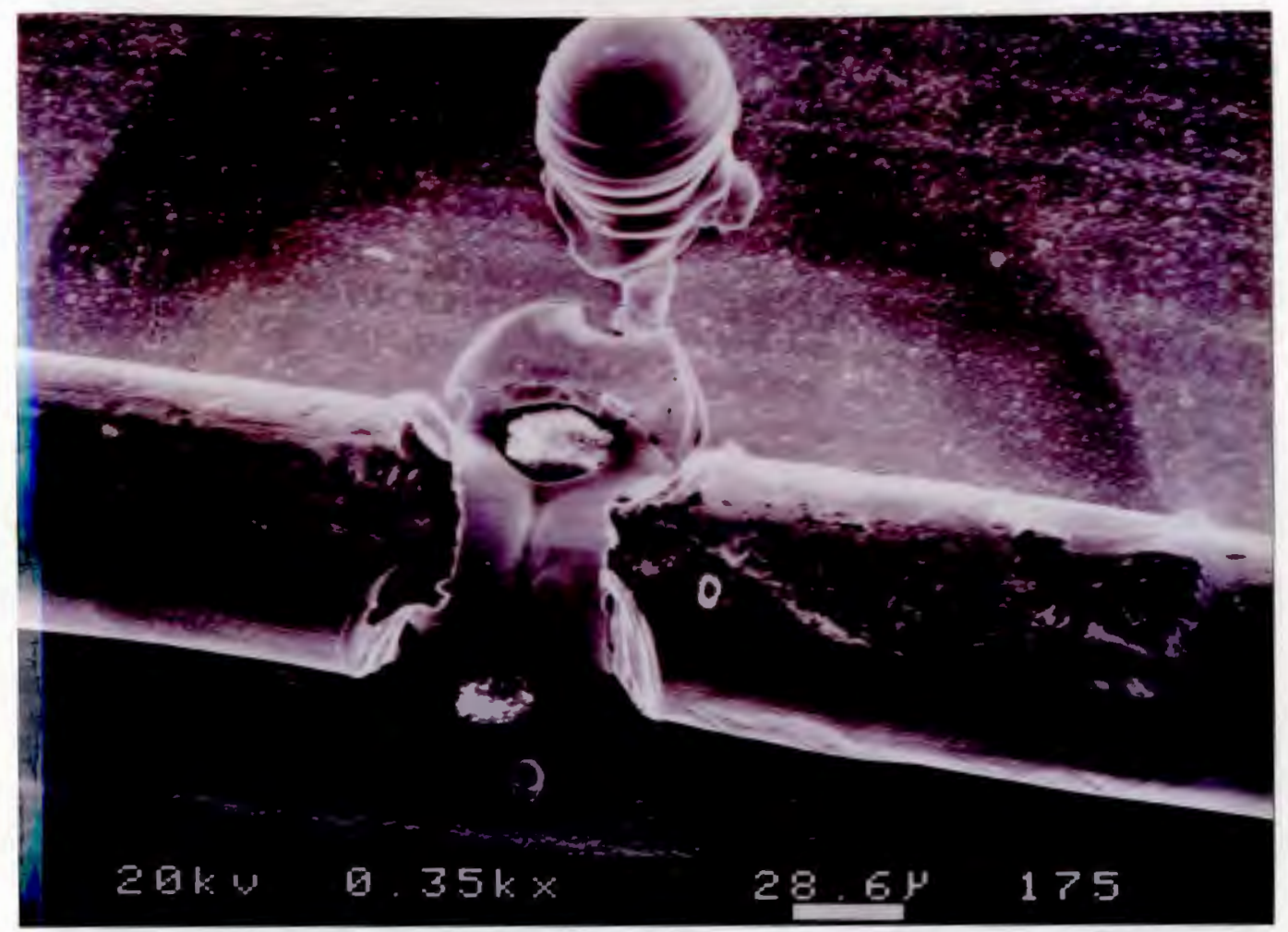

Figure $4 a$

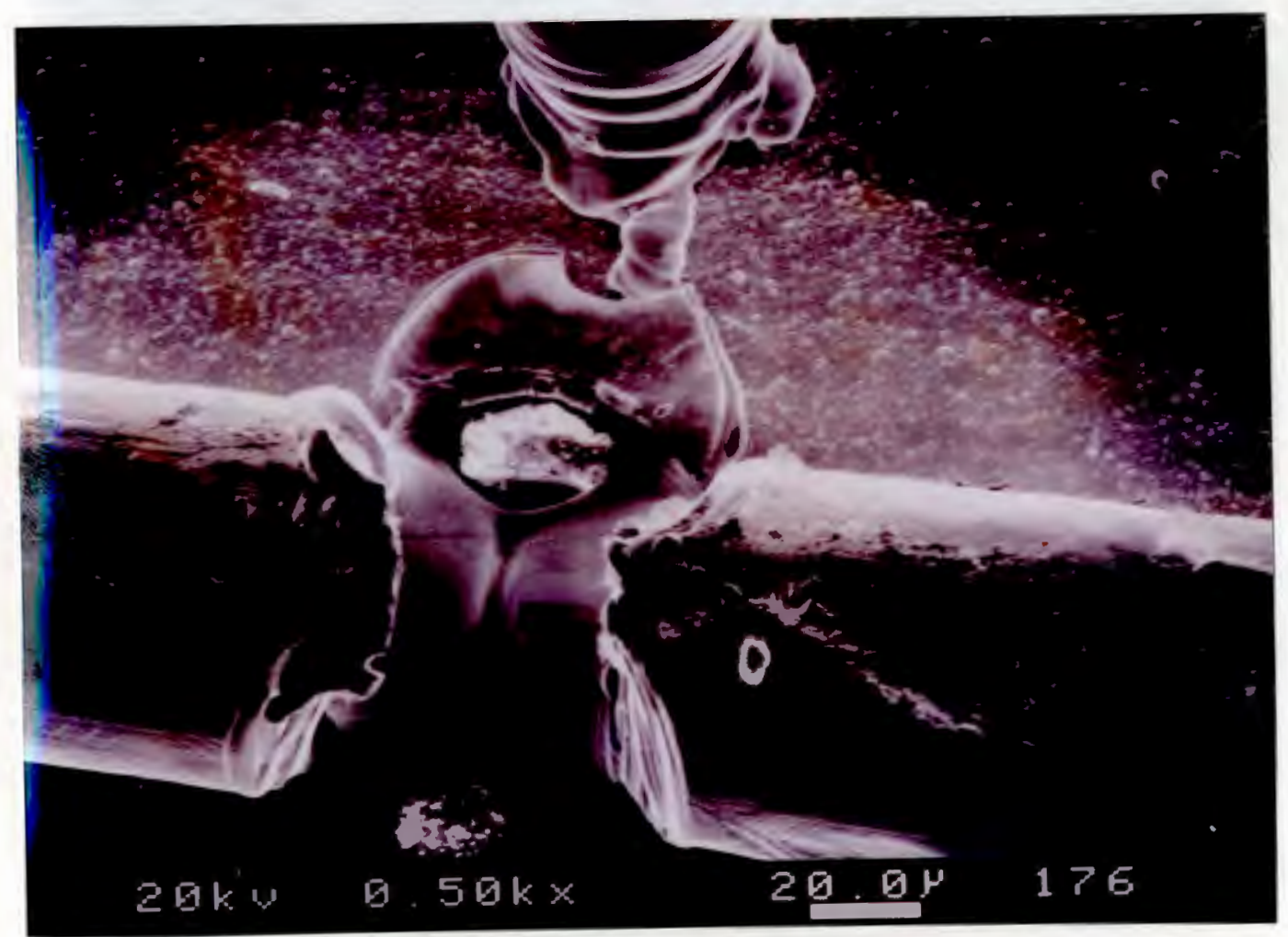

Figure 4b 


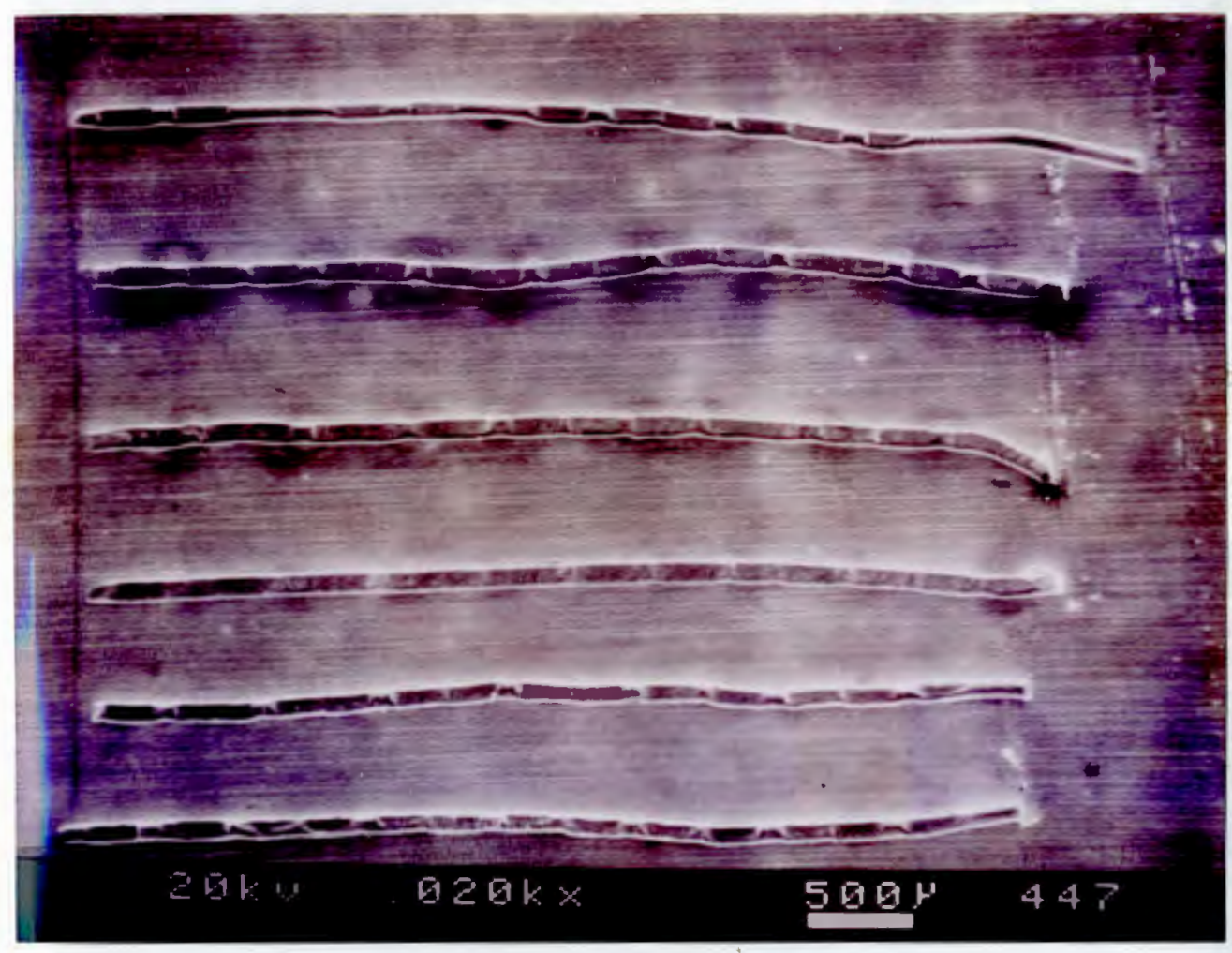

Figure 5 


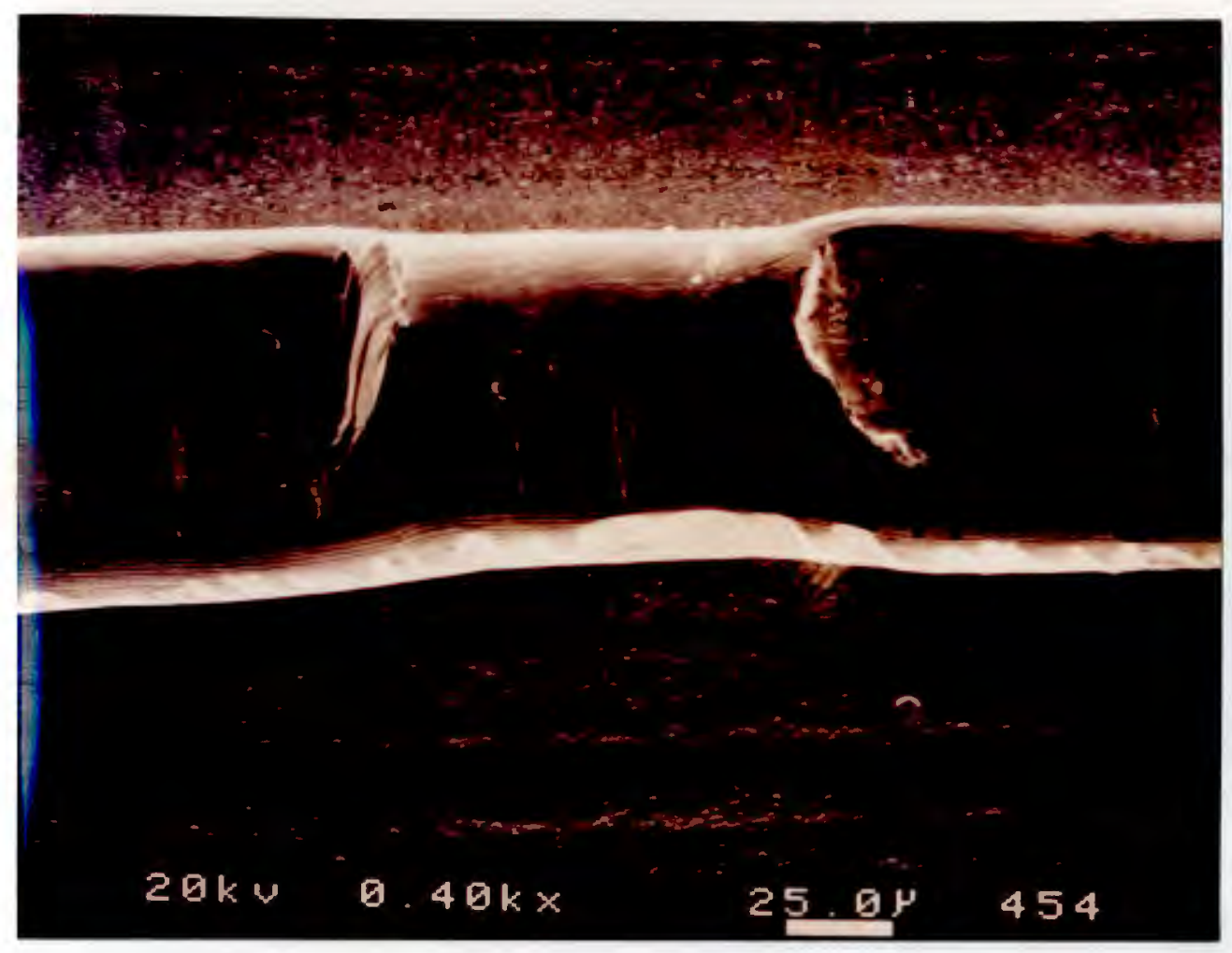

Figure $6 a$

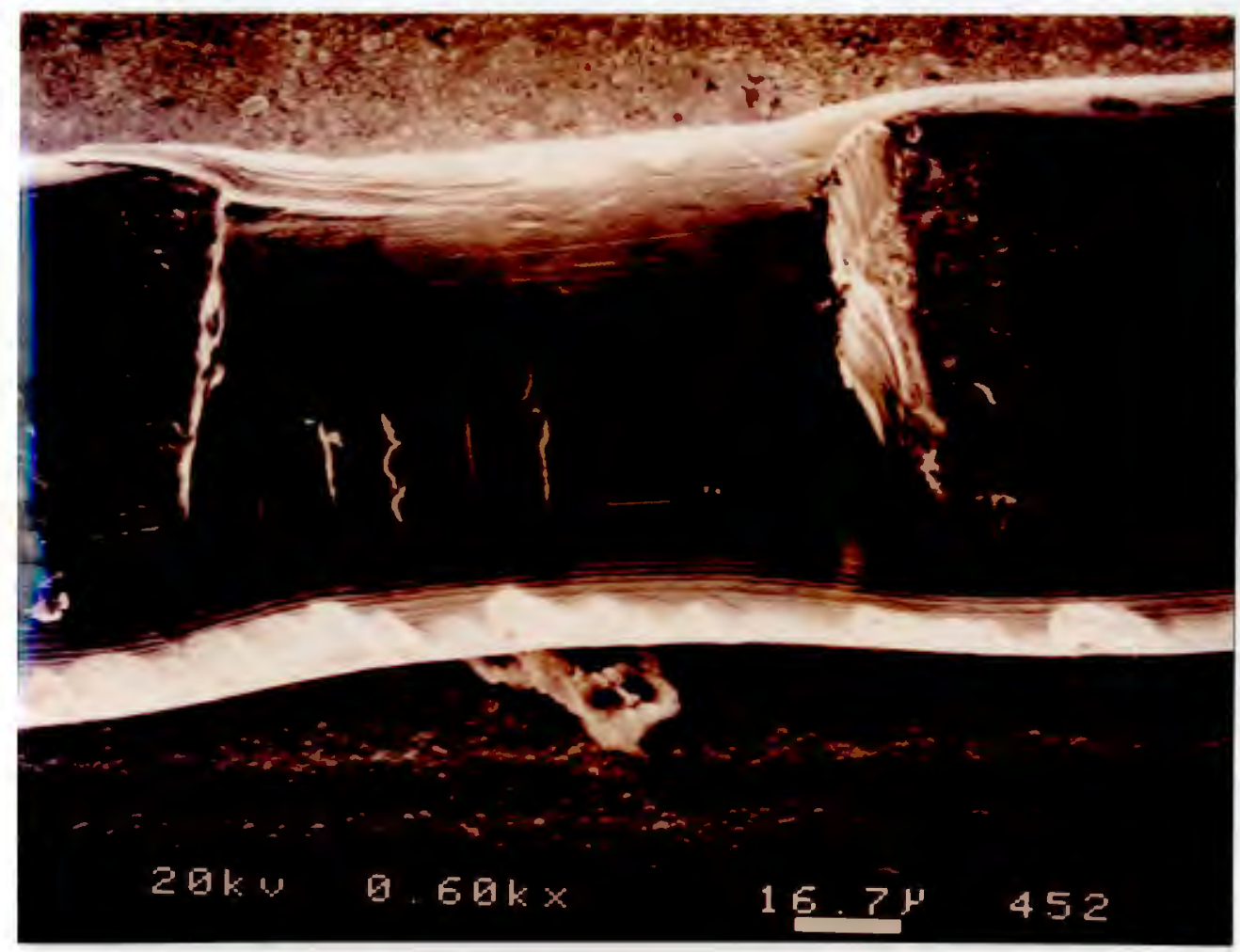

Figure $6 b$ 


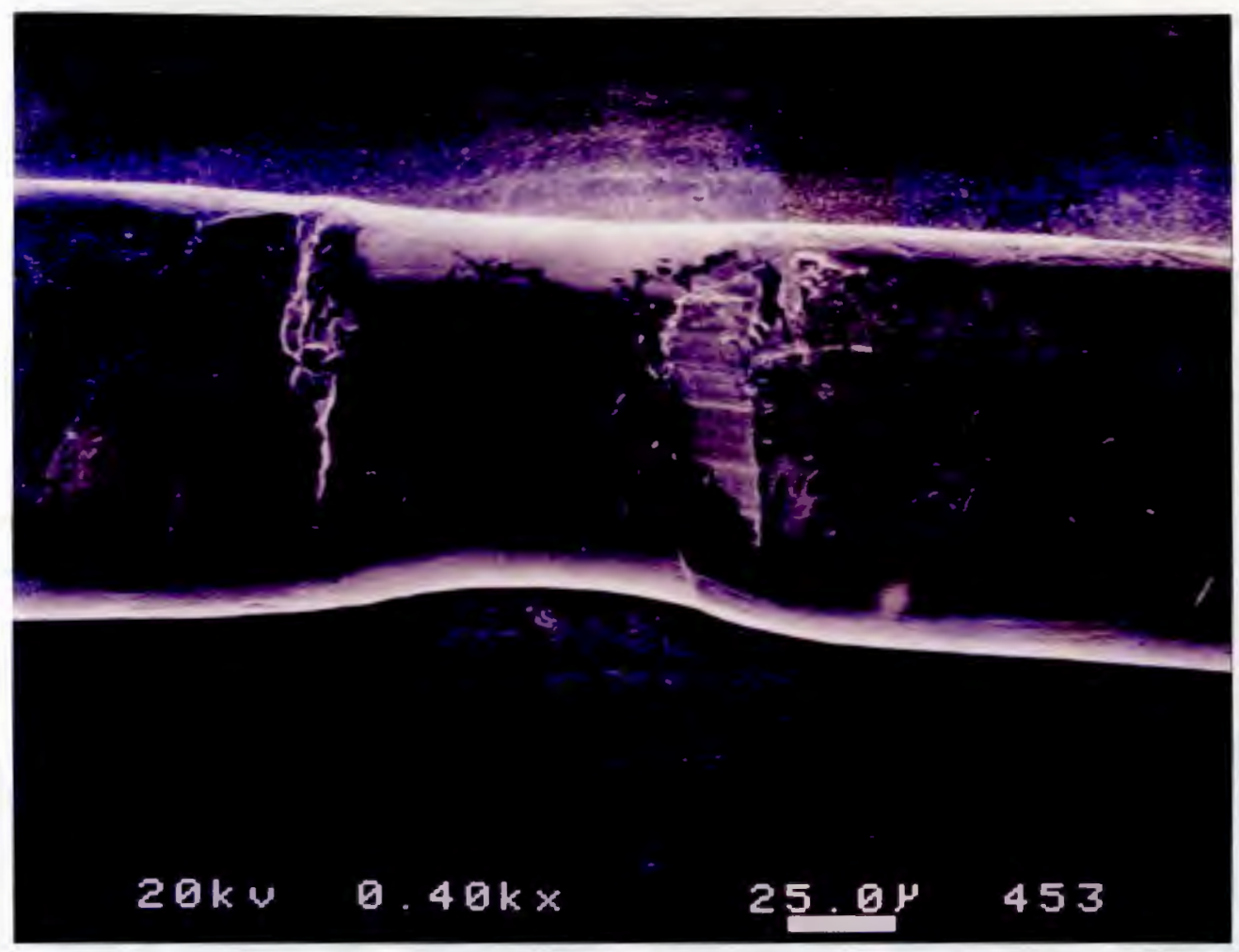

Figure $7 a$

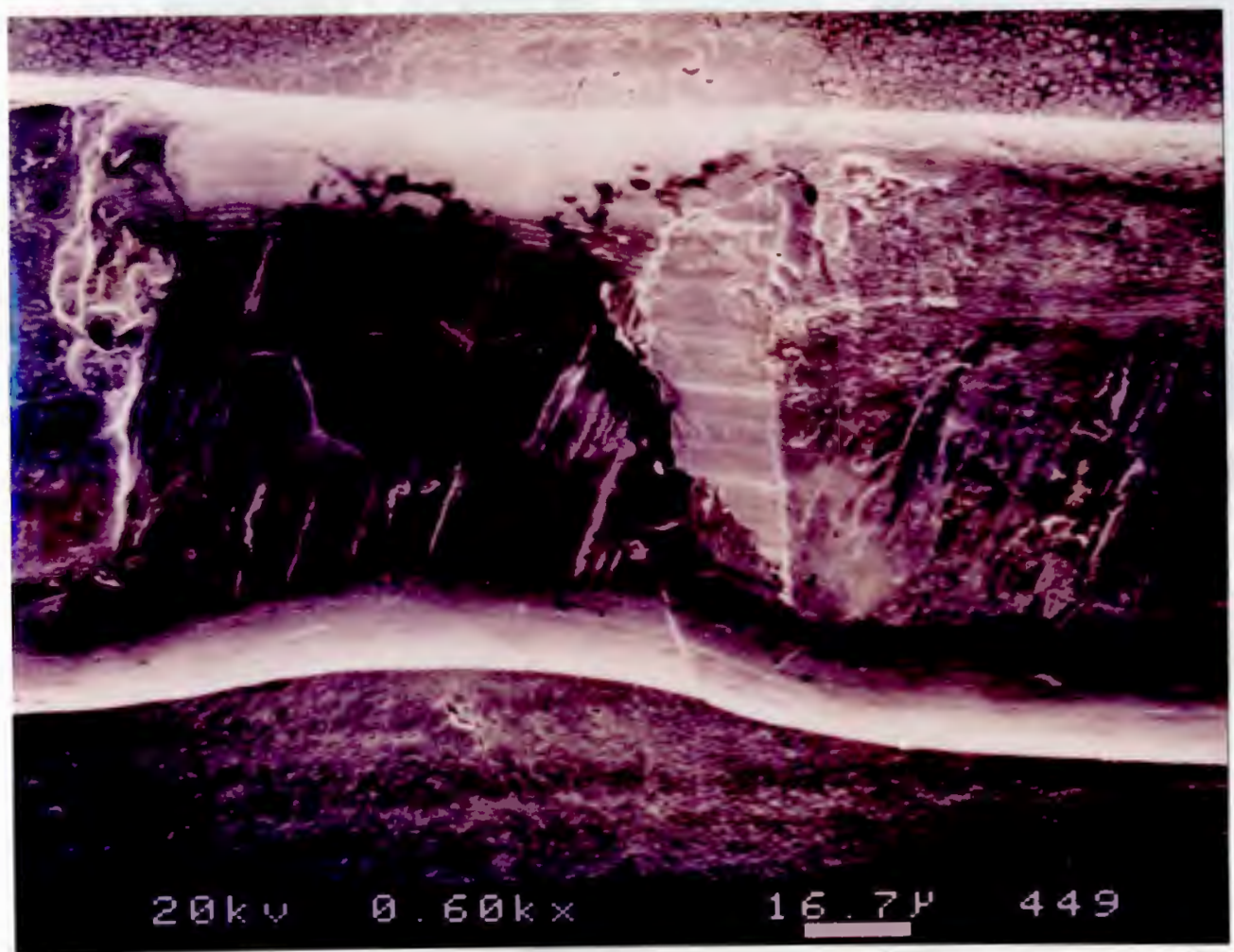

Figure $7 b$ 


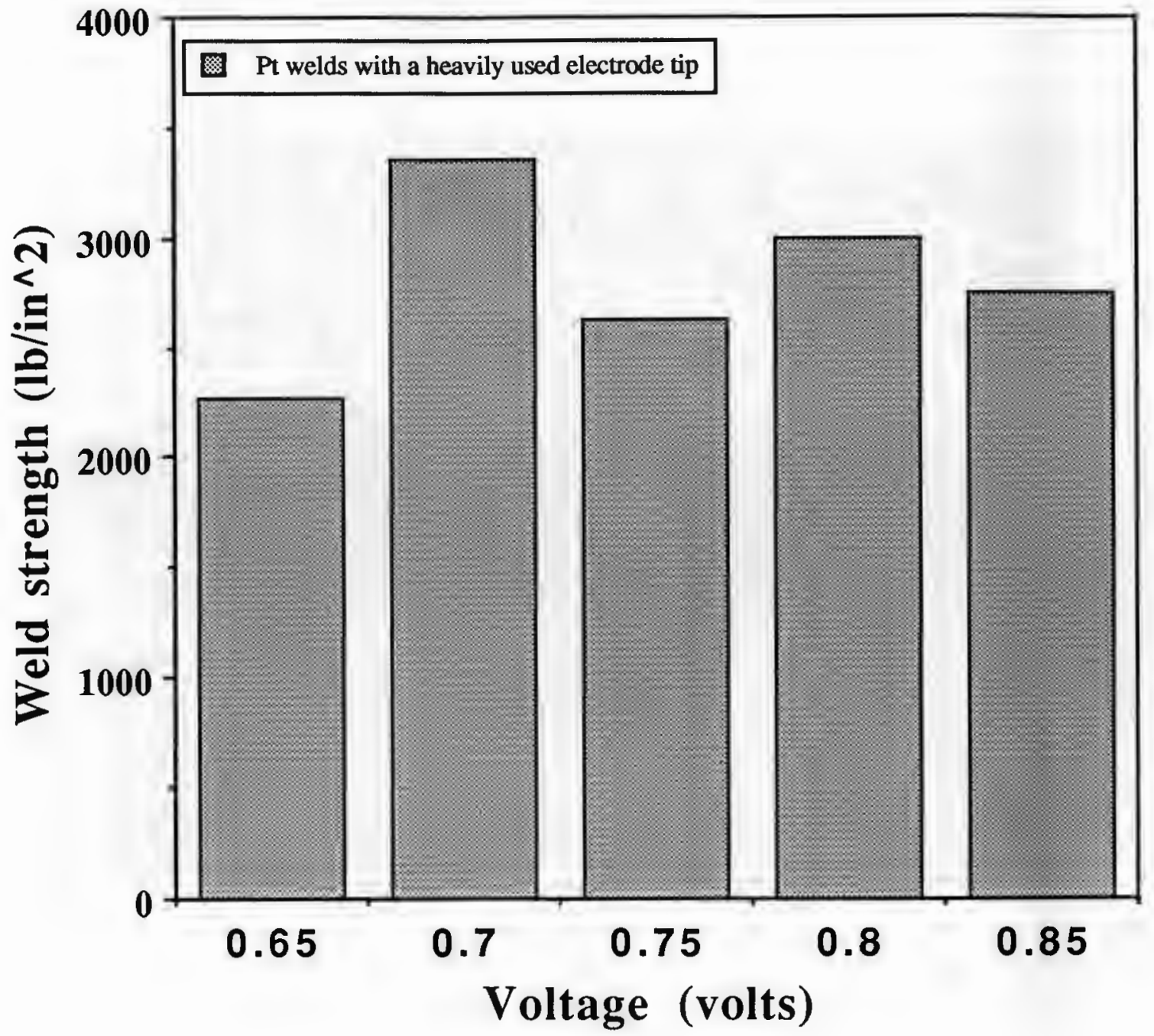

Figure 8 


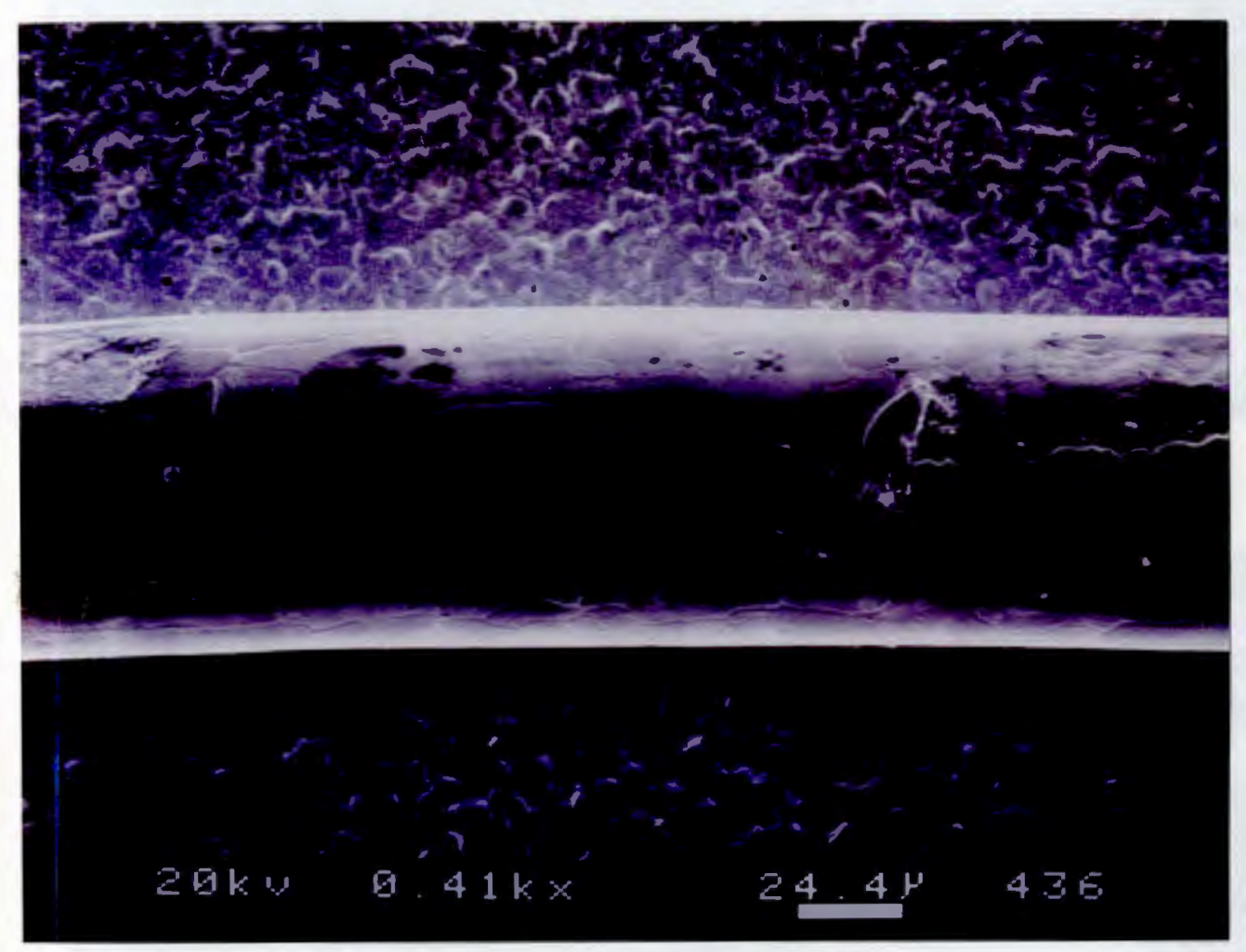

Figure 9 


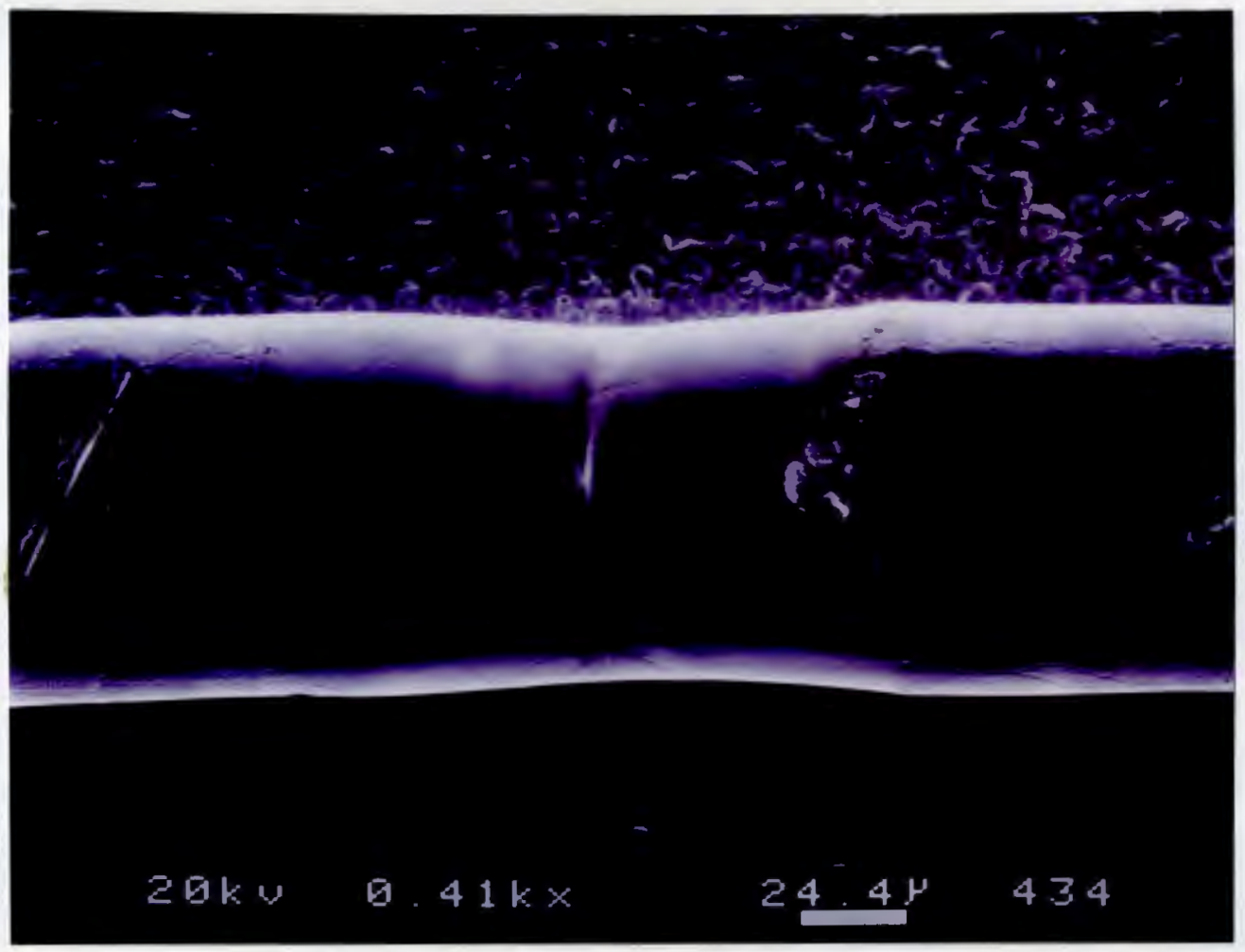

Figure 10a

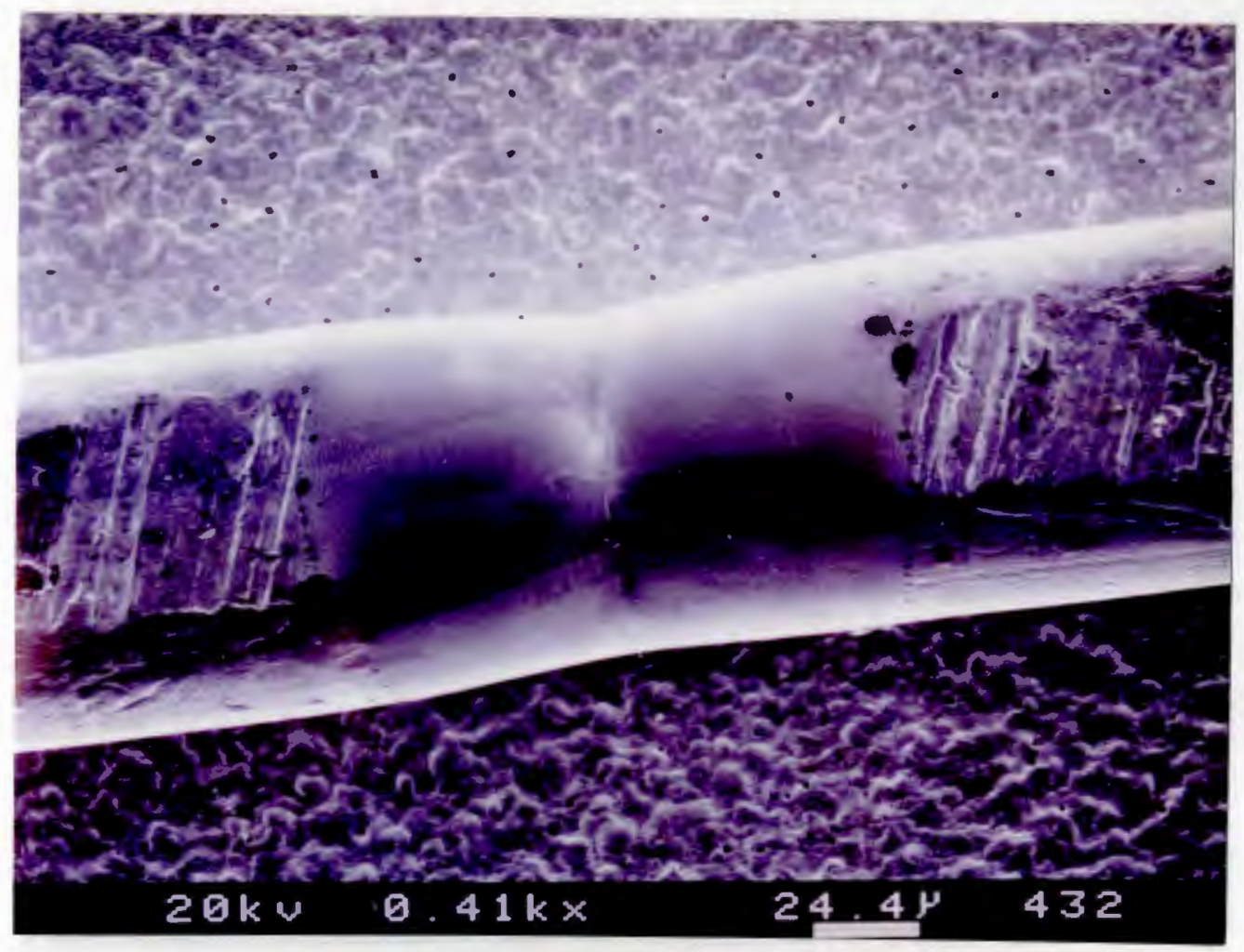

Figure 10b 


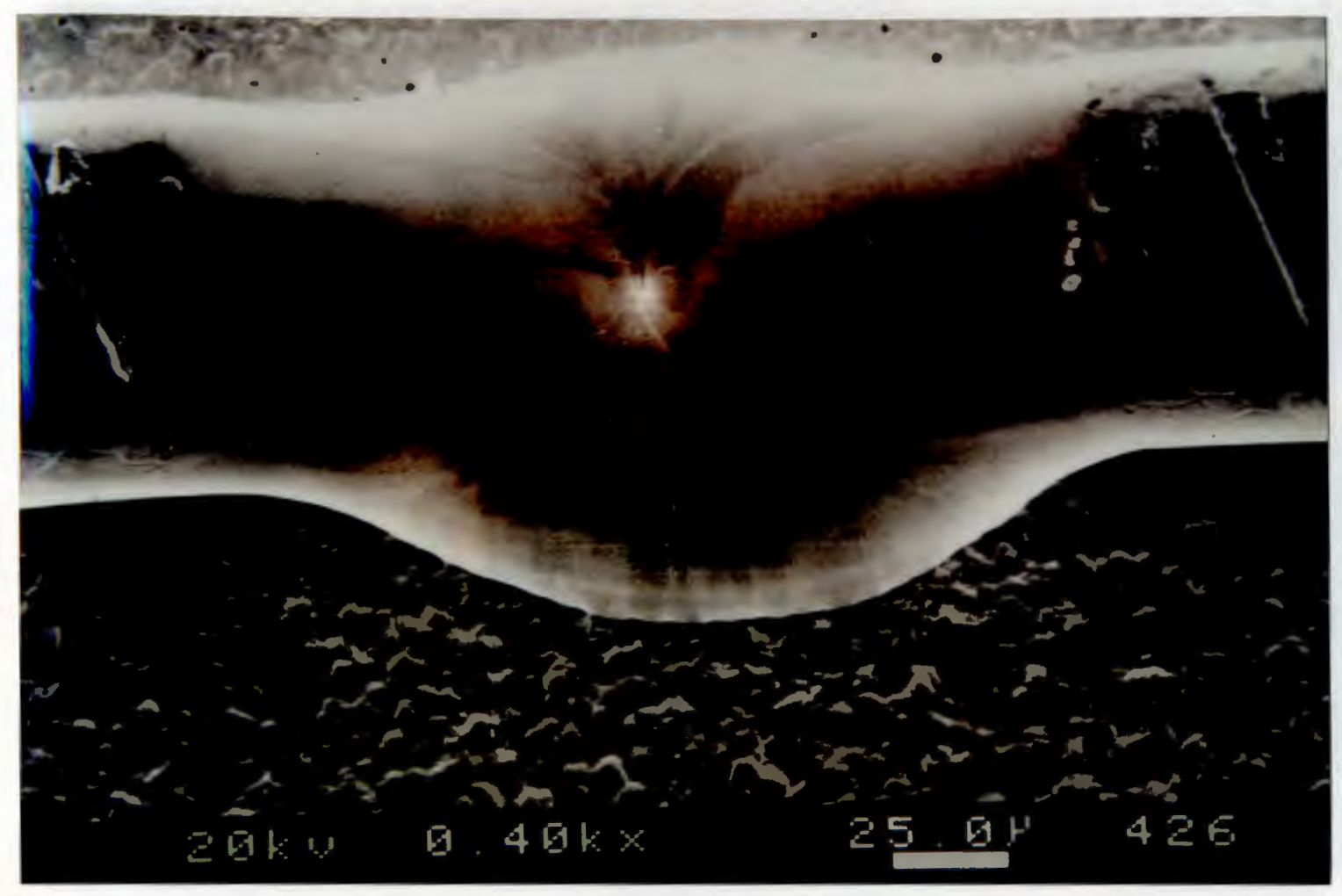

Figure $11 a$

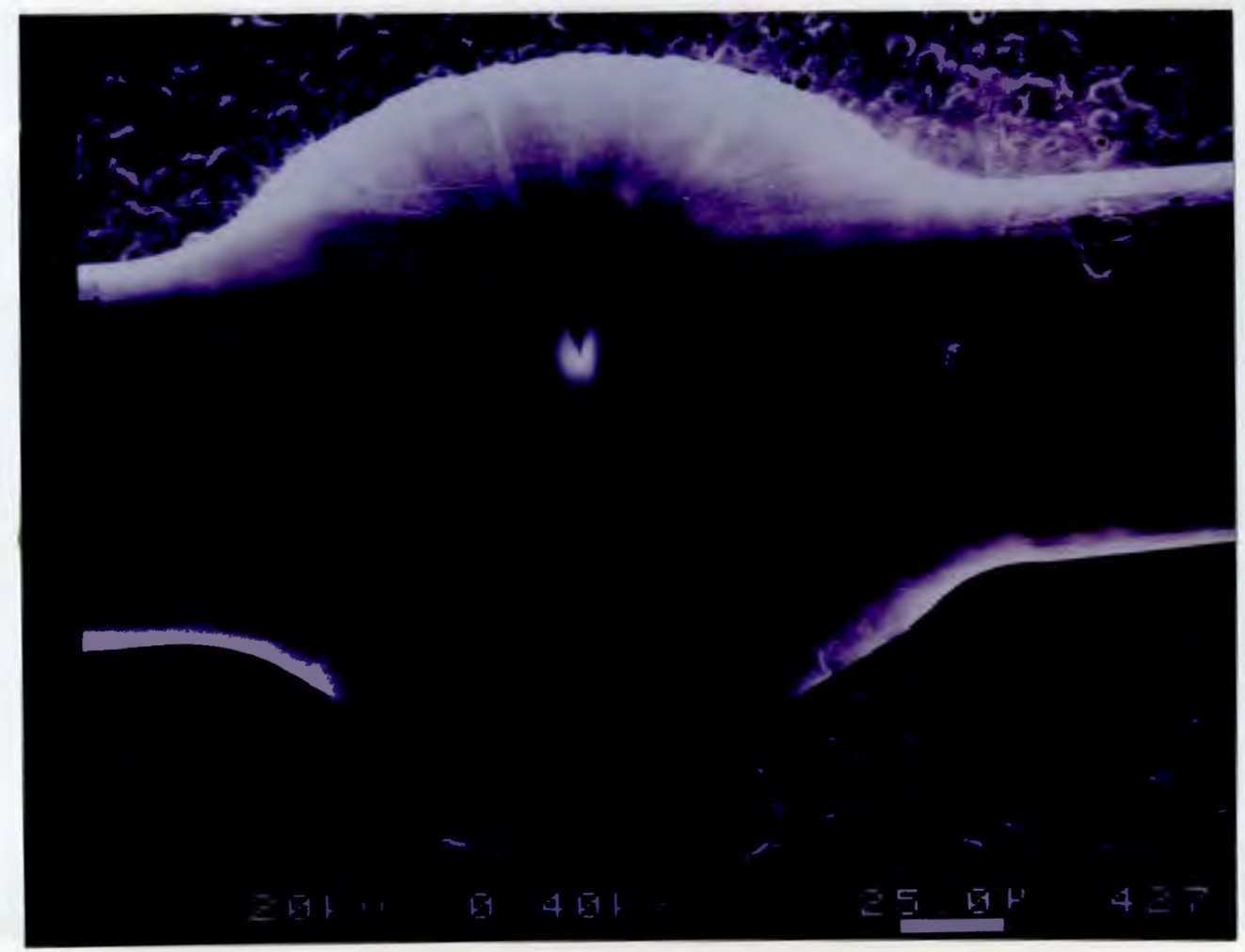

Figure $11 b$ 


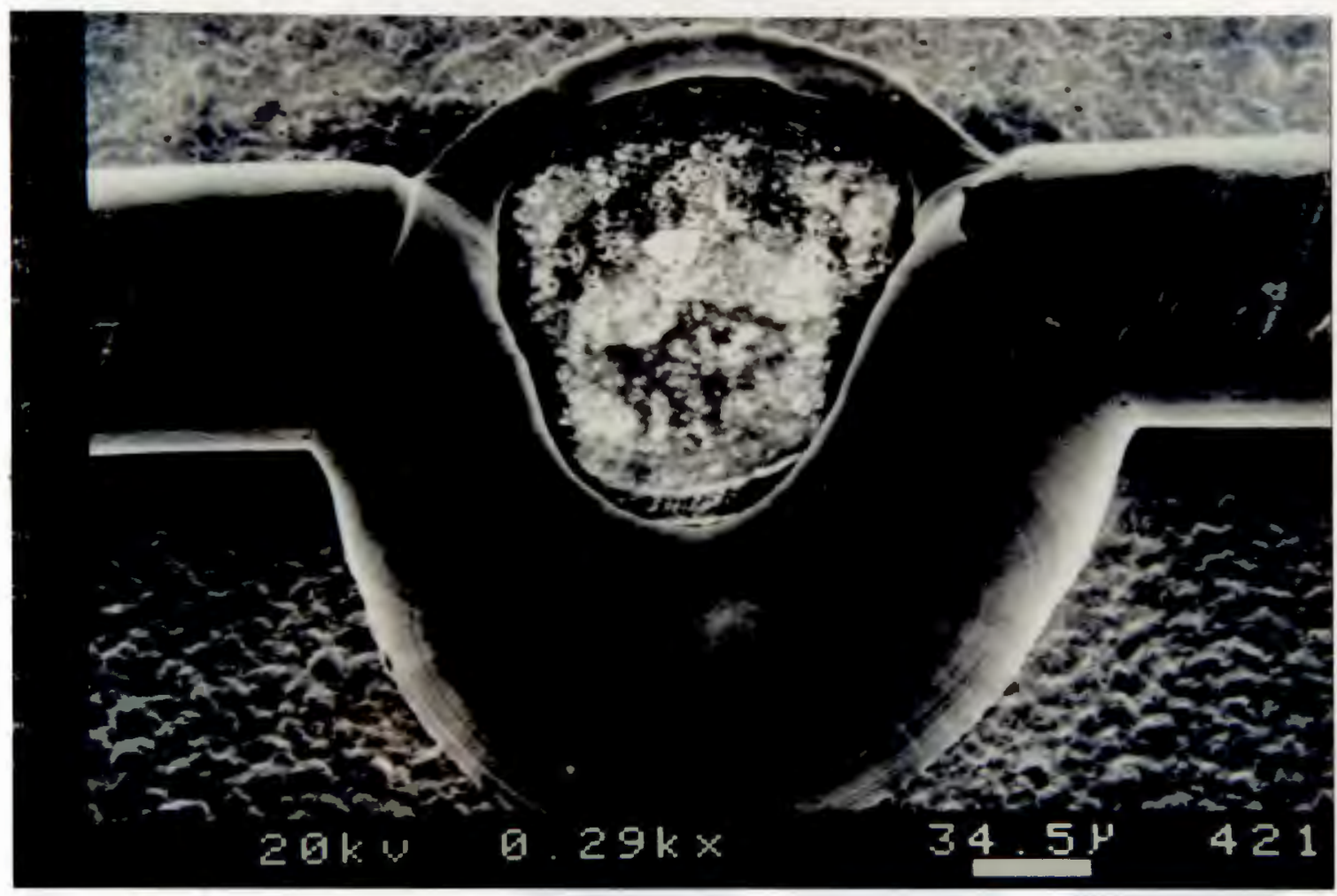

Figure $12 a$

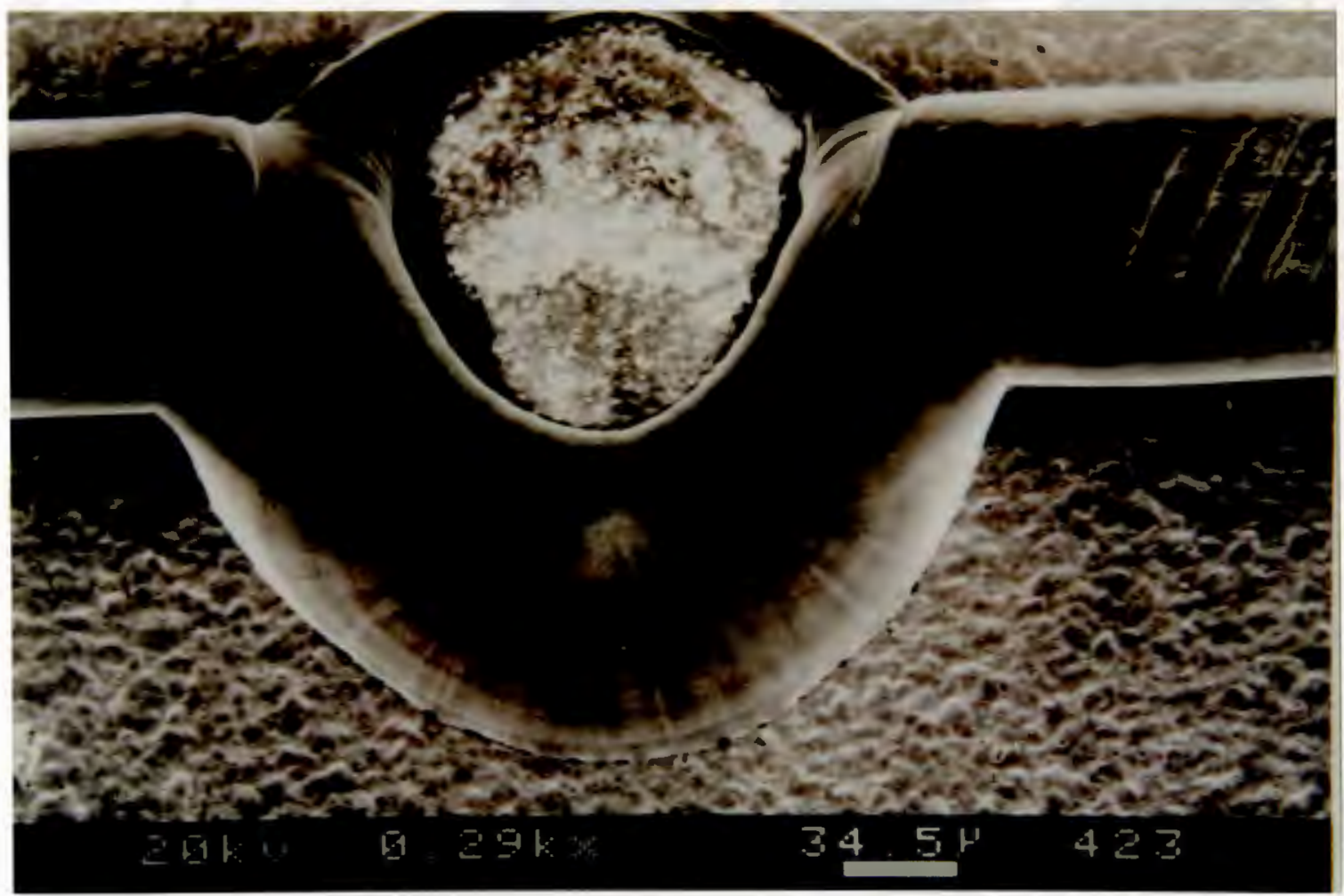

Figure $12 b$ 


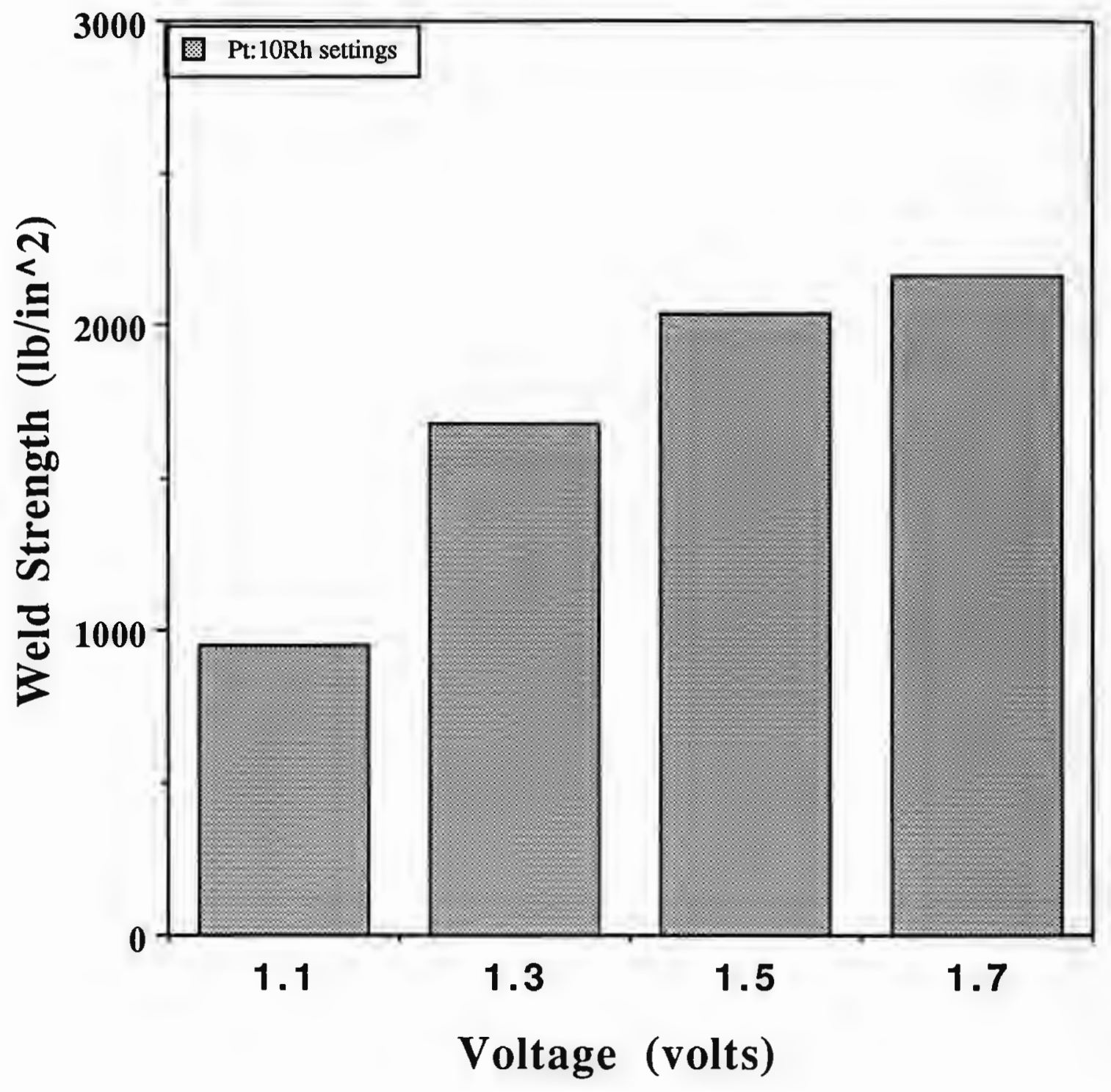

Figure 13 
Appendix D 


\section{Burner rig testing of a type $S$ thin film thermocouple}

A thin film thermocouple was sputter-deposited onto a $1 / 4$ " $\times 1 / 2$ " $\times 4$ " bar of NT154 that was designed to fit in the high temperature burner rig located at AlliedSignal Engines, Phoenix AZ. The fabrication of this sensor was identical to that previously described in manuscript II. This sensor had a $2.2 \mu \mathrm{m}$ sputtered $\mathrm{Al}_{2} \mathrm{O}_{3}$ overcoat and was affixed to the burner rig apparatus shown in Figure 1.

\section{Results and Discussion}

Figure 2 shows a strip chart recording of the thin film thermocouple tested in the burner rig at AlliedSignal Engines. The first cycle of the test employed a rapid ramp rate from ambient temperature to $1800^{\circ} \mathrm{F}\left(982^{\circ} \mathrm{C}\right)$ at which point it was held for 30 minutes. The hot gas flame was shut off after $30 \mathrm{~min}$ and the bar was allowed to cool to ambient temperature. The sensor film survived the first heating cycle and thus, the sample was heated to $2100^{\circ} \mathrm{F}\left(1149^{\circ} \mathrm{C}\right)$ in a subsequent cycle. Again the sensor survived this excursion and the sample was heated yet again to $2100^{\circ} \mathrm{F}$ in a subsequent cycle. Approximately 15 minutes after attaining a temperature of $2100^{\circ} \mathrm{F}$ for the second time, the sensor failed. The sensor failed due to an open circuit (break in the line). The site of the failure was located on the platinum leg of the sensor, approximately one eighth inch from the metal clamping jig, as shown in Figure 3. The failure was located at the edge of the hot zone of the flame, as indicated by the bluing of the $\mathrm{Si}_{3} \mathrm{~N}_{4}$ bar. The area adjacent to the break (on the bond pad side) had been covered by the clamping fixture and thus, was not directly exposed to the flame. Since this area was not exposed to the high temperature exhaust gases from the burner nozzle, the region was significantly cooler than the area exposed to 
the flame. Unfortunately, there was no wire thermocouple to monitor the temperature at this location. It was believed that this very large temperature gradient accelerated the failure of the device in this region, due to the differential expansion of the metal/ceramic couple. Since the covered region of the bar restricted expansion of the metal film in this direction, the film buckled and was removed from the bar by the flame. Earlier furnace tests of sensors showed a similar type of failure associated with an imposed temperature gradient but the consequences were not nearly as rapid as those observed in this case.

SEM micrographs of the failed region (Figure 4) show a complete delamination of the metal film. In addition, microcracking of the $\mathrm{Al}_{2} \mathrm{O}_{3}$ overcoat along the edge of the metal pattern was observed. This observation seems to support the hypothesis that that expansion of the metal film was restricted by the sputtered $\mathrm{Al}_{2} \mathrm{O}_{3}$ overcoat. In order to relieve this stress, the metal film expanded along its length and thus, produced cracks along the edge. This buckling of the thin film is apparent in the micrograph in Figure 5.

With the exception of some slight cracking of the oxide overcoat, the films were continuous on and around the area where the flame was directed. Little crystallization of the $\mathrm{Al}_{2} \mathrm{O}_{3}$ overcoat was observed (Figure 6). 


\section{FIGURE CAPTIONS}

Figure 1a. Burner rig testing apparatus.

Figure 1b. HIP'ed $\mathrm{Si}_{3} \mathrm{~N}_{4}$ with sputtered type $S$ thermocouple affixed in the burner rig setup.

Figure 2. Strip chart recording of the thin film thermocouple temperature.

Figure 3a. Low magnification photograph of the thin film thermocouple after testing.

Figure 3b. High magnification photograph of the thin film thermocouple after testing. Note the break in the platinum leg and the bluing of the bar as a result of the flame test.

Figure 4. SEM micrograph of the failed region on the platinum thermoelement.

Figure 5. SEM micrograph showing a section of the platinum thermoelement that had buckled off the substrate.

Figure 6. SEM high magnification micrograph of the $\mathrm{Al}_{2} \mathrm{O}_{3}$ overcoat. 


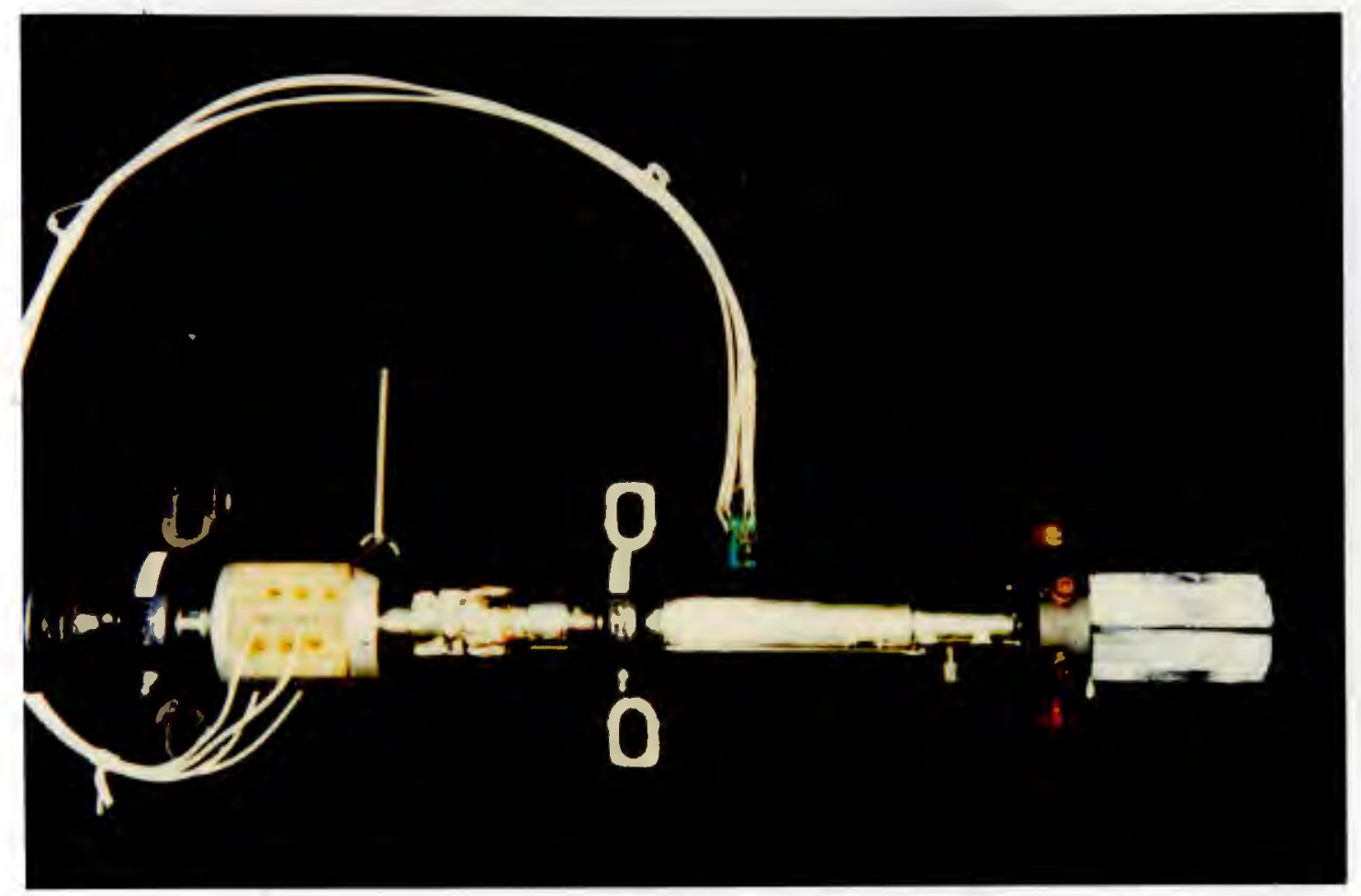

Figure 1a

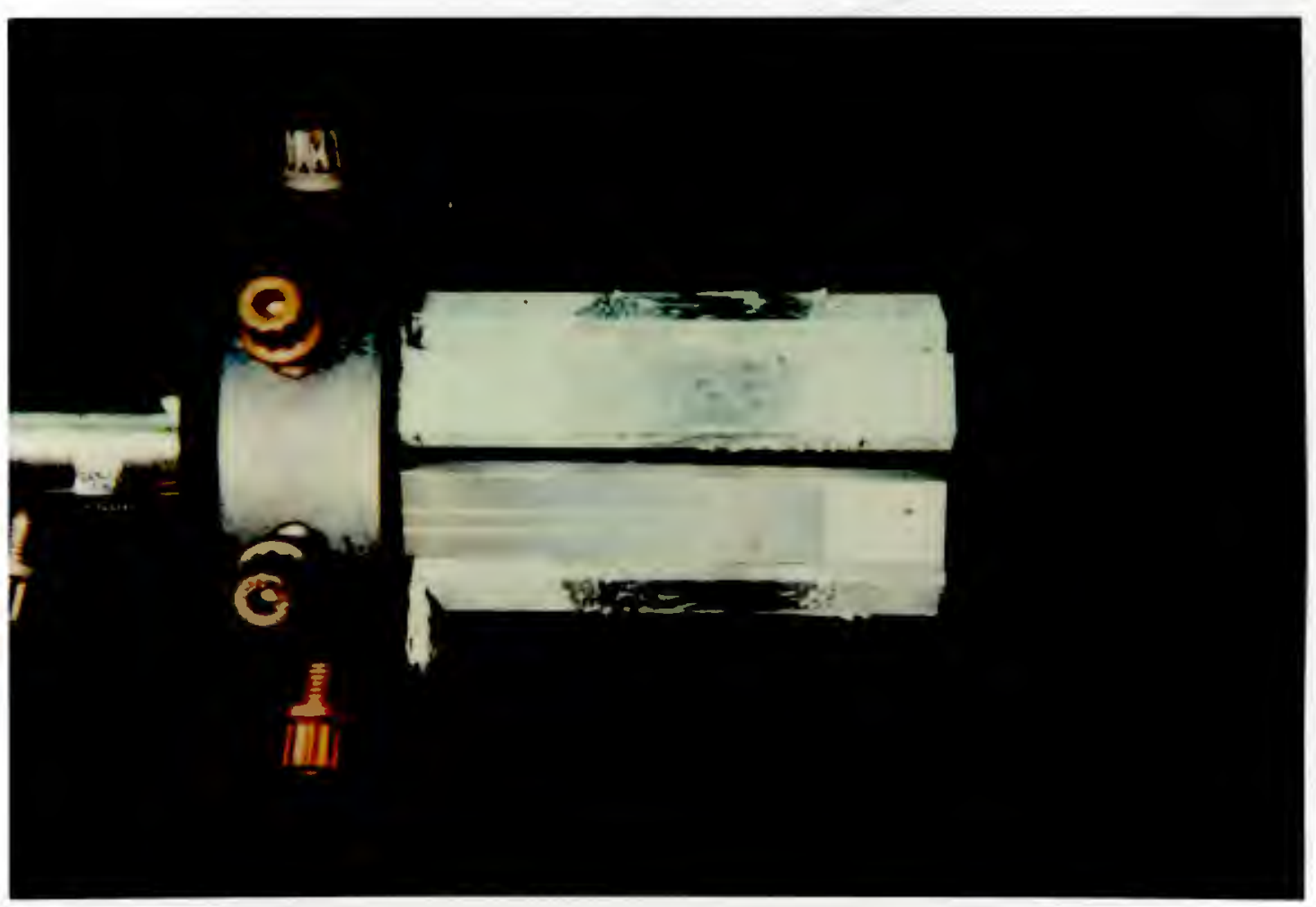

Figure $1 b$ 


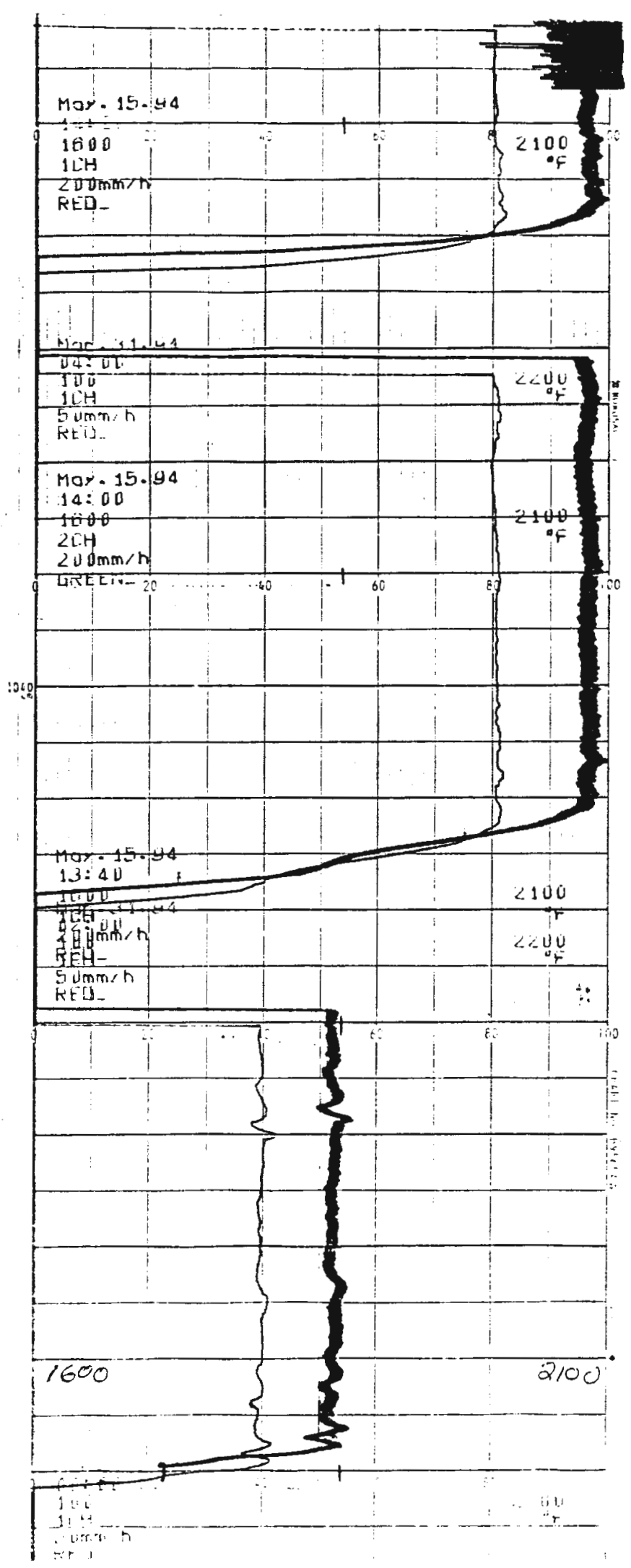

Figure 2 


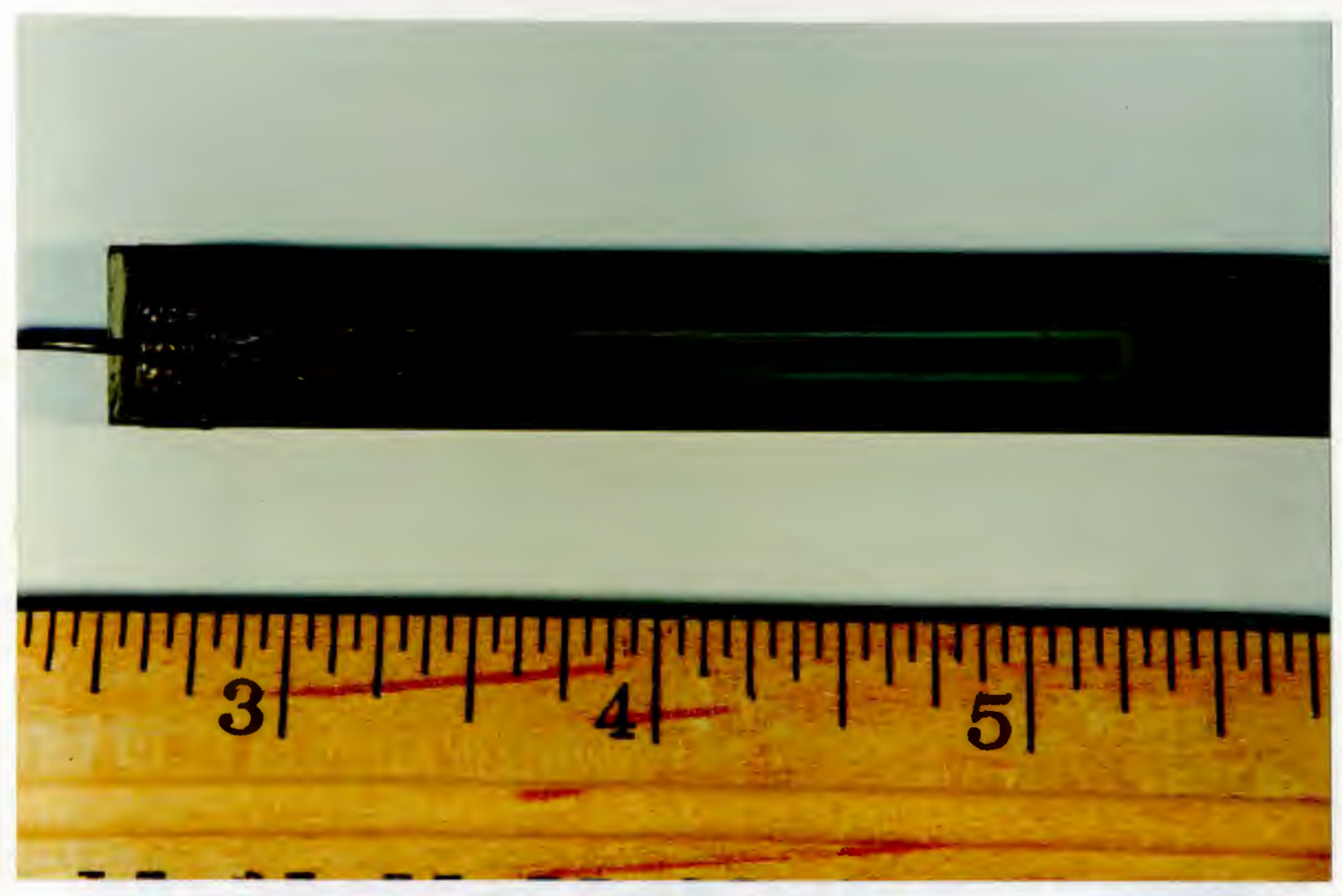

Figure 3a

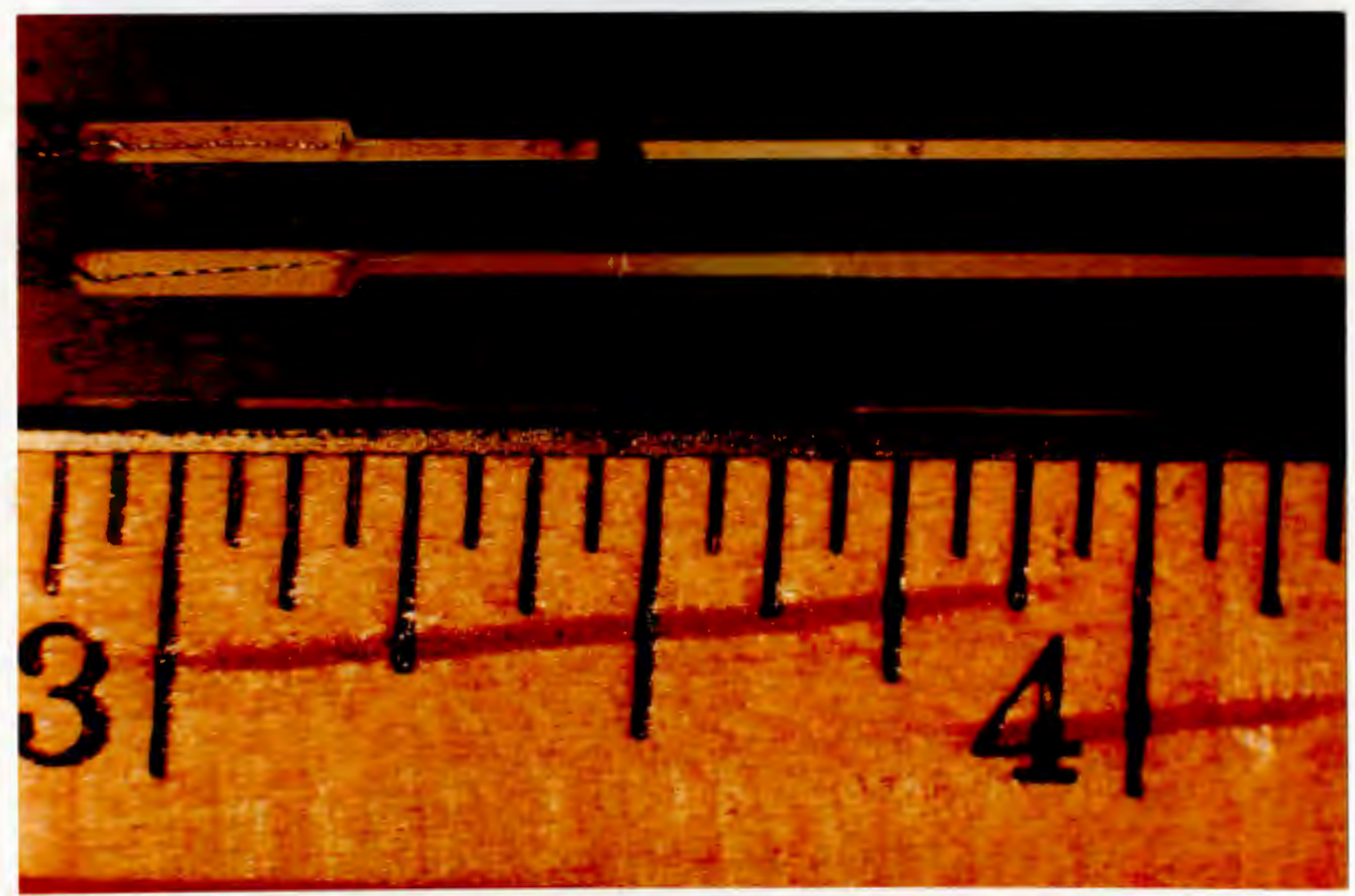

Figure $3 b$ 


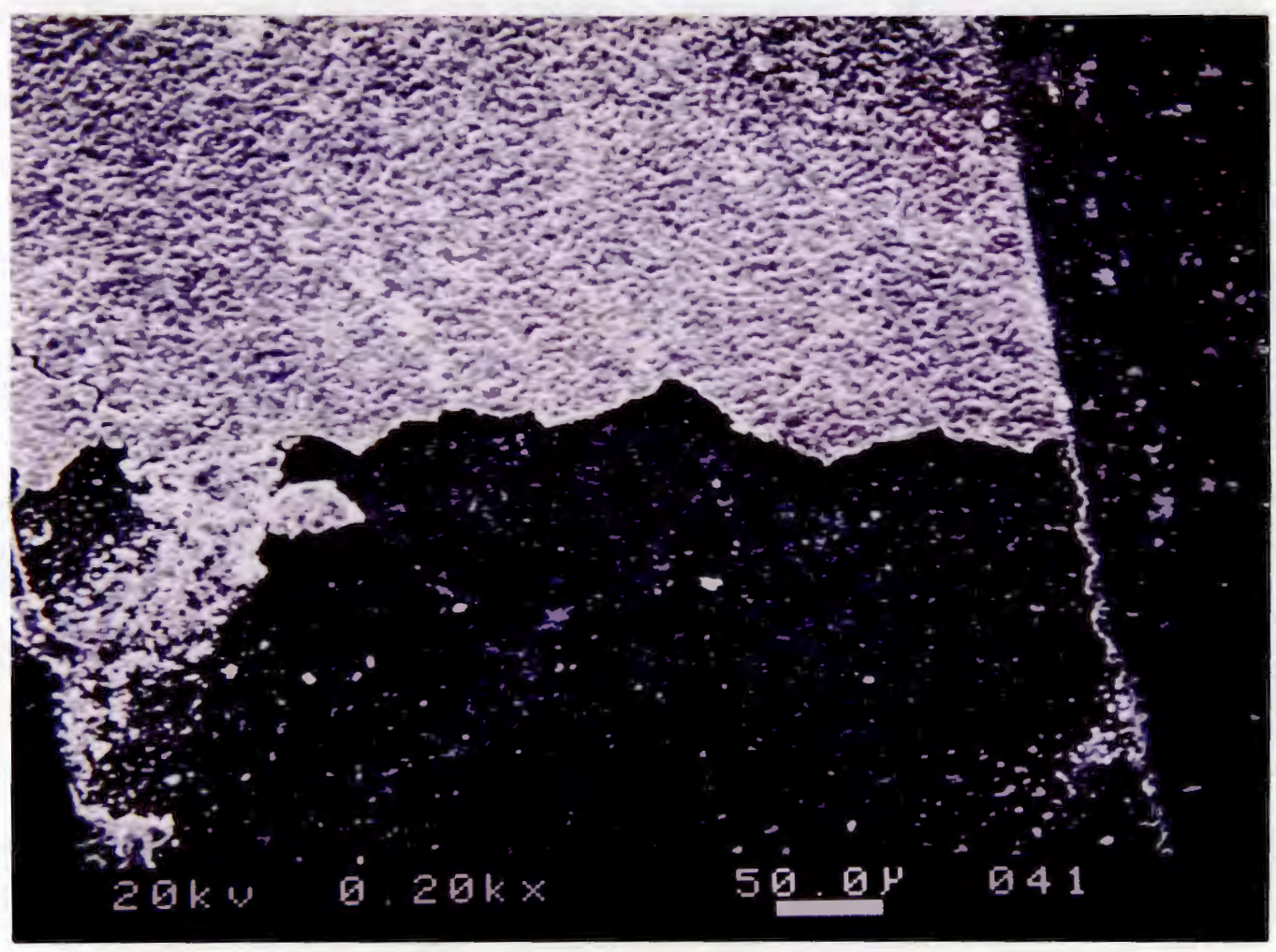

Figure 4 


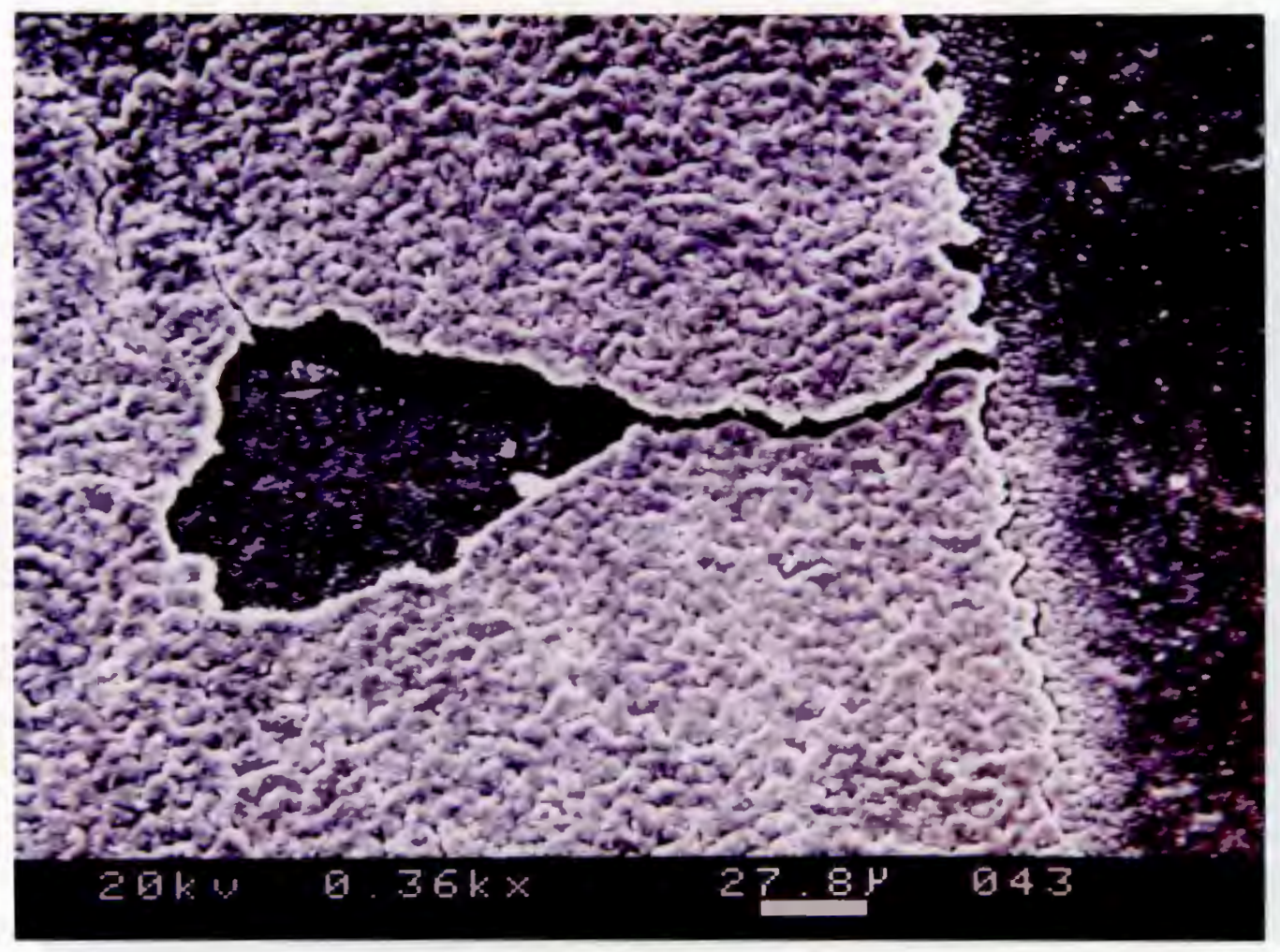

Figure 5 


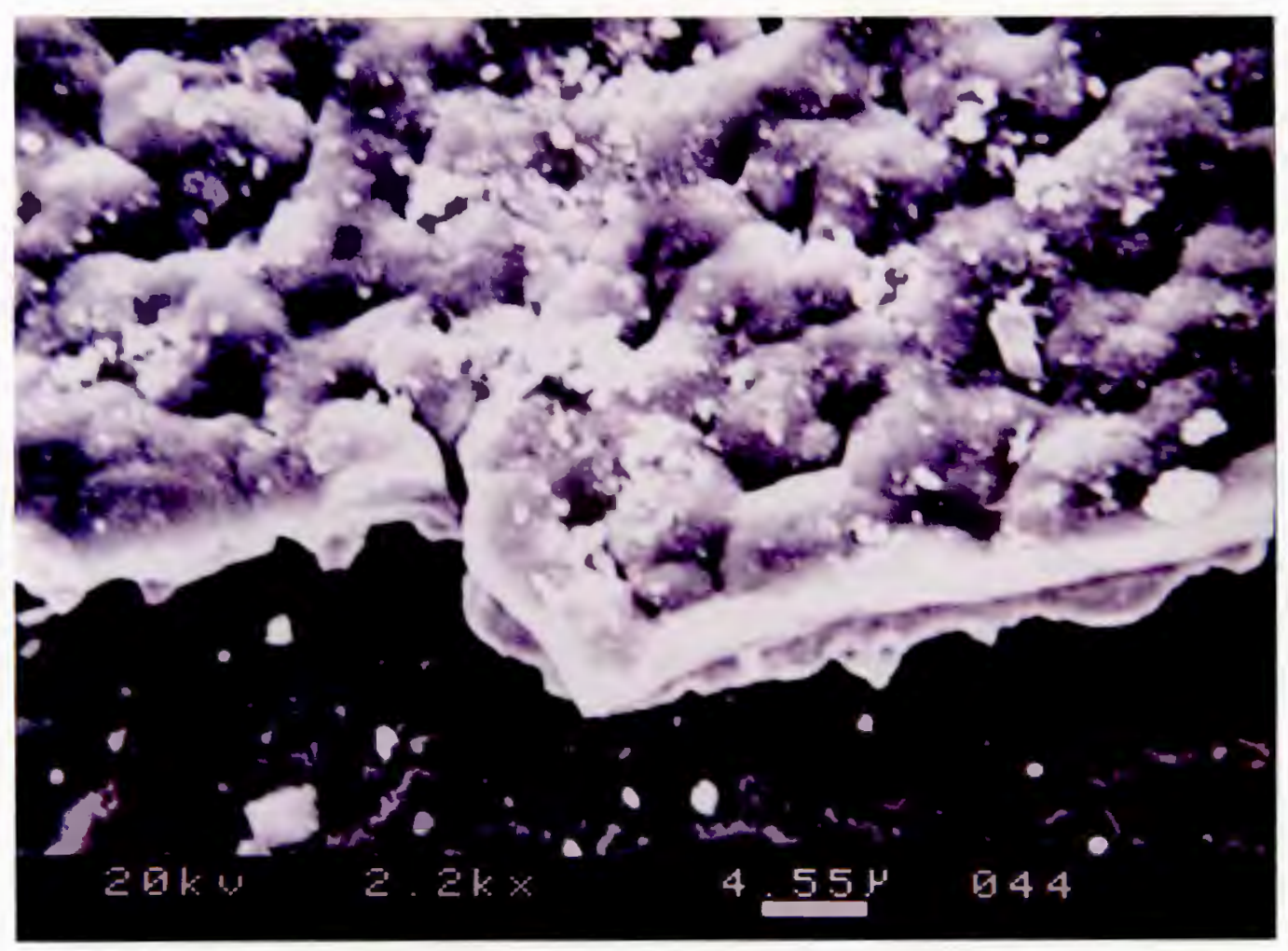

Figure 6 


\section{BIBLIOGRAPHY}




\section{BIBLIOGRAPHY}

Anderson, W. L. and Grant, H. P."High Temperature Strain Gage Technology for Hypersonic Aircraft Development Applications.", NASA Lewis Research Center report CR-189101. PWA 6141, 1992.

Atkinson, W. H.; Cyr, M. A.; and Strange, R. R."Development of Advanced High Temperature Heat Flux Sensors - Phase II Verification Testing.", NASA Lewis Research Center report CR-174973. PWA 5914-39, 1985.

Atkinson, W. H.; Cyr M. A.; and Strange, R. R."Development of Sensors for Ceramic Components in Advanced Propulsion Systems.", NASA Lewis Besearch Center report CR-182111. PWA-6113-12, 1988.

Atkinson, W. H.; Cyr M. A.; and Strange, R. R."Turbine Blade and Vane Heat Flux Sensor Development - Phase II Final Report.", NASA Lewis Research Center report CR-174995. PWA 5914-39, 1985.

Babini, G. N.; Bellosi, A.; and Vincenzini, P.“A Diffusion Model for the Oxidation of Hot Pressed $\mathrm{Si}_{3} \mathrm{~N}_{4}-\mathrm{Y}_{2} \mathrm{O}_{3}-\mathrm{SiO}_{2}$ Materials.", Journal of Materials Science, 19, 1029-1042, 1984.

Bennethum, W. H.; and Sherwood, L. T."Sensors for Ceramic Components in Advanced Propulsion Systems.", NASA Lewis Research Center report CR$180900,1988$.

Budhani, R. C.; Prakash, S.; and Bunshah, R. F."Thin Film Temperature Sensors for Gas Turbine Engines: Problems and Prospects.", Journal of Vacuum Science and Technology, 2609-2617, Nov/Dec 1986.

Choi, D. J.; Fischbach, D. B.; and Scott, W. D."Oxidation of Chemically-VaporDeposited Silicon Nitride and Single-Crystal Silicon.", Journal of the American Ceramic Society, Vol. 7 2, No. 7, 1118-1123, 1989.

Choi, S. R.; Tikare, V.; and Pawlik, R."Crack Healing in Silicon Nitride Due to Oxidation.", Ceramic Engineering and Science Proceedings, 12 [9-10], 21902202, 1991.

Clarke, D. R.; and Lange, F. F."Oxidation of $\mathrm{Si}_{3} \mathrm{~N}_{4}$ Alloys: Relation to Phase Equilibria in the System $\mathrm{Si}_{3} \mathrm{~N}_{4}-\mathrm{SiO}_{2}-\mathrm{MgO}$.", Journal of the American Ceramic Society, Vol. 63 , No. 9-10, 586-593, 1980.

Cranmer, D. C.; Hockey, B. J.; and Wiederhorn, S. M.“Creep and Creep Rupture of HIP'ed $\mathrm{Si}_{3} \mathrm{~N}_{4}$.", Ceramic Engineering and Science Proceedings, 12 [9-10], 1862-1872, 1991.

Cubicciotti, D.; and Lau, K. H."Kinetics of Oxidation of Hot-Pressed Silicon 
Nitride Containing Magnesia.", Journal of the American Ceramic Society, Vol. 61 , No. 11-12, 512-517, 1978.

Du, H.; Houser, C. A.; Tressler, R. E.; Spear, K. E.; and Pantano, C. G."Isotopic Studies of Oxidation of $\mathrm{Si}_{3} \mathrm{~N}_{4}$ and $\mathrm{Si}$ using SIMS.", Journal of the Electrochemical Society, Vol. 137, No. 2, 741-742, 1990.

Du, H.; Tressler, R. E.; and Spear, K. E., "Thermodynamics of the Si-N-O System and Kinetic Modeling of Oxidation of $\mathrm{Si}_{3} \mathrm{~N}_{4}$ ", Journal of the Electrochemical Seciety, Vol. 136, No. 11, 3210-3215, 1989.

Du, H.; Tressler, R. E.; Spear, K. E.; and Pantano, C. G."Oxidation Studies of Crystalline CVD Silicon Nitride.", Journal of the Electrochemical Society, Vol. 136 , No. 5, 1527-1536, 1989.

Dydyk, M.; and Evans, K."Silicon Nitride Masking Integrity Characterization.", Journal of the Electrochemical Society, Vol. 137, No. 12, 3882-3884, 1990.

Falk, L. K. L.; and Engstrom, E. U."Elemental Concentration Profiles in an Oxidized Silicon Nitride Material.", Journal of the American Ceramic Society, Vol. 74 [9], 2286-2292, 1991.

Fourrier, A.; Bosseboeuf, A.; Bouchier, D.; and Gautherin, G."Thermal Oxidation in Wet Oxygen Reactive Ion-Beam Sputter-Deposited Silicon Nitride Films.", Journal of the Electrochemical Society, Vol. 138, No. 4, 1084-1089, 1991.

Gazzara, C. P.; and Messier, D. R.“Determination of Phase Content of $\mathrm{Si}_{3} \mathrm{~N}_{4}$ by $X$-Ray Diffraction Analysis.", American Ceramic Society Bulletin, Vol. 5 6, No. 9, 777-780, 1977.

Ghandhi, S. K., VLSI Fabrication Principles, New York, John Wiley \& Sons, Inc., 1994.

Gimpl, M. L.; McMaster, A. D.; and Fuschillo, N."Amorphous Oxide Layers on Gold and Nickel Films Observed by Electron Microscopy.", Journal of Applied Physics, 35 (12), Dec 1964.

Grant, H. P.; and Przybyszewski, J. S."Thin Film Temperature Sensors - Phase I.", NASA Lewis Research Center report CR-159782. PWA-5526-31, 1980.

Grant, H. P.; and Przybyszewski, J. S.; Anderson, W. L.; and Claing, R. G."Thin Film Strain Gage Development Program, Final Report.", NASA Lewis Research Center report CR- 174707. PWA-5628-69, 1983.

Grant, H. P.; and Przybyszewski, J. S.; and Claing, R. G."Turbine Blade Temperature Measurements Using Thin Film Temperature Sensors - Phase II.", NASA Lewis Research Center report CR-165201, PWA-5604-31, 1981. 
Grant, H. P.; and Przybyszewski, J. S.; and Claing, R. G.; and Anderson, W. L."Thin Film Temperature Sensors Phase III.", NASA Lewis Research Center report CR-165476. PWA-5708-26, 1990.

Gregory, O. J.; and Richman, M. H. "Thermal Oxidation of Sputter-Coated Reaction-Bonded Silicon Nitride.", Journal of the American Ceramic Society, Vol. 67 , No. 5, 335-340, 1984.

Haggerty, J. S.; Lightfoot, A.; Ritter, J. E.; Gennari, P. A.; and Nair, S. V."Oxidation and Fracture Strength of High-Purity Reaction-Bonded Silicon Nitride.", Journal of the American Ceramic Society, Vol. 72 [9], 1675-79, 1989.

Hayafuji, Y.; and Kajiwara, K."Nitridation of Silicon and Oxidized-Silicon.", Journal of the Electrochemical Society: Solid-State Science and Technology, Vol. 129, No. 9, 2102-2108, 1982.

Heuer, A. H. and Lou, V. L. K."Volatility Diagrams for Silica, Silicon Nitride, and Silicon Carbide and Their Applications to High-Temperature Decomposition and Oxidation.", Journal of the American Ceramic Society, Vol. 73 [10], 27853128, 1990.

Hirai, T.; Niihara, K. and Goto, T."Oxidation of CVD $\mathrm{Si}_{3} \mathrm{~N}_{4}$ at $1550^{\circ}$ to $1650^{\circ} \mathrm{C}$.", Journal of the American Ceramic Society, Vol. 63 , No 7-8, 419-424, 1980.

Holanda, R."Development of thin film thermocouples on ceramic materials for advanced propulsion system application.", NASA technical memorandum 106017, April 28-May 2, 1992.

Holanda, R.; Kim, W. S.; Pencil, E.; Groth, M.; and Danzey, G. A."Attachment of Lead Wires to Thin Film Thermocouples Mounted on High Temperature Materials Using the Parallel Gap Welding Process.", NASA technical memorandum 102442, May 1990.

Hulse, C. O.; Bailey, R. S.; Grant, H. P.; Anderson, W. L.; and Przybyszewski, J. S."High Temperature Static Strain Gage Development.", NASA Lewis Research Center report CR-189044. R90-916528-80, 1991.

Hulse, C. O.; Bailey, R. S.; Grant, H. P.; and Przybyszewski, J. S." High Temperature Static Strain Gage Development Contract.", NASA Lewis Research Center report CR-180811, R87-916527-1,1987.

Hulse, C. O.; Stetson, K. A.; Grant, H. P.; Jameikis, S. M.; Morey, W. W.; Rayondo, P.; Grudkowski, T. W.; and Bailey, R. S."Advanced High Temperature Static Strain Sensor Development Program.", NASA Lewis Research Center report CR-179520. R86-995875-28, 1987. 
Jacobson, N. S.“High-Temperature Durability Considerations for HSCT Combustor.", NASA technical paper 3162, 1992.

Kiehle, A. J.; Heung, L. K.; Gielisse, P. J.; and Rockett, T. J."Oxidation Behavior of Hot-Pressed $\mathrm{Si}_{3} \mathrm{~N}_{4}$.", Journal of the American Ceramic Society, Vol. 58 , No. 1-2, 17-20, 1975.

Kofstad, P. High Temperature Corrosion, Elsevier Science Publishing Co., New York, 1988.

Koller, A. C."Status of three techniques for the surface temperature measurements of ceramic components.", High Temperature Program Review NASA contract NAS3-25140, OCT. 29-30, 1991.

Kreider, K. G."Thin Film Thermocouples for Internal Combustion Engines.", Journal of Vacuum Science and Technology Vol. 4, No. 6, 2618-2623, Nov/Dec 1986.

Kreider, K. G.; Semancik, S.; and Olson, C."Advanced Thin Film Thermocouples.", NASA Lewis Research Center report NBSIR 84-2949. C54715, 1984.

Lange, F. F.; and Davis, B. I." Compressive Creep and Oxidation Resistance of an $\mathrm{Si}_{3} \mathrm{~N}_{4}$ Material Fabricated in the System $\mathrm{Si}_{3} \mathrm{~N}_{4}-\mathrm{Si}_{2} \mathrm{~N}_{2} \mathrm{O}-\mathrm{Y}_{2} \mathrm{Si}_{2} \mathrm{O}_{7}$.", Communications of the American Ceramic Society, C-98-C-99, 1983.

Loewenstein, L. M.; and Tipton, C. M."Chemical Etching of Thermally Oxidized Silicon Nitride: Comparison of Wet and Dry Etching Methods.", Journal of the Electrochemical Society, Vol. 138, No. 5, 1389-1394, 1991.

Luthra, K. L.“A Mixed Interface Reaction/Diffusion Control Model for Oxidation of $\mathrm{Si}_{3} \mathrm{~N}_{4}$.", Journal of the Electrochemical Society, Vol. 138, No. 10, 3001-3007, 1991.

Luthra, K. L."Some New Perspectives on Oxidation of Silicon Carbide and Silicon Nitride.", Journal of the American Ceramic Society, Vol. 74 [5], 10951103, 1991.

Middleman, S. and Hochberg, A. K., Process Engineering Analysis in Semiconductor Device Fabrication, New York, McGraw-Hill Inc., 1993.

Mieskowski, D. M.; and Sanders, W. A."Oxidation of Silicon Nitride Sintered with Rare-Earth Oxide Additions.", Journal of the American Ceramic Society, Vol. 68 [7], C-160-C-163, 1985.

Ogbuji, L. U. J. T.; and Smialek, J. L.“Evidence from Transmission Electron Microscopy for an Oxynitride Layer in Oxidized $\mathrm{Si}_{3} \mathrm{~N}_{4}$.", Journal of the 
Electrochemical Society, Vol. 138, No. 10, L51-L56, 1991.

Ohashi, M.; Kanzaki, S.; and Tabata, H."Processing, Mechanical Properties, and Oxidation Behavior of Silicon Oxynitride Ceramics.", Journal of the American Ceramic Society, Vol. 74, [1], 109-114, 1991.

Prakash, S.; Budhani, R. C.; and Bunshah, R. F."Development of Thin Film Temperature Sensors for High Performance Turbo-Jet Engines.", Materials Research Bulletin, Vol. 23, 187-195, 1988.

Presland, A. E. B.; Price, G. L.; and Trimm, D. L."Kinetics of Hillock and Island Formation During Annealing of Thin Silver Films.", Progress in Surface Science, 3, 63, 1972.

Singhal, S. C. "Thermodynamics and Kinetics of Oxidation of Hot-Pressed Silicon Nitride.", Journal of Materials Science, 11, 500-509, 1976.

Smith, S. W., "Fabrication of Thin Film Thermocouples for Gas Turbine Engine Applications', Masters Thesis, The University of Rhode Island, 1989.

Strangeman, T. E.; and Fox D. S."Strength Retention of NT154 Silicon Nitride Exposed to High-Temperature Oxidation and Hot Corrosion Environments", Presented at the 184th Meeting of The Electrochemical Society, New Orleans, LA, October 12, 1993.

Tripp, W. C.; and Graham, H. C."Oxidation of $\mathrm{Si}_{3} \mathrm{~N}_{4}$ in the Range $1300^{\circ}$ to $1500^{\circ} \mathrm{C} . "$, Journal of the American Ceramic Society, Vol. 5 9, No. 9-10, 399-403, 1976.

Vaughn, W. L. and Machs, H. G. "Active-to-Passive Transition in the Oxidation of Silicon Carbide and Silicon Nitride in Air.", Journal of the American Ceramic Society, Vol. 73 [6], 1540-1543, 1990.

Vander Voort, G. V., Metallography Principles and Practice, New York, McGrawHill Inc., 1984.

Wu, C. C.; McKinney, K. R.; Rice, R. W.; McDonough, W. J.; and Freiman, S. W."Oxidation Weight Gain and Strength Degradation of $\mathrm{Si}_{3} \mathrm{~N}_{4}$ with Various Additives.", Journal of Material Science, 16, 3099-3104, 1981.

Wu, N. L.; and Phillips, J."Reaction-Enhanced Sintering of Platinum Thin Films during Ethylene Oxidation.", Journal of Applied Physics, 59 (3), Feb 1986. 